University of Rhode Island

DigitalCommons@URI

Open Access Master's Theses

2017

\title{
A Comparison of Wave and Erosion Modeling Methods for the 100 -Year Storm in Southern Rhode Island
}

Lauren Schambach

University of Rhode Island, Ischambach@my.uri.edu

Follow this and additional works at: https://digitalcommons.uri.edu/theses

\section{Recommended Citation}

Schambach, Lauren, "A Comparison of Wave and Erosion Modeling Methods for the 100-Year Storm in Southern Rhode Island" (2017). Open Access Master's Theses. Paper 978.

https://digitalcommons.uri.edu/theses/978

This Thesis is brought to you for free and open access by DigitalCommons@URI. It has been accepted for inclusion in Open Access Master's Theses by an authorized administrator of DigitalCommons@URI. For more information, please contact digitalcommons-group@uri.edu. 
A COMPARISON OF WAVE AND EROSION MODELING METHODS FOR THE 100-YEAR STORM IN SOUTHERN RHODE ISLAND

BY

LAUREN SCHAMBACH

A THESIS SUBMITTED IN PARTIAL FULFILLMENT OF THE

REQUIREMENTS FOR THE DEGREE OF

MASTER OF SCIENCE

IN

OCEAN ENGINEERING

UNIVERSITY OF RHODE ISLAND

2017 
MASTER OF SCIENCE THESIS

$\mathrm{OF}$

LAUREN SCHAMBACH

\title{
APPROVED:
}

Thesis Committee:

\author{
Major Professor Annette R. Grilli \\ Stéphan T. Grilli \\ Tetsu Hara \\ Nasser H. Zawia \\ DEAN OF THE GRADUATE SCHOOL
}

\section{UNIVERSITY OF RHODE ISLAND}




\begin{abstract}
This body of work consists of two manuscripts related to modeling ocean waves and erosion associated with the 100-year storm in southern Rhode Island.

\section{Predicting the 100-year storm inundation along the Narragansett Bay shoreline}

The lack of confidence in FEMA maps after Hurricane Sandy (2012) led to question the accuracy of the methodology used in FEMA Flood Insurance Rate Maps (FIRM). The present analysis presents a case study, re-computing the 100year inundation maps in Washington County, RI, using a chain of two-dimensional models. Presented results focus on the West Passage of the Narragansett Bay, Rhode Island, USA, an area characterized by a complex shoreline. The selection of the initial and boundary conditions for ocean wave simulations are based on results of fully coupled 2-D surge and wave models, the ADvanced CIRCulation model (ADCIRC) and the phase-averaged STeady state spectral WAVE model (STWAVE), respectively, from the North Atlantic Coast Comprehensive Study (NACCS) performed by the U.S. Army Corps of Engineers. Waves are simulated using STWAVE over a series of high-resolution grids in near-shore and overland areas. The method is referred to as the NAST method. Results are mapped and compared with FEMA's results along transects. Cross-sections across the Base Flood Elevation (BFE) at the site of the FEMA 1-D transects are in relatively good agreement using both methodologies, with larger discrepancies shown in the northern section of the bay. Discrepancies are primarily due to a difference in the 100-year wind assumption and secondarily to the 100-year storm surge assumption, which, besides defining the depth and extension of the inundation, controls the wave impact over land. Mapping the results reinforces the importance of adopting a 2-D approach to fully represent the inundation, showing that the selected
\end{abstract}


transects often miss the sites of the most extreme wave incursion and most destructive impacts. The analysis highlights the differences in methods and results but also suggests adopting, besides a 2-D approach, a scenario-based approach to the 100-year storm rather than a deterministic single map to assess the uncertainty associated with this event.

\section{Modeling the erosion associated with the 100-year storm on the south- ern Rhode Island coast}

The erosion due to a synthetic 100-year storm is modeled on the southern shore of Rhode Island using the process-based morphodynamic model XBeach (Roelvink et al., 2009). The study area includes barrier beaches, coastal ponds, and residential areas. The model is forced using a synthetic storm time series extracted from the North Atlantic Coast Comprehensive Study (NACCS; Cialone et al., 2015, Nadal-Caraballo et al., 2015) database, selected as a proxy 100-year storm.

An empirical method (Stockdon et al., 2006; Stockdon et al., 2012) is used to parameterize wave setup, swash, and runup to estimate the erosion impact regime (Sallenger, 2000), using NACCS water levels and offshore wave heights as inputs at seven cross-shore transects within the study area. As the storm is expected to evolve from the collision regime to the overwash and inundation regimes over time, the two-step XBeach model calibration process suggested by Nederhoff (2014) is followed. The first step consists of adjusting the facua wave skewness/asymmetry parameter to calibrate the collision regime. The second step involves testing the sensitivity to friction across the dune to calibrate the overwash regime. The sensitivity of the model to the facua parameter is tested by modeling a historical storm that stayed within the collision regime. Hurricane Irene (August, 2011) is selected and simulated erosion is compared to measured erosion at five cross-shore profiles 
monitored by the University of Rhode Island Graduate School of Oceanography (GSO). GSO performed measurements and data collection before and after Irene's impact at the site. For the 100-year storm, results of four simulation scenarios are presented: the facua parameter is tested for the default and maximum suggested values of 0.1 and 0.3 , respectively, and the bottom friction is either set to a constant Manning's $n$ of 0.02 or a variable Manning's $n$ bed friction coefficient based on land cover.

The resulting eroded dunes for the four simulations are presented in 2-D maps as well as 1-D cross-sections at the seven cross-shore locations. Two additional transects to the GSO transects are included, located at the Federal Emergency Management Agency (FEMA) coastal transect sites that were used to create the 100-year Flood Insurance Rate Map (FIRM) for the region. Results are compared at these two sites with FEMAs dune erosion protocol. Additionally, the simulated dune is compared to the generalized barrier profile for a 100-year storm developed for the region by Oakley (2015). 


\section{ACKNOWLEDGMENTS}

I would like to thank my advisor, Dr. Annette Grilli, for being such a positive role model for me these past few years. I have greatly enjoyed working on these projects with her and am so thankful for everything she has taught me. Along with Dr. A. Grilli, I would like to thank all my professors for the time and effort they put into teaching us. I hope to put everything that I've learned in class to good use.

I must also acknowledge my parents, Daryl and Lynn Schambach, for being so loving, encouraging, and supportive for everything I do. I would also like to express my gratitude to my brother and sister, they are truly the best.

Kerry, Amanda, and John have been the most incredible friends and have stuck by and encouraged me whenever I needed it. I also want to thank Maggie for being one of the best friends and roommates anyone could ask for, I promise I will finally have time to clean the apartment soon.

Finally, I would like to thank my officemates, Mike, Scott, Boma, Chris, Fatima, and Pat for all of the fun we've had helping each other to solve problems and understand difficult concepts. I must also mention my thanks to Fritzi, Wendy, Marissa, Ali and Matt, grad school would not have been the same without them. 


\section{PREFACE}

This thesis is written in manuscript format; it consists of two manuscripts with the overarching theme of modeling the coastal impact of the 100-year storm in southern Rhode Island. The first manuscript is entitled "Predicting the 100-year storm inundation along the Narragansett Bay shoreline" and the second manuscript is entitled "Modeling the erosion associated with the 100-year storm on the southern Rhode Island coast." Both manuscripts are in preparation for submission to the American Society of Civil Engineers (ASCE) Journal of Waterway, Port, Coastal, and Ocean Engineering. 


\section{TABLE OF CONTENTS}

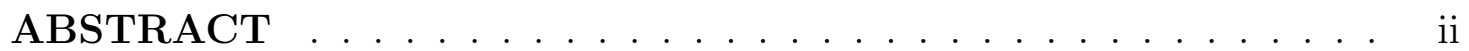

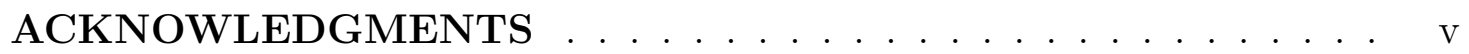

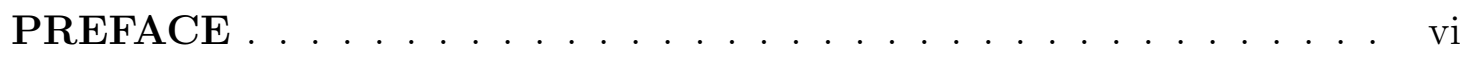

TABLE OF CONTENTS ................... . . vii

LIST OF TABLES . . . . . . . . . . . . . . . . ix

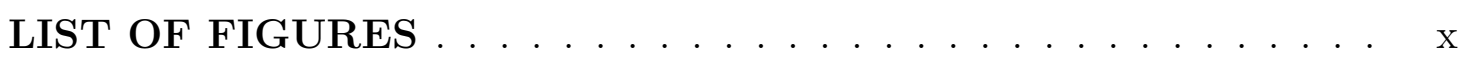

\section{MANUSCRIPT}

1 Predicting the 100-year storm inundation along the Narragansett Bay shoreline . . . . . . . . . . . . . 1

1.1 Introduction . . . . . . . . . . . . . . . . . 3

1.2 Methodology . . . . . . . . . . . . . . . . . 6

1.3 Results . . . . . . . . . . . . . . . . . . 11

1.3.1 Sensitivity analysis . . . . . . . . . . . . . . 12

1.3 .2 Inundation maps . . . . . . . . . . . . . . . . 17

1.3 .3 Transects . . . . . . . . . . . . . . . 22

1.4 Conclusions . . . . . . . . . . . . . . . . 26

List of References . . . . . . . . . . . . . . . . . . . . 28

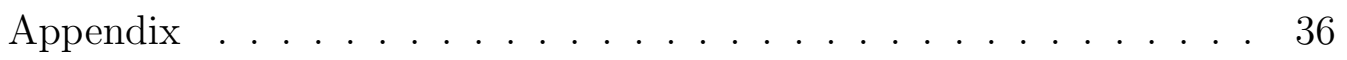

2 Modeling the erosion associated with the 100-year storm on the southern Rhode Island coast . . . . . . . . . . . . 37

2.1 Introduction . . . . . . . . . . . . . . . . . . . 39 


\section{Page}

2.2 Methods . . . . . . . . . . . . . . . . . . . 46

2.2 .1 XBeach Model . . . . . . . . . . . . . . . . . . . 46

$2.2 .2 \quad$ XBeach Model Setup . . . . . . . . . . . . . . . 53

2.2 .3 Hurricane Irene . . . . . . . . . . . . . . . . . . . . 55

$2.2 .4 \quad 100-Y e a r$ Storm . . . . . . . . . . . . . . . . . . . . 59

2.2.5 Expected 100-Year Storm Erosion Impact Regime . . . . 61

2.3 Results and Discussion . . . . . . . . . . . . . . . . . 63

2.3 .1 Hurricane Irene . . . . . . . . . . . . . . . . . . 63

$2.3 .2 \quad 100-$ Year Storm . . . . . . . . . . . . . . . . . . . 64

2.4 Conclusion . . . . . . . . . . . . . . . . . . 71

List of References . . . . . . . . . . . . . . . . . . . . . 72 


\section{LIST OF TABLES}

Table

Page

1.1 Narragansett Bay grid (G4) parameters, Coordinates are UTM

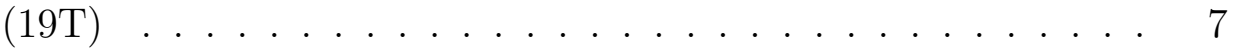

1.2 Summary of spectral boundary conditions for the Narragansett Bay grid $(\mathrm{G} 4)$. . . . . . . . . . . . . . 10

1.3 Simulations of 100-year storm in grid G4: control, base, wind, extreme wind cases and sensitivity scenario parameters . . . . . 13

2.1 Study area transect locations, 5 GSO and 2 FEMA transects (Figure 2.4) . . . . . . . . . . . . . . . . . . . . . 55

$2.2 \quad$ Hurricane Irene Simulation Scenarios . . . . . . . . . . . . . . 58

2.3 NACCS 100-Year Parameters vs. Storm 457 Parameters . . . . 59

2.4 100-Year Storm Simulation Scenarios modeled with XBeach . . 61

2.5 Sallenger regime calculated with Stockdon parameterization for NACCS 100-year values . . . . . . . . . . . . 63 


\section{LIST OF FIGURES}

Figure

Page

1.1 Study area in Washington County (grids G1-G4) and Block Island (grid G5). (a) Relative location of the study area (grid G4) among other computational grids. (b) Grid G4: area of FEMA transects 33-66 and location of three specific sites detailed in this study (red boxes). Color scale is bathymetry $(j 0)$ and topography $(i 0)$ in meters. . . . . . . . . . . . .

1.2 (a) West Passage transect (WP-T); (b) Significant wave height in control test results compared to the base case (scenario 1) along the WP-T: water depth (NAVD88; black), propagation only (scenario 0a; blue - matches no wind), no wind (scenario 0b; red), and base case (scenario 1; yellow). . . . . . . . . 14

1.3 Sensitivity of model significant wave height results to (a) grid resolution and (b) bottom friction along the West Passage (WP$\mathrm{T}$; Figure 1.2a) . . . . . . . . . . . . . . .

1.4 Sensitivity of model significant wave height results to (a) wind speed and (b) wind direction along the West Passage crosssection (WP-T; Figure 1.2a) . . . . . . . . . . . . .

1.5 Comparison of significant wave height computed at the origin of the FEMA transects 45 to 66 in the upper part of the West Passage of Narragansett Bay: FEMA (red), NAST no wind (scenario 0 ; black), base case (scenario 1; blue, filled circle), wind case (scenario 2; blue circle) and extreme wind case (scenario 3; blue triangle) . . . . . . . . . . . . . . . . . . 17

1.6 Significant wave height (m) computed in the Narragansett Bay for base case (scenario 1) and the three selected focus areas (white boxes) . . . . . . . . . . . . . .

1.7 Results of NAST 100-year storm simulations at the Narragansett Beach site: (a) Wave crest (m) scenario 1; (b) BFE (m) scenario 1; (c) Wave crest (m) scenario 3; (d) BFE (m) scenario 3. Numbered transects are local FEMA transects. . . . 
1.8 Results of NAST 100-year storm simulations at the Bonnet Shores site: (a) Wave crest (m) scenario 1; (b) BFE (m) scenario 1; (c) Wave crest (m) scenario 3; (d) BFE (m) scenario 3. Numbered transects are local FEMA transects. . . . . . . . . . 20

1.9 Results of NAST 100-year storm simulations at the Wickford site: (a) Wave crest (m) scenario 1; (b) BFE (m) scenario 1; (c) Wave crest (m) scenario 3; (d) BFE (m) scenario 3. Numbered transects are local FEMA transects. . . . . . . . . . . . . . . 22

1.10 Cross section at the location of FEMA's transect 43 across Narragansett Beach: (a) using NAST method, (b) as reported by FEMA (Obtained from FEMA, 2015). (a) shows the predicted BFE for NAST scenario 1 (blue) and 3 (red) compared to FEMA's (dashed black); bathymetry is shown in solid black; (b) shows FEMA's wave envelope as provided (ft) with VE zone (red), AE zone (blue), 500-year SWEL (grey) and topography

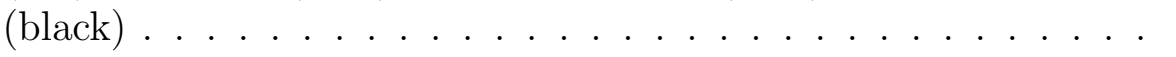

1.11 Cross section at the location of FEMA's transect 48 across Bonnet Shores: (a) using NAST method, (b) as reported by FEMA (Obtained from FEMA, 2015). (a) shows the predicted BFE for NAST scenario 1 (blue) and 3 (red) compared to FEMA's (dashed black); bathymetry is shown in solid black; (b) shows FEMA's wave envelope as provided (ft) with VE zone (red), AE zone (blue), 500-year SWEL (grey) and topography (black) . . .

1.12 Cross section at the location of FEMA's transect 60 across Wickford: (a) using NAST method, (b) as reported by FEMA (Obtained from FEMA, 2015). (a) shows the predicted BFE for NAST scenario 1 (blue) and 3 (red) compared to FEMA's (dashed black); bathymetry is shown in solid black; (b) shows FEMA's wave envelope as provided (ft) with VE zone (red), AE zone (blue), 500-year SWEL (grey) and topography (black) . . . 25

1.13 Comparison between NAST mean BFE (m - red) and FEMA's reported BFE (m - black) for the (a) AE and (b) VE zones at the local FEMA transects. . . . . . . . . . . . . . . 26

2.1 Study area on the southern RI coast . . . . . . . . . . . 41 
2.2 Water elevation(m-NAVD88; BFE, bold lines; SWEL + wave setup, light lines) versus landward cross-shore distance (m) along FEMA transects 19 and 20, for FEMA (red) and NAST (blue) (modified from Spaulding et al. (2016) . . . . . . . . . 44

2.3 Component modules in XBeach. Arrows indicate connectivity and terms in italics indicate relative output parameters. The black dotted lines encompass the hydrodynamic (top) and morphodynamic (bottom) modules. Boundary conditions are only used in the first cycle. (Daly, 2009) . . . . . . . . . . . .

2.4 XBeach model domain with URI GSO and FEMA transect locations. Grid is at 116 degrees counterclockwise from East. Red dot is grid origin. GSO transects include: EST1, EST2, CHABW, CHATB, GRH; FEMA transects include: FEMA19, FEMA20 ......................... 54

2.5 GSO cross-shore profiles (black) pre-(solid) and post- (dashed) Hurricane Irene with XBeach model input bathymetry (blue) (Table 2.1, Figure 2.4) . . . . . . . . . . . . . . . 56

2.6 Hurricane Irene wave height, peak period, and water elevation time series at XBeach offshore boundary, obtained from an ADCIRC-SWAN regional grid simulation . . . . . . . . 58

2.7 NACCS 457 significant wave height, peak period, and water elevation time series at XBeach offshore boundary . . . . . . . 60

2.8 Sketch defining the relevant morphologic and hydrodynamic parameters in the storm impact scaling model of Sallenger (2000) (modified from Stockdon et al., 2009)(from Stockdon et al., 2012) 61

2.9 Hurricane Irene simulation results at GSO transects for 5 scenarios in Table $2.2 \ldots \ldots$. . . . . . . . . . . . . . . 64

2.10 Difference between pre- and post- storm elevation $(\mathrm{m})$ for the 4 scenarios in Table 2.4: a) 457 Case1 (facua $=0.1$, bed friction $=0.02) ;$ b) 457 Case $2($ facua $=0.3$, bed friction $=0.02)$; $)$ 457 Case3 $($ facua $=0.1$, bed friction $=$ variable $) ;$ d) 457 Case 4 $($ facua $=0.3$, bed friction $=$ variable $) \ldots \ldots . .$. 
2.11 100-Year Storm Simulated Profiles at 5 URI GSO Transects (positive $\mathrm{x}$ seaward) with blue lines indicating a facua parameter $=0.1$, red lines indicating a facua parameter of 0.3 , solid lines indicating constant bed friction coefficient $=0.02$, dashed lines indicating variable bed friction, and black as the input model bathymetry .................... 68

2.12 100-Year Storm Simulated Profiles at FEMA Transects (positive $\mathrm{x}$ seaward) with blue lines indicating a facua parameter $=$ 0.1 , red lines indicating a facua parameter of 0.3 , solid lines indicating constant bed friction coefficient $=0.02$, dashed lines indicating variable bed friction, and black as the input model bathymetry .................. . . 69

2.13 FEMA and Oakley eroded profiles at FEMA transects (positive x seaward $\ldots \ldots \ldots$. . . . . . . . . . . . . 70 


\title{
MANUSCRIPT 1
}

\section{Predicting the 100-year storm inundation along the Narragansett Bay shoreline}

\author{
by \\ Lauren Schambach, Annette R. Grilli, and Malcolm L. Spaulding \\ In preparation for submission to the American Society of Civil Engineers Journal \\ of Waterway, Port, Coastal, and Ocean Engineering
}


Abstract. The lack of confidence in FEMA maps after Hurricane Sandy (2012) led to question the accuracy of the methodology used in FEMA Flood Insurance Rate Maps (FIRM). The present analysis presents a case study, re-computing the 100year inundation maps in Washington County, RI, using a chain of two-dimensional models. Presented results focus on the West Passage of the Narragansett Bay, Rhode Island, USA, an area characterized by a complex shoreline. The selection of the initial and boundary conditions for ocean wave simulations are based on results of fully coupled 2-D surge and wave models, the ADvanced CIRCulation model (ADCIRC) and the phase-averaged STeady state spectral WAVE model (STWAVE), respectively, from the North Atlantic Coast Comprehensive Study (NACCS) performed by the U.S. Army Corps of Engineers. Waves are simulated using STWAVE over a series of high-resolution grids in near-shore and overland areas. The method is referred to as the NAST method. Results are mapped and compared with FEMA's results along transects. Cross-sections across the Base Flood Elevation (BFE) at the site of the FEMA 1-D transects are in relatively good agreement using both methodologies, with larger discrepancies shown in the northern section of the bay. Discrepancies are primarily due to a difference in the 100-year wind assumption and secondarily to the 100-year storm surge assumption, which, besides defining the depth and extension of the inundation, controls the wave impact over land. Mapping the results reinforces the importance of adopting a 2-D approach to fully represent the inundation, showing that the selected transects often miss the sites of the most extreme wave incursion and most destructive impacts. The analysis highlights the differences in methods and results but also suggests adopting, besides a 2-D approach, a scenario-based approach to the 100-year storm rather than a deterministic single map to assess the uncertainty associated with this event. 


\section{$1.1 \quad$ Introduction}

The National Research Council (NRC) of the National Academies published a report in 2009 discussing theoretical and practical issues related to the Federal Emergency Management Agency's (FEMA) map accuracy (NRC, 2009). One of NRC's key findings was that the accuracy of the coastal flood maps could be improved significantly through the use of coupled two-dimensional storm surge and wave models and improved process models (NRC, 2009). In this analysis, we present a case study that addresses this particular concern.

Indeed, the severe local impact of Hurricane Sandy on the Rhode Island (RI) shoreline led communities to question the accuracy of FEMA's 2012 Flood Insurance Rate Maps (FIRM) to represent 100-year storm events. As a result, the RI Coastal Resource Management Council (CRMC) requested an independent assessment of the FIRM maps for Washington County. Washington County encompasses the entire south shore of RI, most of the western shoreline of the West Passage of Narragansett Bay, as well as Block Island (Figure 1.1a). The present study addresses CRMC's request, following the NRC recommendation, by re-computing the 100-year inundation maps in Washington County using an alternative methodology to that used by FEMA for the FIRMs, i.e., a chain of 2-D models rather than 1-D models along cross-shore transects. The study uses FEMA's accepted models only.

Recent works have re-assessed the validity of FEMA maps using a statisticaldeterministic approach in which synthetic storms are generated with physical models using a statistically defined storm environment. In this respect, Orton et al. (2016) have focused on the New York Harbor inundation risk, while Lin et al. (2012) extended the method to a dynamical-statistical approach, in which they simulated synthetic storms associated with climate model simulations to account 
for future storm climatology changes. The latter method was applied to assess the storm surge risk on specific coastal communities (Lin and Emanuel, 2016).These state-of the art research approaches only focused on the storm surge risk.

In this study we use a similar statistical-deterministic approach, using the results of the North Atlantic Coast Comprehensive Study (NACCS; Cialone et al., 2015), performed by the U.S. Army Corps of Engineers (USACE), to determine the 100-year storm surge, which we use as initial and boundary conditions for wave simulations performed in high resolution nested coastal grids. In the NACCS, the USACE generated synthetic tropical and historical extra-tropical storms to simulate surge and waves along the U.S. East Coast, using the fully-coupled ADvanced CIRCulation hydrodynamic (ADCIRC) and the phase-averaged STeady state spectral wave (STWAVE) models (Smith et al., 1991; Massey et al., 2011; Anderson and Smith, 2015). Resulting storm surge and wave spectral parameters were saved at hundreds of virtual stations in the study area, and provided in a probabilistic form (return period) (Nadal-Caraballo et al., 2015).

In RI, FEMA has historically simulated wave elevations over land using the 1-D Wave Height Analysis for Flood Insurance Studies model (WHAFIS), which was developed in 1977 and revised in 1988 to include wave growth and decay through vegetation (FEMA, 1988, 2007b). FEMA's storm surge values used in RI have been empirical, based on a statistical Extreme Value Analysis of time series recorded at three tide gages: New London, CT (West of Washington County), Newport and Providence, RI (at the mouth and end of the Narragansett Bay, respectively). In the RI 2012 FIRM, wave setup was estimated based on Saville's (1961) explicit experimental formulation, as recommended by the Shore Protection Manual (SPM, 1984) or, implicitly, based on either the TAW runup methodology (Technical Advisory Committee for Water Retaining Structures) proposed by van 
der Meer $(1992,2002)$ or Stoa's runup curves as implemented in FEMA's runup module (FEMA, 1991; Stoa, 1978). In FEMA's method, calculations are done along each transect using one of the above formulations and continuous values are estimated along the RI coastline by interpolation in between transects. FEMA's method uses erosion and runup modules when criteria for those processes to occur are met. In addition, when a potentially fragile structure is present on a transect, a new land profile is built, assuming that the structure has failed, thus limiting the protection of areas further inland.

In this study, we built on the results of the NACCS by integrating their regional scale surge estimations with local scale wave modeling. For the latter, we elected to use STWAVE in order to comply with FEMA's authorized model list. Our chain of 2-D models is referred to in the following as the NAST (NACCSSTWAVE) approach.

Besides the 2-D extension, the main focus of the work is on the impact of waves in the inundation zone. Our method provides the 2-D approach that FEMA's method is currently lacking, providing a 2-D representation of the inundation zone, including wave elevation at a very fine scale (waves propagated in a $10 \mathrm{~m}$ grid and mapped on a $5 \mathrm{~m}$ interpolated grid), as well as a reliable method to capture specific 2-D processes associated with wave propagation, such as refraction, which is particularly relevant in an area defined by complex bathymetric and topographic features such as the Narragansett Bay (Figure 1.1).

The methodology as applied in this case study carries some simplified assumptions: (1) No protocol to assess the inundation zone in case of failure of a structure is applied; (2) Dunes are assumed kept intact. Although we have developed a protocol that simulates wave propagation across an eroded dune following a 100-year dune profile along the southern shoreline of RI (Spaulding et al., 2016; Grilli et al., 
2016), we have neglected this process in this more sheltered section of the coastline; (3) since STWAVE is not a phase resolving model, it does not simulate the runup, therefore this process is not included in the simulations. In the following, we first describe the NAST methodology as applied in the case study area; then, we present the resulting new inundation maps as well as selected cross-sections across the inundation zone to illustrate the comparison FEMA/NAST at the site of FEMA's transects.

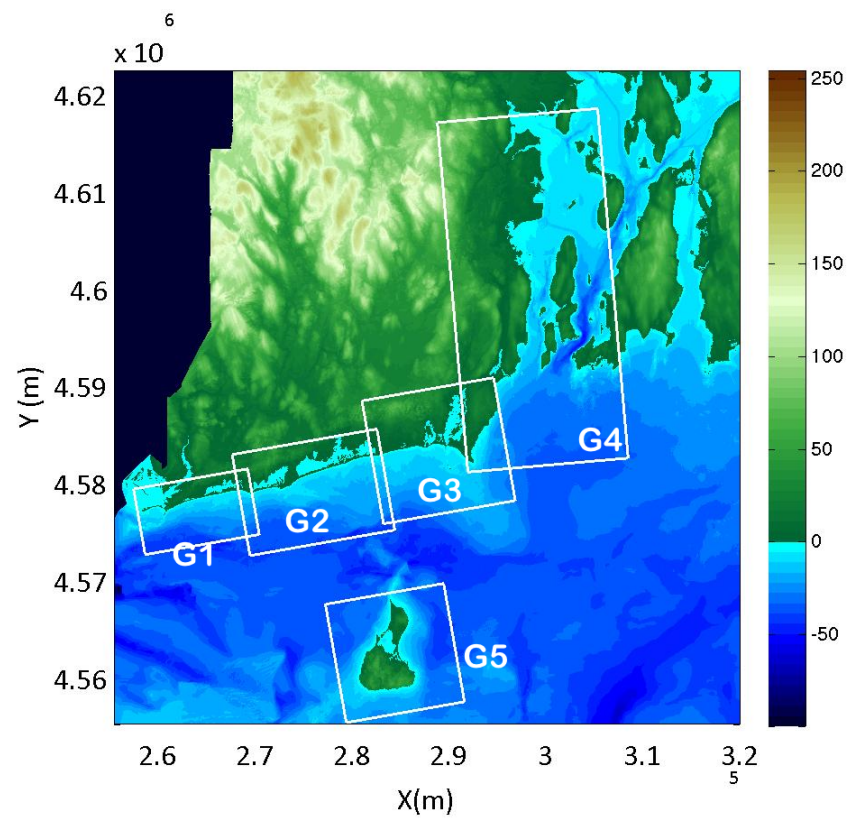

(a)

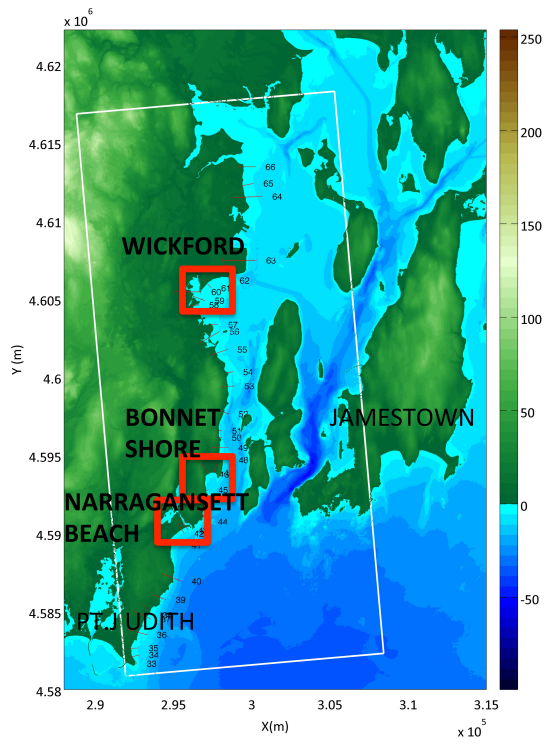

(b)

Figure 1.1: Study area in Washington County (grids G1-G4) and Block Island (grid G5). (a) Relative location of the study area (grid G4) among other computational grids. (b) Grid G4: area of FEMA transects 33-66 and location of three specific sites detailed in this study (red boxes). Color scale is bathymetry $(j 0)$ and topography $(i 0)$ in meters.

\subsection{Methodology}

Washington County was divided into several Cartesian computational grids with resolution of $\Delta \mathrm{x}=10 \mathrm{~m}$, designed to maximize topographic/bathymetric resolution and reflect the local wave climate. Waves are simulated across these grids using NACCS results as initial and boundary conditions. 
Characteristics of the Narragansett Bay grid G4 are summarized in Table 1.1 (Figure 1.1). The grid is oriented along the dominant wave direction of propagation (cross-shore, $\mathrm{x}$ ) with the origin of the grid $\left(\mathrm{x}_{0}, \mathrm{y}_{0}\right)$ at the south-east corner. The angle of rotation of the grid, $\alpha$, is estimated counterclockwise from East (Table 1.1). Bathymetry and topography were derived from the merged 2011 LiDAR and NOAA bathymetry (RIGIS, 2013) (Figure 1.1).

\begin{tabular}{|c|c|c|c|c|c|c|}
\hline GRID & $\mathbf{X}_{0}$ (UTM) & $\mathbf{Y}_{0}$ (UTM) & $\boldsymbol{\alpha}(\mathbf{d e g})$ & $\boldsymbol{\Delta} \mathbf{x}(\mathbf{m})$ & Length (m) & Width (m) \\
\hline G4 & 308430 & 4582310 & 95 & 10 & 36100 & 16560 \\
\hline
\end{tabular}

Table 1.1: Narragansett Bay grid (G4) parameters, Coordinates are UTM (19T)

STWAVE was applied in half-plane mode (energy propagation offshore is neglected) using 2-D incident wave spectra reconstructed from the NACCS parameters as offshore boundary conditions. STWAVE simulates wave propagation in the horizontal plane, including refraction based on geometric optic theory and shoaling based on the conservation of wave action along wave rays (Smith et al., 1991; Massey et al., 2011). The sea state growth through the transfer of momentum from the wind field to the wave field is modeled using Resio's $(1981,1988)$ formulation. Wind energy fed into the waves is redistributed through non-linear interactions from the peak of the spectrum to both lower frequencies, increasing the peak period, and to higher frequencies, where it is dissipated through whitecapping, depth-induced wave breaking, and turbulent effects (Resio, 1987, 1988). This nonlinear energy transfer due to wave-wave interactions, first described by the Boltzmann integrals of Hasselmann (1961), is implemented using Resio's methodology (Resio and Perrie, 1991). The loss of energy by wave breaking is modeled using Miche's (1951) breaking criterion, which includes the effects of both water depth and wave steepness-limited breaking (Smith et al., 1997; Battjes 1982; Battjes and Janssen, 1978). The energy loss is simulated by reducing the spectral 
energy, in each frequency and directional band proportionally to the amount of pre-breaking energy contained in each band. The bottom friction loss is implemented in this version of STWAVE (V6) using a Manning coefficient formulation (Holthuijsen, 2007), which can be specified as a spatially variable parameter.

The directional wave spectrum for the 100-year storm is specified as input offshore boundary conditions for each STWAVE computational grid, based on results and parameters computed in the NACCS study at save points, including the significant wave height, $H_{s}$, peak spectral period, $T_{p}$, and dominant wave direction, $\theta_{0}$. To express the spectrum based on these parameters, we use a TMA energy spectrum since it was shown to optimally represent swell and wind-generated gravity waves in shallow water (Bouws et al., 1985).

The NACCS study used a state-of-the-art stochastic approach to generate a large number (1150) of tropical and extra-tropical storms along the Atlantic Coast, model their propagation, and estimate the return period of storm parameters relevant to coastal vulnerability, in particular, static water elevation and significant wave height. The storms were generated based on primary or generative variables (central pressure deficit, forward speed, radius of maximum wind, heading direction, landfall location) whose initial value varied within confidence intervals based on observed values in historical events. Each of the synthetic storms was modeled using a succession of nested and coupled models forming the Coastal Storm Modeling System (CSTORM-MS). In particular, waves were propagated in deep water using the 3rd generation wind-wave model WAM (WAMDI group, 1988), which provided boundary conditions for STWAVE in coastal waters (on a $200 \mathrm{~m}$ resolution grid). The latter model was fully coupled with the storm surge model ADCIRC. Results were saved at a large number of save points, in terms of value of the relevant parameters for each storm, such as static water elevation and sig- 
nificant wave height, as well as in terms of their return periods.

The 100-year return period values of these parameters (mean and 95\% upper confidence interval) were extracted at each save point located in RI waters (about 1,000 points) and interpolated onto our local high-resolution $10 \mathrm{~m}$ grids (Figure 1.1). The mean value of each relevant parameter at the offshore boundary was selected as the representative offshore value used to reconstruct the local TMA spectra. We selected the standard value for the spectral peak enhancement factor $\gamma$ of 3.3, as well as for the directional spreading factor $\cos ^{n} \theta$ with $n=4$. Parameters for the 100-year storm spectrum and grid boundary conditions are defined in Table 1.2 , and briefly described in the following.

The term still water level (SWL) is commonly used to describe the water level in the absence of wind waves and their effects, and thus includes the astronomical tide and the storm surge (due to wind effects); the static water level (STWL) is defined as the sum of the SWL and the static wave setup/setdown, the mean additional elevation of the water (positive or negative) associated with the presence of waves. NACCS provided the STWL for each 100-year synthetic storm at each save point; this level was interpolated and used as the reference level in our 10 m grids to compute near-shore and overland wave propagation with STWAVE. It should be noted that, in RI, the CRMC elected to use the 100-year upper $95 \%$ confidence interval values, rather than the mean value as the representative 100year STWL. This selection was made in order to be conservative and account for uncertainties in the analyses.

Significant wave height $\left(H_{s}\right)$ : Similarly, the NACCS provides mean significant wave height values at each save point for various return periods and their 95\% confidence interval. However, in this case, extreme value statistical analysis provides unrealistic upper $95 \%$ confidence intervals when considering the physics of 
wave growth and dissipation processes. Therefore the mean 100 -year $H_{s}$ was used as the representative wave height parameter of the 100-year event.

Peak spectral wave period $\left(T_{p}\right)$ : Significant wave height and peak spectral period are correlated and in deep water can reasonably be related by assuming a Pierson Moskowitz fully developed spectrum, with the relationship: $T_{p}=15.6\left(H_{s} / g\right)^{1 / 2}$, with $g$ being the gravitational acceleration. This yields $T_{p}$ $=19.8 \mathrm{~s}$, based on the 100-year mean $H_{s}$ in deep water (about $15 \mathrm{~m}$ ), which is consistent with the 100-year NACCS storm values obtained from extreme statistical analysis at selected offshore save points (e.g., at the US Army Corp of Engineers, Wave Information Studies (WIS) station 79, the 100-year storm has a peak period of $20 \mathrm{~s}$ ). Spectral parameters used in the analysis are summarized in Table 1.2 for the grid G4 (Figure 1.1).

\begin{tabular}{|c|c|c|c|c|c|c|c|}
\hline GRID & Spectrum ID & Spectrum Type & Depth $(\mathbf{m})$ & $\boldsymbol{H}_{\boldsymbol{s}}(\mathbf{m})$ & $\boldsymbol{T}_{\boldsymbol{p}}(\mathbf{m})$ & Offshore BC & Side BC \\
\hline G4 & S4 & TMA & 38 & 9 & 20 & S4 & Open \\
\hline
\end{tabular}

Table 1.2: Summary of spectral boundary conditions for the Narragansett Bay grid (G4)

Wind speed $(U)$ : an extreme value analysis provides offshore wind speeds of $37 \mathrm{~m} / \mathrm{s}$ and $35 \mathrm{~m} / \mathrm{s}$ for the 100-year upper $95 \%$ confidence interval event, based on NACCS and WIS station 79 data respectively (WIS, 2010). The 100-year associated wind directional sector is based on a joint probability, since wind speed and direction are correlated. At WIS station 79, sustained wind conditions above $20 \mathrm{~m} / \mathrm{s}$ only occur from NW and NE sectors for events with at least a 1\% probability occurrence. When approaching the shore, the wind speed generally reduces due to land roughness, by about $20 \%$ when reaching the coastline as compared to offshore winds (Hasager et al., 2005; Swartz et al., 2010). This would result in 100-year wind at the shoreline on the order of $28 \mathrm{~m} / \mathrm{s}$. This value, combined with a NE sector, was selected as the NAST base case scenario (NE was selected to maximize 
fetch along the NE-NW sector). This value is consistent with FEMA's protocol that adopts 100-year values of 80 and $60 \mathrm{mph}(36 \mathrm{~m} / \mathrm{s}$ and $27 \mathrm{~m} / \mathrm{s})$ for unlimited and limited fetch, respectively (FEMA, 2007a). NAST wind and extreme wind case scenarios assume southerly winds of $35 \mathrm{~m} / \mathrm{s}$ and $50 \mathrm{~m} / \mathrm{s}$ respectively (Table $1.3)$.

Bottom friction: Wave propagation over inundated land is simulated using a spatially variable Manning coefficient related to land coverage (RIGIS, 2015). A Manning coefficient value is assigned for each land use category, resulting in a Manning Coefficient Map with variations from 0.02 in open water to 0.1 over woody wetlands (Wamsley et al., 2009, 2010; Arcement and Schneider, 1989).

\subsection{Results}

Results of simulations are presented as maps and 1-D transects at the locations of FEMA transects. The inundation zone is defined as the intersection of STWL with the topography and the shoreline (0 m, NAVD88). STWAVE results are mapped from offshore to the end of the inundation zone in the form of wave crest elevation, $\eta_{c}$, and Base Flood Elevation (BFE) maps. The wave crest elevation according to FEMA's terminology is defined as $\eta_{c}=0.7 H_{c}$ (National Academy of Sciences, 1977), with $H_{c}$, the controlling wave height, equal to the mean of $1 \%$ of the highest waves. Assuming that waves are linear and Rayleigh distributed, the controlling wave height and significant wave height are related by $H_{c}=1.66 H_{s}$. The BFE is the maximum water elevation of the controlling wave crest riding over the STWL, referenced to NAVD88 $\left(\mathrm{BFE}=\mathrm{STWL}+\eta_{c}\right)$. FEMA's $V E$ and $A E$ zones are defined by a wave crest threshold of $0.9 \mathrm{~m}(3 \mathrm{ft})$. The VE zone is an inundated area with a controlling wave crest larger than $0.9 \mathrm{~m}\left(H_{s}>0.8 \mathrm{~m}\right)$; the AE zone is an inundated area with a controlling wave crest smaller than $0.9 \mathrm{~m}$. The limit of moderate wave action (LiMWA) in the AE zone is the limit of wave 
crests larger than $0.45 \mathrm{~m}\left(1.5 \mathrm{ft} ; H_{s}>0.4 \mathrm{~m}\right)$. Note that neither dynamic setup nor runup is included in the current estimation of NAST BFE.

Wave simulations were performed for the 100-year spectral parameters, as defined in the previous section, specified as boundary and initial conditions. The model was first tested for a range of grid sizes, friction values, and wind speed and direction to assess the associated uncertainty. Significant wave height results were plotted along a transect SW-NE crossing the Narragansett Bay West Passage from the mouth of the bay up to Prudence Island in the north of the bay (Figure 1.2a).

\subsubsection{Sensitivity analysis}

Table 1.3 summarizes the scenarios designed for wave simulation in the coastal grid G4. Simulations were performed for three hypothetical 100-year storm scenarios: the base case (scenario 1), a wind case (scenario 2), and an extreme wind case (scenario 3). These three scenarios have identical boundary conditions, but different local wind assumptions. In addition, we performed a sensitivity analysis to model grid size (scenarios 4a-d), friction (scenarios 5a-c), wind speed (scenarios 6a-c), and direction (scenarios 7a-1). Scenario 0 is the control test, propagation only and propagation without wind (includes wave-wave interactions). 


\begin{tabular}{|l|l|l|l|l|}
\hline Scenarios & $\begin{array}{l}\text { Grid } \\
\text { Resolution } \\
(\mathbf{m})\end{array}$ & $\begin{array}{l}\text { Bottom } \\
\text { Friction }\end{array}$ & $\begin{array}{l}\text { Wind } \\
\text { Speed } \\
(\mathbf{m} / \mathbf{s})\end{array}$ & $\begin{array}{l}\text { Wind } \\
\text { Direction } \\
\text { (deg) }\end{array}$ \\
\hline $\begin{array}{l}\text { 0a. Control test: } \\
\text { propagation only }\end{array}$ & 10 & 0.02 & - & - \\
\hline $\begin{array}{l}\text { 0b. Control test: } \\
\text { no wind }\end{array}$ & 10 & 0.02 & 0 & - \\
\hline 1. Base case & 10 & Manning & 28 & 34 \\
\hline 2. Wind case & 10 & Manning & 35 & 180 \\
\hline $\begin{array}{l}\text { 3. Extreme wind } \\
\text { case }\end{array}$ & 10 & Manning & 50 & 180 \\
\hline $\begin{array}{l}\text { 4a-d. Sensitivity to } \\
\text { resolution }\end{array}$ & $10,20,40,80$ & 0.02 & 28 & 34 \\
\hline $\begin{array}{l}\text { 5a-c. Sensitivity to } \\
\text { friction }\end{array}$ & 10 & $0.01,0.02,0.03$ & 28 & 34 \\
\hline $\begin{array}{l}\text { 6a-c. Sensitivity to } \\
\text { wind speed }\end{array}$ & 10 & 0.02 & $28,35,50$ & 34 \\
\hline $\begin{array}{l}\text { 7a-l. Sensitivity to } \\
\text { wind direction }\end{array}$ & 10 & 0.02 & 28 & $\begin{array}{l}0-360[30 \\
\text { deg. bins }]\end{array}$ \\
\hline
\end{tabular}

Table 1.3: Simulations of 100-year storm in grid G4: control, base, wind, extreme wind cases and sensitivity scenario parameters 

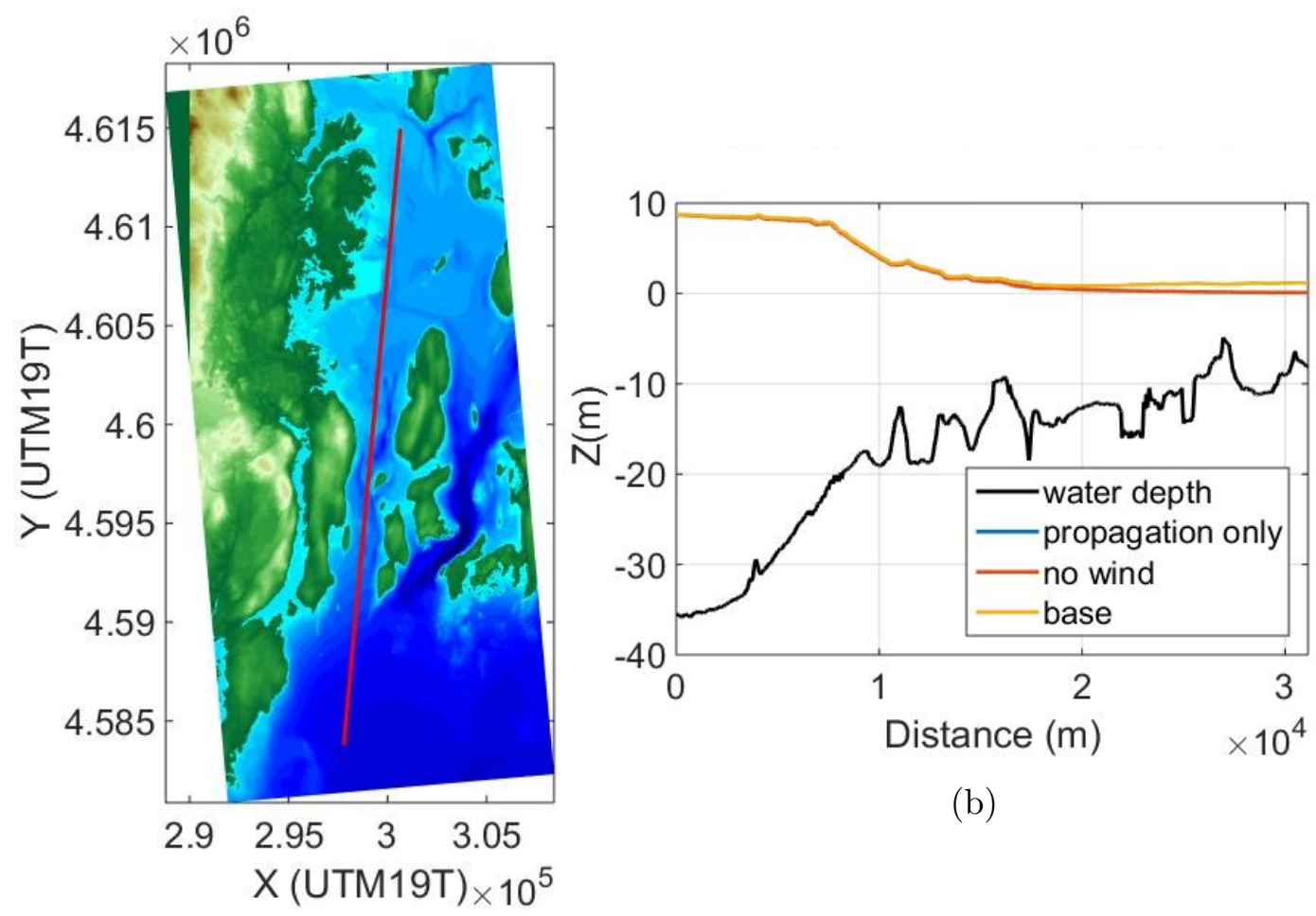

(b)

(a)

Figure 1.2: (a) West Passage transect (WP-T); (b) Significant wave height in control test results compared to the base case (scenario 1) along the WP-T: water depth (NAVD88; black), propagation only (scenario 0a; blue - matches no wind), no wind (scenario 0b; red), and base case (scenario 1; yellow).

Figure $1.2 \mathrm{~b}$ plots the significant wave height for the base case scenario (scenario 1) and the control test simulations, (scenario 0a and 0b), along the West Passage transect (WP-T) (Figure 1.2a). As expected, simulations 0a and 0b provide nearly identical results as the only difference between these cases is the inclusion of the wave-wave interactions in the no wind case. The bathymetry shown in the figure illustrates the correlation between wave dissipation by breaking and decrease in water depth, showing a significant drop in wave height when the depth decreases to about $15 \mathrm{~m}$. The base case shows an increase of the significant wave height as compared to the control tests when waves are progressing in the bay, noticeable about $17 \mathrm{~km}$ from the most offshore point of the transect (mouth of the 
bay), demonstrating the process of wave generation when the fetch is significant.

Figures $1.3 \mathrm{a}$ and $1.3 \mathrm{~b}$ show the sensitivity of model results to the grid resolution and to the friction respectively, which both have negligible effects. Figures $1.4 \mathrm{a}$ and $1.4 \mathrm{~b}$ show the sensitivity of model results to the wind speed and direction, both illustrating the impact of fetch combined with the wave re-generation through local wind.

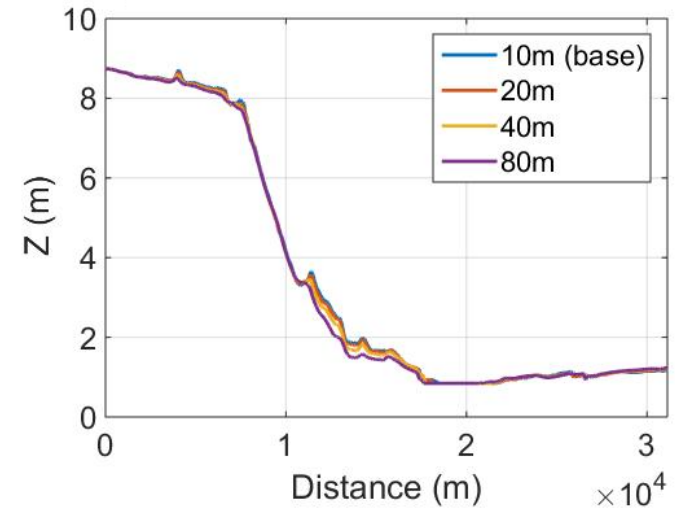

(a)

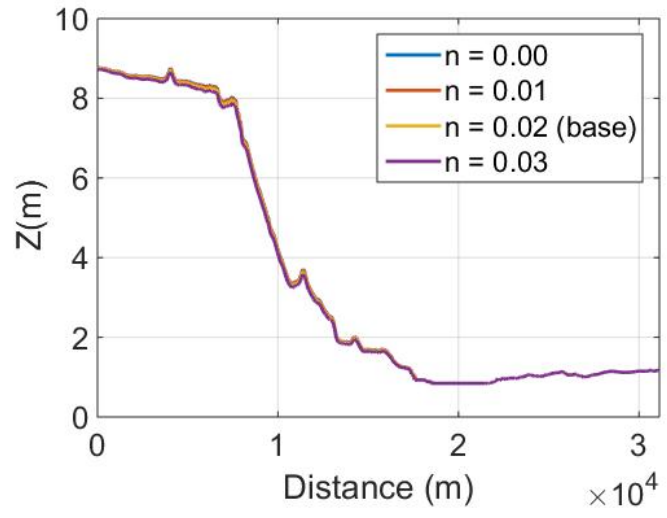

(b)

Figure 1.3: Sensitivity of model significant wave height results to (a) grid resolution and (b) bottom friction along the West Passage (WP-T; Figure 1.2a)

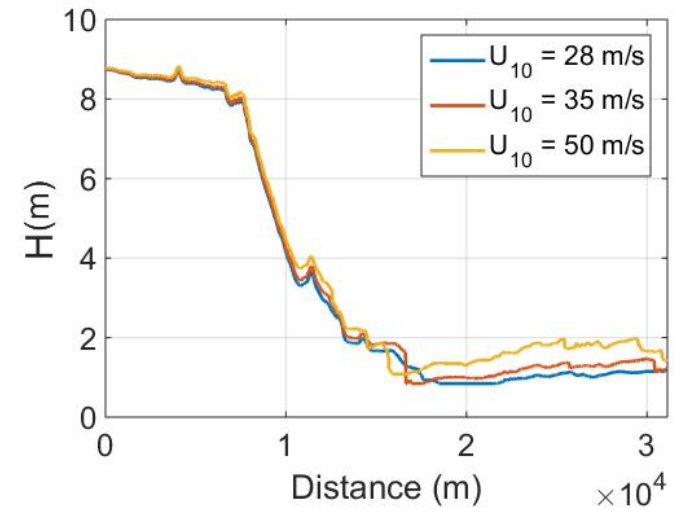

(a)

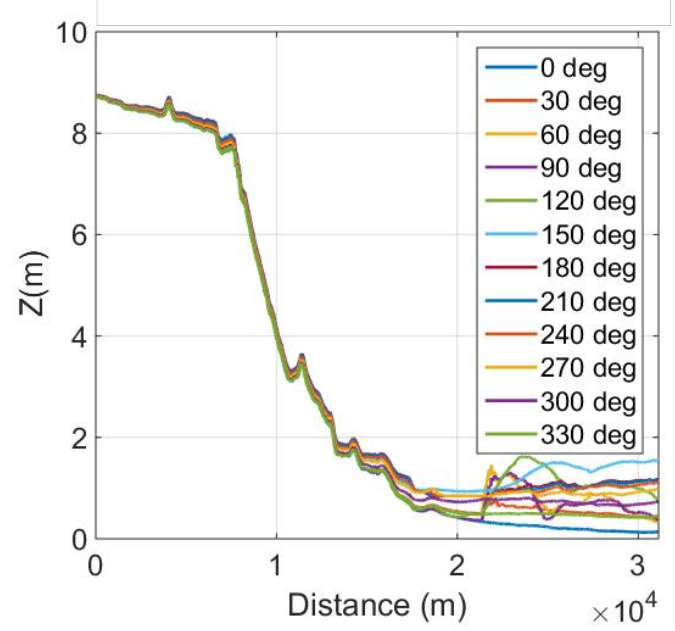

(b)

Figure 1.4: Sensitivity of model significant wave height results to (a) wind speed and (b) wind direction along the West Passage cross-section (WP-T; Figure 1.2a) 
A comparison of the NAST significant wave height computed at the origin of the FEMA transects (Figure 1.5), for scenario 1 (base), with the documented FEMA values of their significant wave height, shows a significant discrepancy in the estimated 100-year coastal wave elevation. While NAST simulations show large wave heights in the southern, most exposed, section of the bay $\left(H_{s}\right.$ on the order of 5 to $3 \mathrm{~m})$ and smaller wave heights in the upper section of the bay $\left(H_{s}<1 \mathrm{~m}\right)$, FEMA's wave heights seem to have suffered less dissipation from the southern to the northern part of the bay, providing larger wave height values mostly varying between 4 and $2 \mathrm{~m}$. The sensitivity analysis results shows that only the local wind can create such an increase in wave elevation in the upper part of the bay. Figure 1.5 shows results of NAST simulations for scenarios 2 and 3 (wind and extreme wind). We can see that in these extremely windy conditions, the local wind can regenerate significant waves in the bay. However, from a statistical perspective, winds associated with scenario 2 and 3 do not reflect 100-year winds, but much larger return period storms. However, in view of the current observed change in storm frequency and intensity it might be wise to use a design storm associated with more extreme winds than the current 100-year winds. 


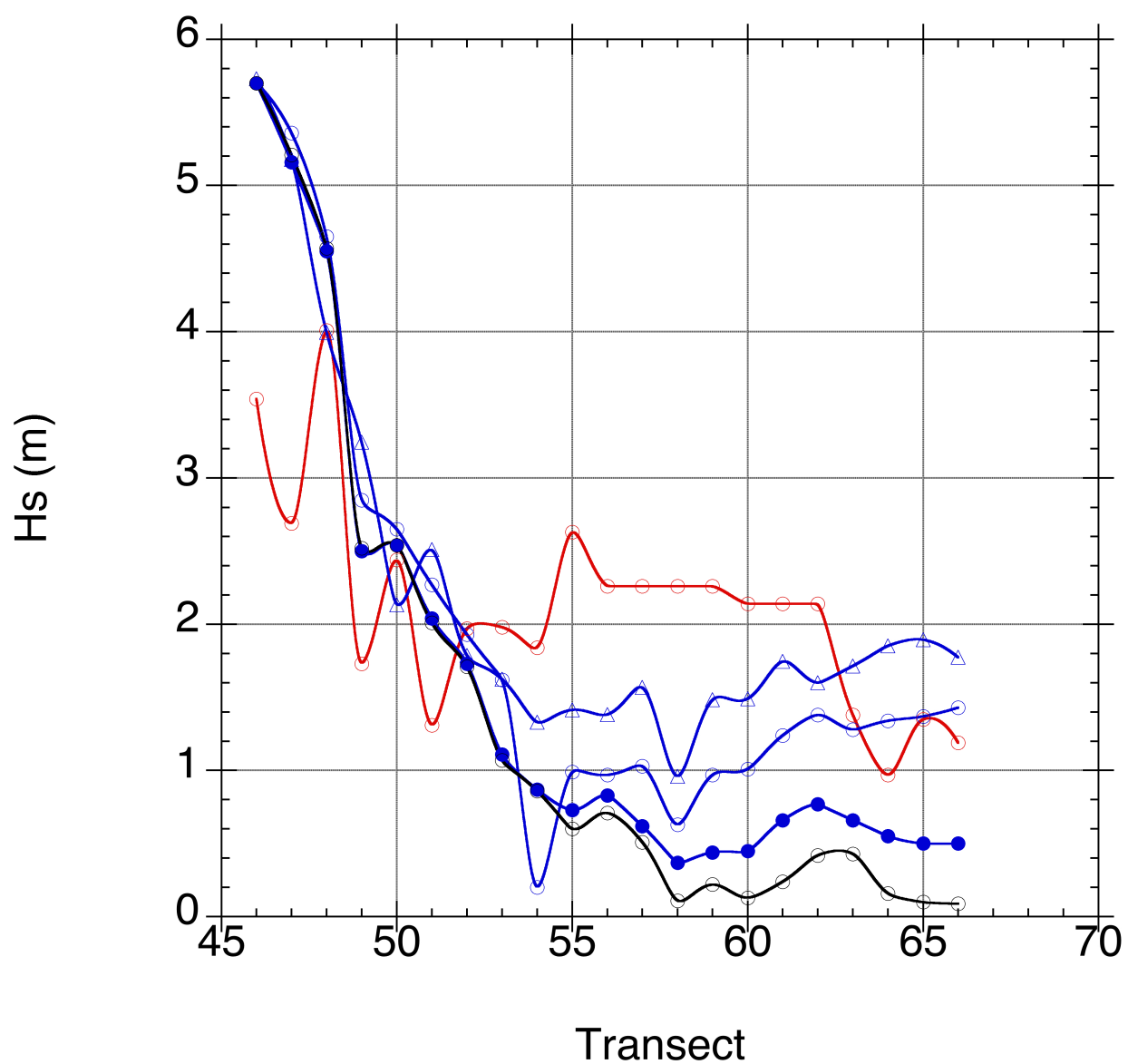

Figure 1.5: Comparison of significant wave height computed at the origin of the FEMA transects 45 to 66 in the upper part of the West Passage of Narragansett Bay: FEMA (red), NAST no wind (scenario 0; black), base case (scenario 1; blue, filled circle), wind case (scenario 2; blue circle) and extreme wind case (scenario 3; blue triangle)

\subsubsection{Inundation maps}

Figure 1.6 shows that, for the NAST 100-year storm base case (scenario 1), large waves $\left(H_{s}\right.$ on the order of $\left.8 \mathrm{~m}\right)$ are entering Narragansett Bay and propagating into shallow water, progressively losing energy by breaking and bottom friction dissipation and, consequently, decreasing in height. The refraction associ- 
ated with the complex bathymetry affects wave propagation, concentrating energy on underwater ridges and spreading it out in bay areas.

Three areas marked in Figure 1.6 in the West Passage of Narragansett Bay, Narragansett Beach, Bonnet Shores and Wickford, were selected to illustrate the resulting overland inundation maps (Figures 1.7 through 1.9). Narragansett Beach and Bonnet Shores have been historically strongly impacted by extreme storms such Sandy (October, 2012). Wickford is located further north in the bay, in a more sheltered site but harbors a pristine marina. All sites are at the heart of vibrant communities. For each area, we plot the wave crest elevation and the BFE to capture the overland wave propagation and the resulting BFE when combined with the surge. In addition, FEMA's transects are marked and cross-sections for selected transects are presented in the next section.

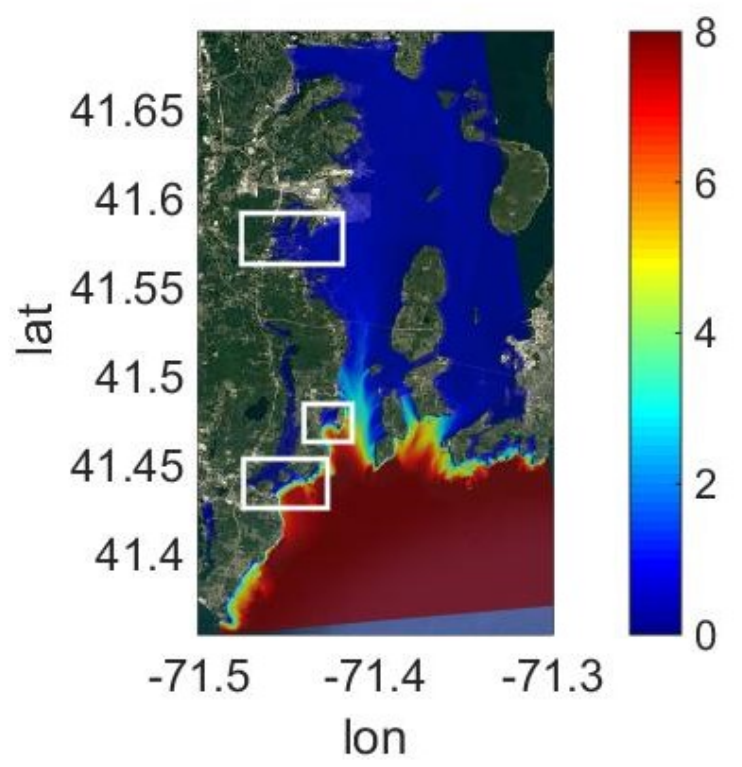

Figure 1.6: Significant wave height $(\mathrm{m})$ computed in the Narragansett Bay for base case (scenario 1) and the three selected focus areas (white boxes)

Figure 1.7 shows the wave crest elevation (Figure 1.7a) and the BFE (Figure 1.7b) computed at the southern site, Narragansett Beach, for scenario 1 (base 
case). Figures $1.7 \mathrm{c}$ and $1.7 \mathrm{~d}$ show similar results for scenario 3 (extreme wind case). Figures 1.8 and 1.9 show identical results for the two sites further north within the bay, Bonnet Shores and Wickford, respectively.

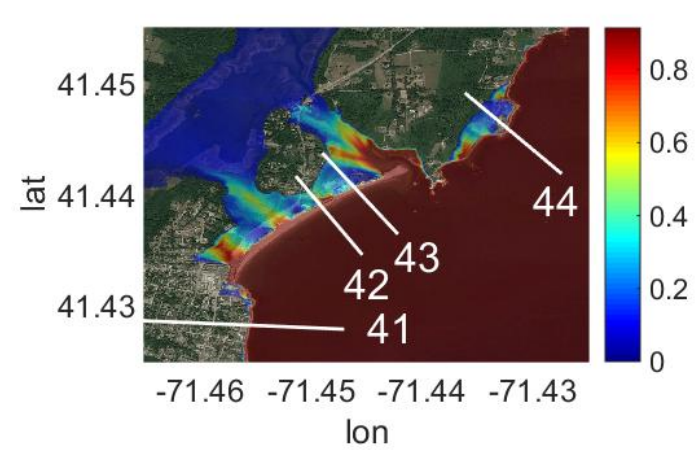

(a)

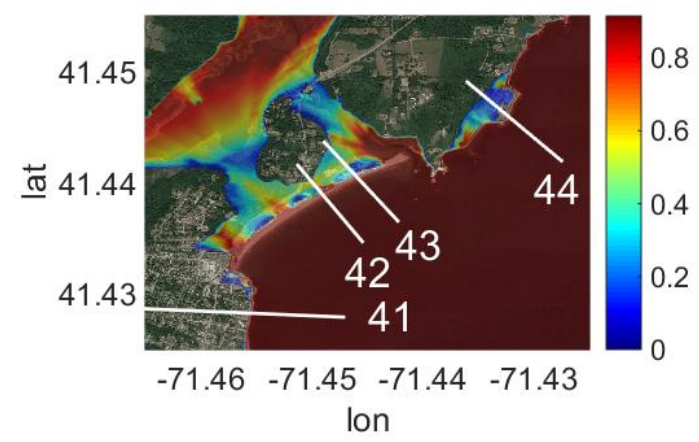

(c)

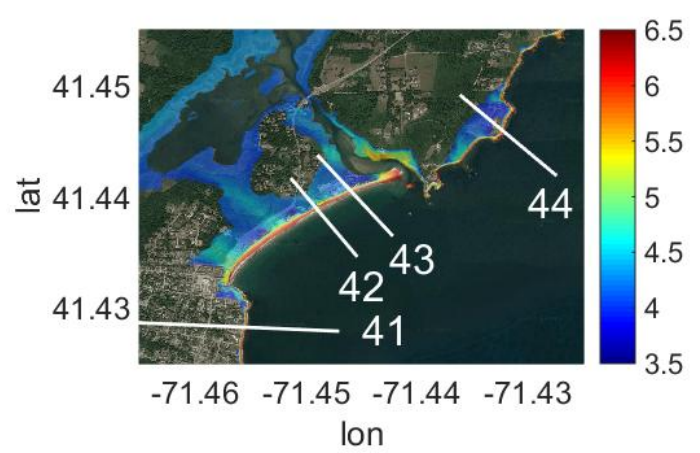

(b)

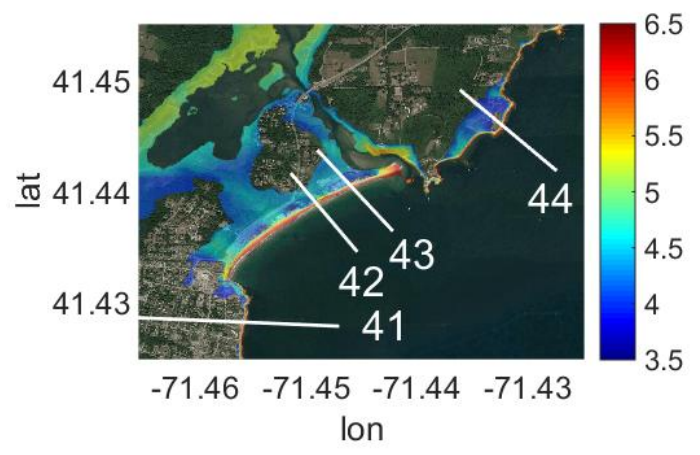

(d)

Figure 1.7: Results of NAST 100-year storm simulations at the Narragansett Beach site: (a) Wave crest (m) scenario 1; (b) BFE (m) scenario 1; (c) Wave crest (m) scenario 3; (d) BFE (m) scenario 3. Numbered transects are local FEMA transects. 


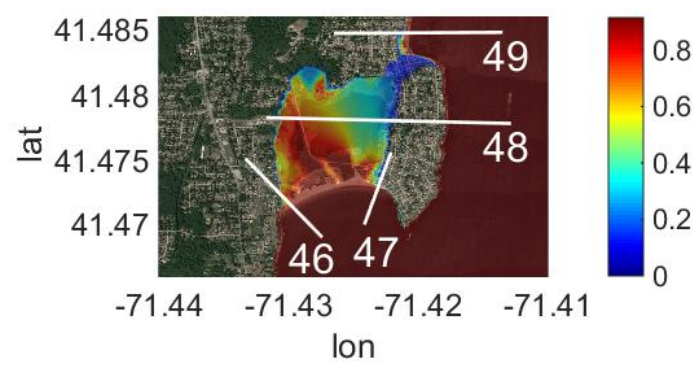

(a)

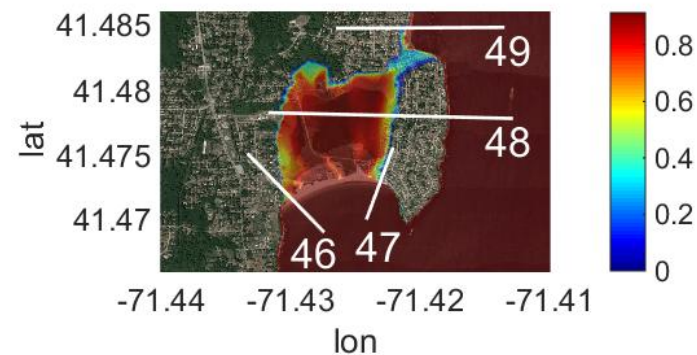

(c)

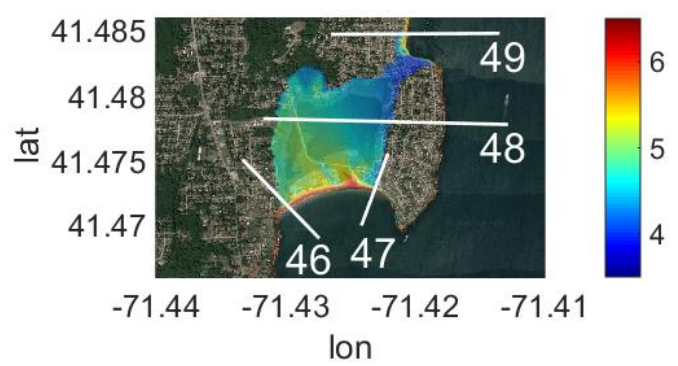

(b)

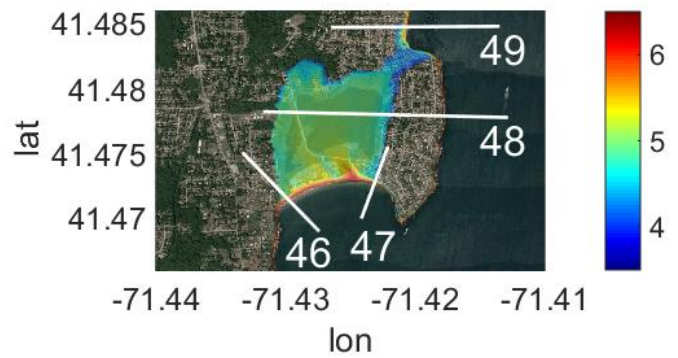

(d)

Figure 1.8: Results of NAST 100-year storm simulations at the Bonnet Shores site: (a) Wave crest (m) scenario 1; (b) BFE (m) scenario 1; (c) Wave crest (m) scenario 3; (d) BFE (m) scenario 3. Numbered transects are local FEMA transects.

The wave propagation at the mouth of the Petaquamscutt river at the north of Narragansett beach is finely modeled, showing waves (on the order of $1 \mathrm{~m}$ of controlling wave crest) propagating upstream, at the top of the surge across the salt marsh surrounding the river, locally increasing the BFE from $4 \mathrm{~m}$ up to 5.5 m (scenario 1; base case); for the high wind case, waves are penetrating slightly further upstream into the river. Wave regeneration due to the extreme southerly winds in the river is also apparent, increasing the BFE on the far shore.

In Narragansett Beach, the dunes, assumed intact for the current simulations, are creating a strong barrier, forcing the waves to break and preventing them 
from overflowing inland as they do in the no-dune/parking lot areas. In these unprotected areas, waves with an order of $1 \mathrm{~m}$ wave crest are propagating across the main road. While FEMA uses a relatively high density of transects in this area, none of these are capturing the maximum amplitude of the inundation, which crosses the main road and therefore isolates the northern section of the town from the southern one.

Similarly in Bonnet Shores and Wickford, none of the FEMA transects are able to capture the largest waves propagating across the beach in the inundation zone. In Bonnet Shores, Transect 48 intersects the main road, however, further north of the beach, where overland waves are already reduced. In Wickford, since the harbor is in a protected area, only relatively small waves are reaching the harbor. However, since NAST's SWEL is higher than FEMA's, waves are likely propagating further overland as shown on Transect 60. Runup might be a significant issue on the wall protecting the marina and a phase resolving model would be recommended to more accurately assess the vulnerability of this area. 


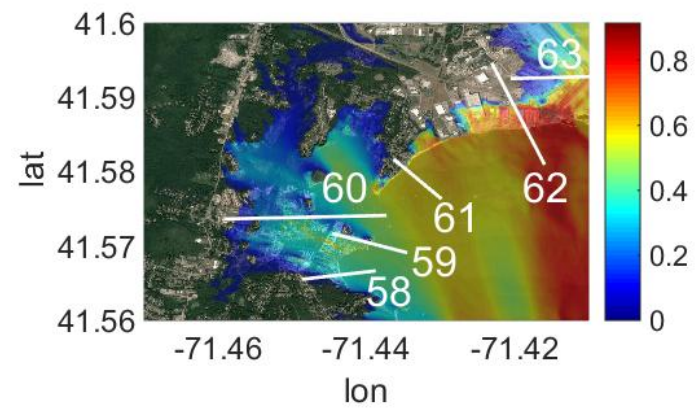

(a)

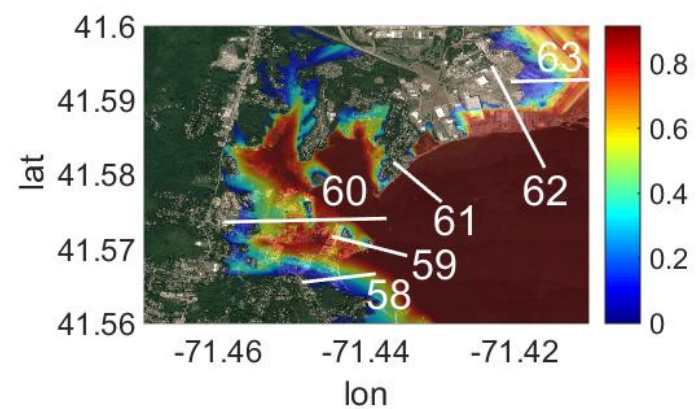

(c)

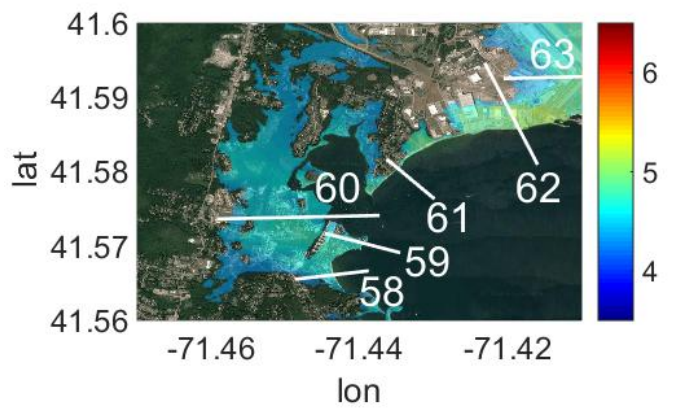

(b)

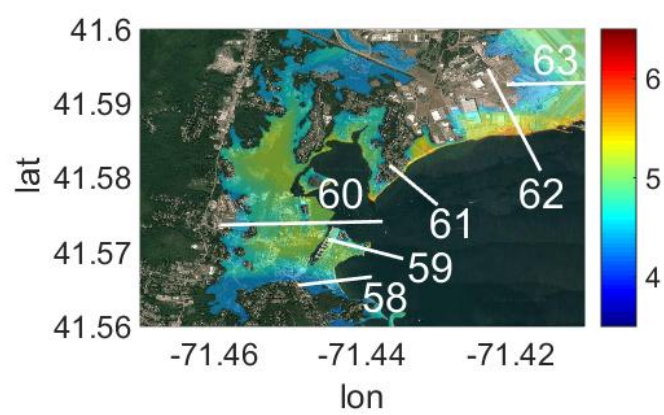

(d)

Figure 1.9: Results of NAST 100-year storm simulations at the Wickford site: (a) Wave crest (m) scenario 1; (b) BFE (m) scenario 1; (c) Wave crest (m) scenario 3; (d) BFE (m) scenario 3. Numbered transects are local FEMA transects.

\subsubsection{Transects}

FEMA's inundation maps are based on the value of the BFE along selected transects crossing the inundation zone. A systematic comparison of FEMA- and NAST-based transects shows that, in average, both methods provide a relatively similar BFE, when comparing NAST simulations with the final wave envelope. Figures 1.10 to 1.12 show a comparison of FEMA and NAST cross-sections, for selected transects in each of the three sites mapped above, based on the wave envelope as provided by FEMA.

A systematic comparison of the FEMA and NAST base case BFE elevations 
shows that on average NAST AE and VE zones are larger by $0.79 \mathrm{~m}$ and 0.44 m relative to FEMA's, respectively (Figure 1.13). This general overestimation is largely due to the higher SWEL in the NAST method as well as to the higher waves allowed to propagate overland since the SWEL is assumed to be higher. However, the largest differences occur in the northern section of the West Passage where FEMA's offshore significant wave height is significantly higher than in our simulations. Consequently, in this area, FEMA's estimated VE zone is unexpectedly larger than in our estimation. SWEL, VE and AE zone elevations as documented by FEMA are presented in Appendix 1, next to NAST's estimations for all of the Narragansett Bay transects (33 to 66).

It is interesting to note that the discrepancies between FEMA's BFE, as reported in the 2012 report (FEMA, 2012), and NAST's BFE (Appendix 1) seem larger than observed when we compare the transects. The VE zone elevation is indeed defined as the average BFE observed in the VE zone; FEMA and NAST however use slightly different methodologies to define the VE zone offshore limit. NAST restricts a priori the offshore limit of the VE zone to the contour line 0 NAVD88, which means that the VE zone is defined only if waves larger than 3ft are propagating overland, while FEMA does not restrict the VE zone to an overland area. Indeed FEMA defines the offshore limit of the VE zone relatively vaguely, specifying that the area is subject to breaking wave heights of 3 or more ft $(0.91 \mathrm{~m})$, which occurs where stillwater depth equals or exceeds $3.85 \mathrm{ft}(1.17 \mathrm{~m})$ (assuming wave height limited to 0.78 times still water depth)( Hatheway et al., 2005). Although it is not clearly specified how far offshore the zone extends, it is clear that the area extends in the coastal area around the $1.17 \mathrm{~m}$ breaking wave area, even if this area is not overland. This explains why NAST has barely any VE zone in the upper part of the Bay while FEMA has a relatively high VE zone since 
those are based on coastal values (offshore in the sense not overland). Transect 48 in Bonnet Shores is such an example, with a NAST VE of $5.7 \mathrm{~m}$ and a FEMA VE of $6.1 \mathrm{~m}$; this zone does not actually extend overland but is confined on the beach, beyond the ridge protecting the site; similarly in transect 60 in Wickford, NAST has no VE zone since overland waves are smaller than $3 \mathrm{ft}$ while FEMA shows a $5.2 \mathrm{~m}$ VE zone based on coastal waves.

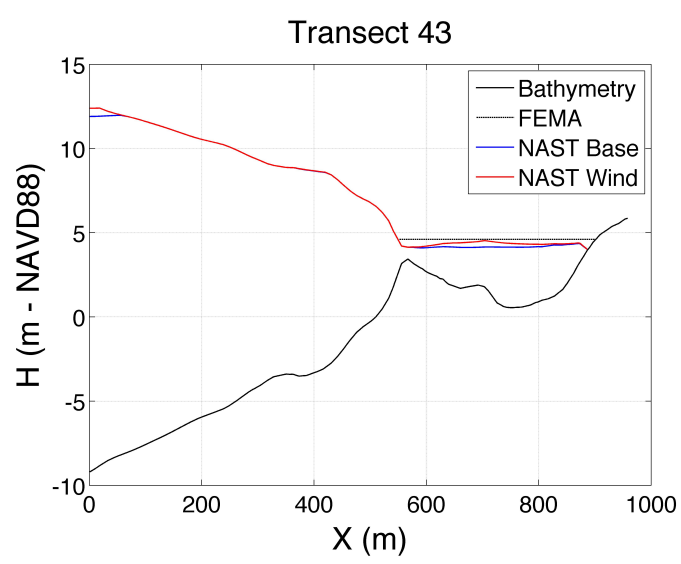

(a)

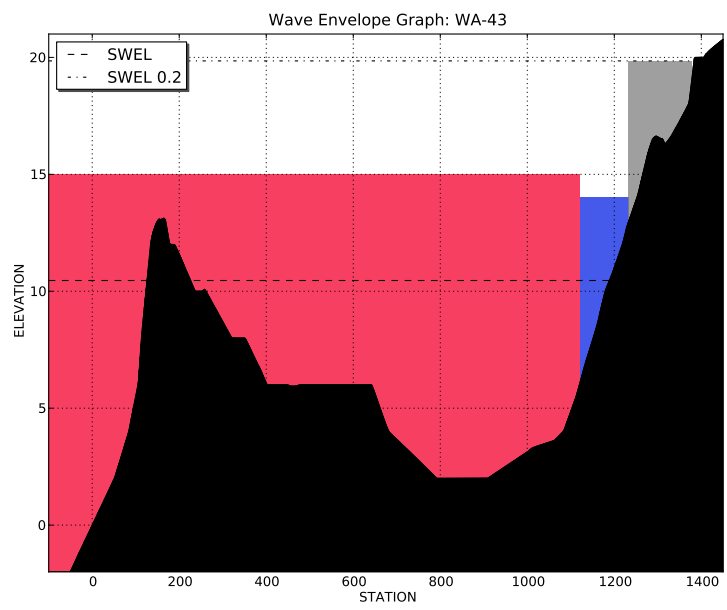

(b)

Figure 1.10: Cross section at the location of FEMA's transect 43 across Narragansett Beach: (a) using NAST method, (b) as reported by FEMA (Obtained from FEMA, 2015). (a) shows the predicted BFE for NAST scenario 1 (blue) and 3 (red) compared to FEMA's (dashed black); bathymetry is shown in solid black; (b) shows FEMA's wave envelope as provided (ft) with VE zone (red), AE zone (blue), 500-year SWEL (grey) and topography (black) 


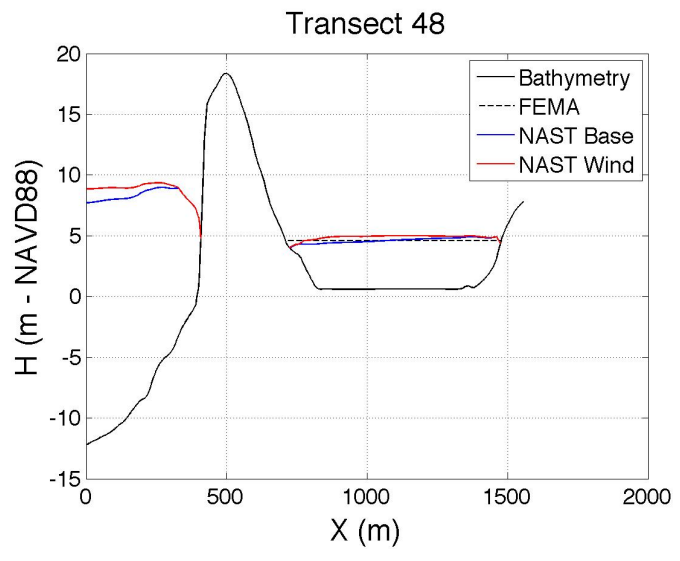

(a)

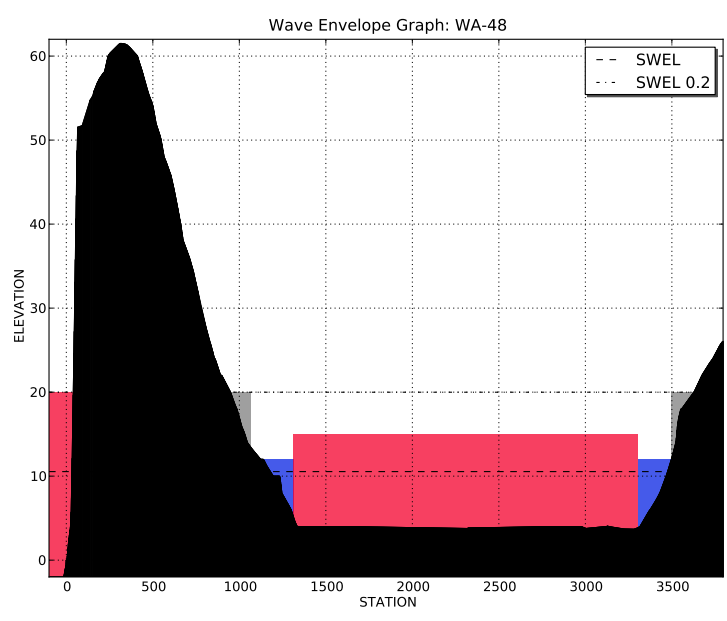

(b)

Figure 1.11: Cross section at the location of FEMA's transect 48 across Bonnet Shores: (a) using NAST method, (b) as reported by FEMA (Obtained from FEMA, 2015). (a) shows the predicted BFE for NAST scenario 1 (blue) and 3 (red) compared to FEMA's (dashed black); bathymetry is shown in solid black; (b) shows FEMA's wave envelope as provided (ft) with VE zone (red), AE zone (blue), 500-year SWEL (grey) and topography (black)

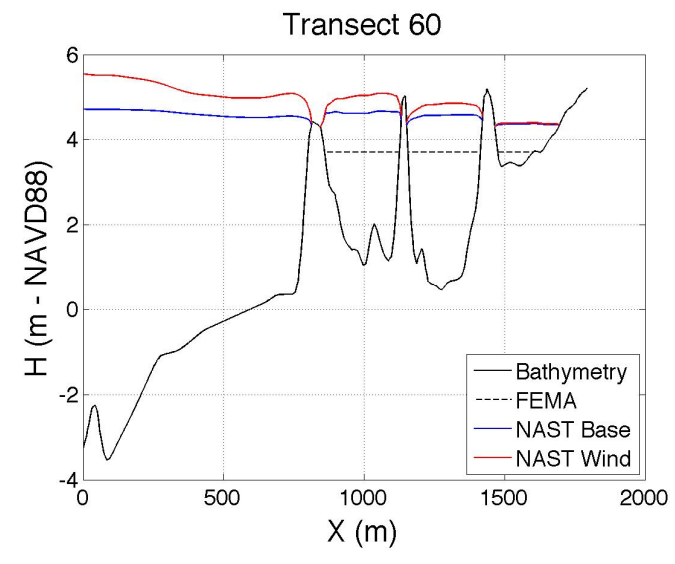

(a)

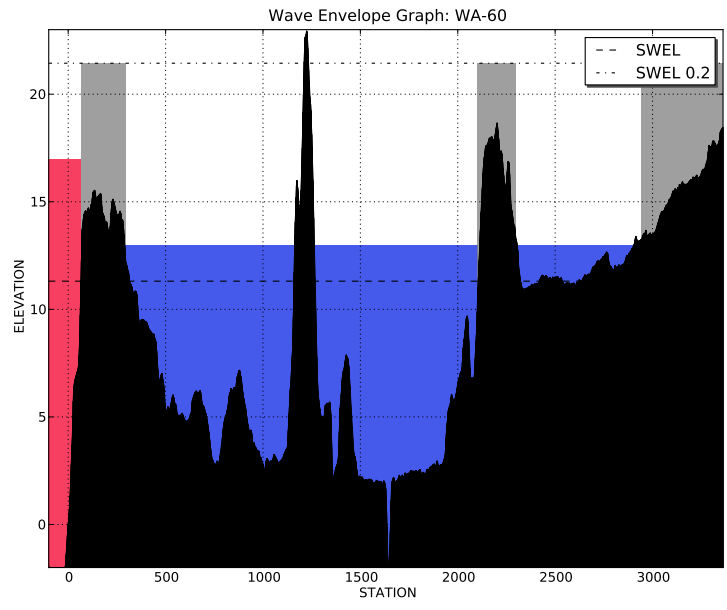

(b)

Figure 1.12: Cross section at the location of FEMA's transect 60 across Wickford: (a) using NAST method, (b) as reported by FEMA (Obtained from FEMA, 2015). (a) shows the predicted BFE for NAST scenario 1 (blue) and 3 (red) compared to FEMA's (dashed black); bathymetry is shown in solid black; (b) shows FEMA's wave envelope as provided (ft) with VE zone (red), AE zone (blue), 500-year SWEL (grey) and topography (black) 


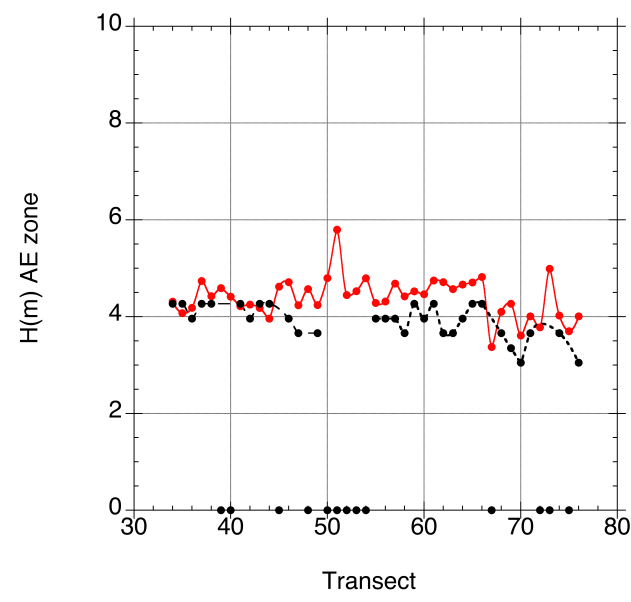

(a)

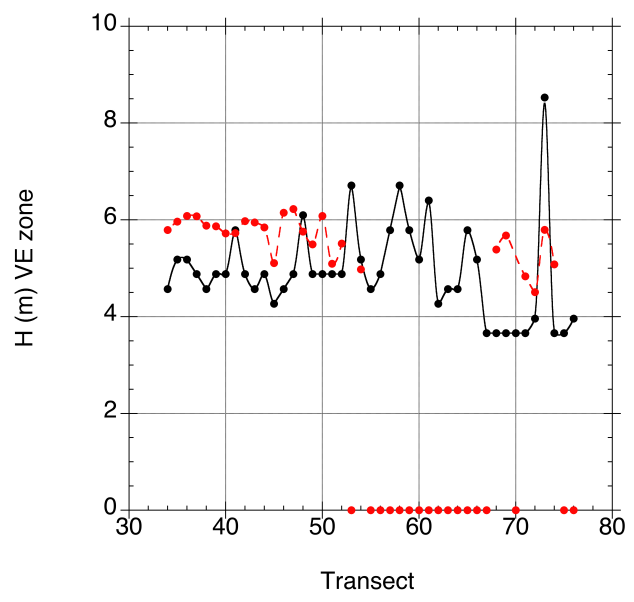

(b)

Figure 1.13: Comparison between NAST mean BFE ( $\mathrm{m}$ - red) and FEMA's reported BFE (m - black) for the (a) AE and (b) VE zones at the local FEMA transects.

\subsection{Conclusions}

The use of the state-of-the-art NACCS statistical-deterministic methodology to define the 100-year storm surge at many virtual stations provides theoretically a more accurate estimation of the 100-year STWL than in earlier work. The method largely reduces the epistemic uncertainty associated with the use of multiple methodological steps, such as used for FEMAs 2012 RI FIRM: empirical analysis at a limited number of tidal gages, extreme statistical analysis, use of several independent methods for estimating wave setup and spatial linear interpolation in between transects.

The NACCS analysis restricts the validity of the 100-year inundation zone estimation to the near future. The method assumes a steady-state storm climate, with no sea level rise and no change in storm frequency. However, recent research in dynamical statistical modeling (Lin, 2012) has shown that a 100-year storm based on historical data might today correspond to a only 20 year storm with $1 \mathrm{~m}$ 
of SLR.

The two-dimensional modeling in shallow water and overland at high resolution using STWAVE addresses many of the deficiencies of the wave analysis method (WHAFIS along 1-D transects) used to develop the current FEMA maps. Problematic interpolations are no longer required, which improves the accuracy in areas between transects. Model predictions at a $10 \mathrm{~m}$ resolution reveal details on the structure of the wave field in inundated areas, and provide transect independent estimates of the FEMA flood zones and associated BFEs.

Cross-sections across the BFE, at the sites of the FEMA 1-D transects, are in relatively good agreement using both methodologies. A large part of the discrepancies are due to the difference in the 100-year storm surge assumption. NAST has adopted the upper 95\% confidence interval value of the storm surge as the representative parameter of the 100-year STWL, while FEMA uses the mean value.

However, larger discrepancies occur in the upper part of the West passage of Narragansett Bay, where FEMA's predicted waves and resulting VE zones are significantly larger than NAST. These discrepancies are found to be mostly due to two factors: (1) a difference in the 100-year wind assumption; (2) differences in shoreline definition.

1. The sensitivity analysis performed in this work has shown that the critical parameter which explains larger waves in the upper part of the bay, such as described by FEMA, is an increase in wind speed and a shift in wind direction, with wind coming from the southern sector, with at least a category 3 hurricane velocity $(50 \mathrm{~m} / \mathrm{s})$. Such conditions however are unrealistic with the constraint of the 100-year return period.

2. NAST defines the offshore limit of the VE zone at the limit of the shoreline, the contour line 0 NAVD88. FEMA's VE zone offshore limit is, although not clearly 
defined, around the wave breaking zone, independently of happening overland or not. The VE zones might therefore be inflated in well protected areas, such as in transect 60 , where no waves are propagating overland and where the VE elevation is based on an offshore (in the sense of not overland) limit.

Mapping the results reinforces the importance of adopting a 2-D approach to fully represent the inundation, showing that the selected transects often miss the sites of the most extreme wave incursion and most destructive impacts. The analysis highlights the differences in methods and results but also suggests adopting, besides a 2-D approach, a scenario-based approach to the 100-year storm rather than a deterministic single map to assess the uncertainty associated with the event.

It should be pointed out that the NAST method does not model wave runup nor reflection. We are currently testing a similar approach, but using a phase resolving model in coastal areas to model these processes, although such a model is not currently validated.

Acknowledgments. The authors gratefully acknowledge support for this work from the RI Coastal Resource Management Council. For providing the results of the NACCS study, we are indebted to Mary Cialone, Norberto Nadal-Carabello, and Jeff Melby of the US Army Corps of Engineers and many others on their team. We also thank John Burin for providing FEMA's documents relevant to the RI, Washington County, 2012 FIRM. For providing bathymetric and land use data, we are also indebted to Chris Damon.

\section{List of References}

Arcement, G.J., Schneider, V.R., 1989. Guide for selecting Mannings roughness coefficients for natural channels and flood plains USGS Water Supply Paper 2339. U.S. Geological Survey, Denver, CO. 
Anderson, M.E., and J. McKee-Smith , 2015. Implementation of Wave Dissipation by Vegetation in STWAVE. ERDC/CHL CHETN-I-85, Vicksburg, MS: U.S. Army Engineering Research and Development Center.

Battjes, J. A. ,1982. A case study of wave height variations due to currents in a tidal entrance, Coast. Engrg. 6, 47-57.

Battjes, J. A., and J. P. F. M. Janssen,1978. Energy loss and set-up due to breaking of random waves. Proc. 16th Coast. Engrg. Conf., ASCE, 569-587.

Blake, E. S., Kimberlain, T. B., Berg, R. J., Cangialosi, J. P., and J.L. Beven, 2012. NOAA Tropical Cyclone Report. Hurricane Sandy.

Bouws, E., et al., 1985. Similarity of the wind wave spectrum in finite depth water: 1. Spectral form. J. Geophys. Res.: Oceans (19782012) 90.C1: 975-986.

Cialone,M.A., Massey C.T., Anderson,M.E., Grzegorzewski, A.S., Jensen,R.E., Cialone, A., Mark, D.J., Pevey, K.C., Gunkel, B.L., McAlpin,T.O., NadalCaraballo, N.N., Melby, J.A., and J.J. Ratcliff, 2015. North Atlantic Coast Comprehensive Study (NACCS) Coastal Storm Model Simulations: Waves and Water Levels. U.S. Army Engineer Research and Development Center, Technical Report. ERDC-CHL-TR-XX-draft

Dean, R., Collins, I., Divoky, D., Hatheway,D., and N. Scheffner, 2005. FEMA Coastal Flood Hazard Analysis and Mapping Guidelines: Wave set up. Focused Study Report. 
Dean, R. G., and C.J. Bender, C. J., 2006. Static wave setup with emphasis on damping effects by vegetation and bottom friction. Coastal engineering, 53(2), 149-156.

FEMA, 2005. Guidelines and Specifications for Flood Hazard Mapping Partners [January 2005] Chapter D.4.5. Wave Setup, Runup, and Overtopping.

FEMA, 2007a. Guidelines and Specifications for Flood Hazard Mapping Partners [February 2007] Chapter D.2.7 Overland Wave Propagation

FEMA, 1988. Wave Height Analysis for Flood Insurance Studies. technical documentation for WHAFIS program version 3.0.

FEMA, 2007b. Supplementary Whafis Documentation Version 4.0

FEMA, 2012b: Summary Report of Coastal Engineering Analyses, DFIRM Update for Coastal Analysis for Washington County, RI; Task Order 1: Coastal Hazard Analysis. Prepared by STARR Flood Insurance Studies Throughout FEMA Region I.

FEMA, 2012a: Flood Insurance Study. Washington County Rhode Island, Volume 1 of 2 .

FEMA, 1991. Technical Documentation for RUNUP program version 2.0. Report prepared for FEMA by Dewberry and Davis, Fairfax, Virginia, April 1991. 
FEMA, 2011. Operating Guidance N0.7-11. Application of TAW Runup Methodology to FEMA Need, Prepared by R.G. Dean, Gainsville, Florida.

Hatheway, D.,Coulton, K., Delcharco, M., Jones, C., 2005. Flood Hazard Zones. FEMA Coastal Flood Hazard Analysis And Mapping Guidelines. Focus Study Report.

Hasselmann, K., Barnett, T. P., Bouws, E., Carlson, H., Cartwright, D. E., Enke, K., Ewing, J. A., Gienapp, H., Hasselmann, D. E., Kruseman, P., Meerburg,A., Muller, P., Olbers, D. J., Richter, K., Sell, W., and Walden, H., 1973.Measurements of wind-wave growth and swell decay during the Joint NorthSea Wave Project (JONSWAP), Deut. Hydrogr. Z., Suppl. A, 8(12), 1-95.

Hasager, Charlotte Bay, et al., 2006. Quantifying offshore wind resources from satellite wind maps: study area the North Sea. Wind Energy 9.12 (2006): 63-74.

Holthuijsen, L.H., 2007. Wave in ocean and coastal waters. Cambridge University Press. 387 pp.

Lin, N. and Emanuel, K., 2016. Grey swan tropical cyclones. Nature Climate Change, 6(1), pp.106-111.

Lin, N., Emanuel, K., Oppenheimer, M., and Vanmarcke, E., 2012. Physically based assessment of hurricane surge threat under climate change. Nature Climate Change 2:16. 
Massey, T.C., Anderson, M.E., McKee-Smith, J., Gomez, J., and J. Rusty, 2011. STWAVE: steady state spectral wave model. Users manual for STWAVE, version 6.0 .

Miche, M. 1951. Le pouvoir reflechissant des ouvrages maritimes exposes a laction de la houle. Annals des Ponts et Chaussess. 121e Annee: 285-319 (translated by Lincoln and Chevron, University of California, Berkeley, Wave Research Laboratory, Series 3, Issue 363, June 1954).

Nadal-Caraballo, N. C., Melby, J.A, Gonzalez V. M., and A.T. Cox, 2015. North Atlantic Coast Comprehensive Study (NACCS): Coastal Storm Hazards from Virginia to Maine. U.S. Army Engineer Research and Development Center (ERDC), Technical Report. ERDC-CHL-TR-15-5

National Academy of Sciences, 1977. Methodology for Calculating Wave Action Effects Associated with Storm Surges, Washington, D.C.

National Research Council. 2009. Mapping the Zone: Improving Flood Map Accuracy. Washington, DC: The National Academies Press. doi: 10.17226/12573.

Orton, P.M., Hall, T.M., Talke, S.A., Blumberg, A.F., Georgas, N. and Vinogradov, S., 2016. A validated tropicalextratropical flood hazard assessment for New York Harbor. Journal of Geophysical Research: Oceans

Resio, D. T., 1987. Shallow-water waves. I: Theory. Journal of Waterway, Port, 
Coastal, and Ocean Engineering, 113(3), 264-281.

Resio, D.T., 1988. Shallow-water waves. II: Data comparisons. J. Waterway, Port, Coastal and Ocean Engineering. ASCE. 114(1):50-65.

Resio, D.T. and W. Perrie,1991. A numerical study of nonlinear energy fluxes due to wave-wave interactions Part 1. Methodology and basic results. Journal of Fluid Mechanics, 223, pp 603-629 doi:10.1017/S002211209100157X

Resio, D. T., 1981. The estimation of wind-wave generation in a discrete spectral model. J. Phys. Oc., 11(4), 510-525.

RIGIS, 2013. Digital Elevation Model, DEM11. Rhode Island Geographic Information System (RIGIS) Data distribution System, URL: http://www.edc.uri.edu/rigis, Environmental Data Center, University of Rhode Island (last date accessed: 25 July 2013).

RIGIS, 2015. Rhode Island Land Use and Land Cover 2011. Rhode Island Geographic Information System (RIGIS) Data Distribution System, URL: http://www.edc.uri.edu/rigis, Environmental Data Center, University of Rhode Island, Kingston, Rhode Island (last date accessed: 15 July 2015).

Saville, T. (1961). Experimental determination of wave set-up. In Proc. 2nd Tech. Conf. on Hurricanes, Miami Beach, FL., Nat. Hurricane Res. Proj. Rep. 50. 
Shi, F., J.T. Kirby, J.C. Harris, J.D. Geiman and S.T. Grilli 2012. A High-Order Adaptive Time-Stepping TVD Solver for Boussinesq Modeling of Breaking Waves and Coastal Inundation. Ocean Modeling, 43-44: 36-51

Smith, J.M., Sherlock, A.R., and D.T. Resio, 2001. STWAVE: Steady-state wave model users manual for STWAVE, version 3.0. ERDC/CHL SR-01-01, Vicksburg, MS: U.S. Army Engineering Research and Development Center.

Smith, J.M., Resio, D.T., and C.L. Vincent, 1997. Current-induced breaking at an idealized inlet. Proc. Coastal Dynamics 97. ASCE. 993-1002.

Schwartz, M., Heimiller, D., Haymes, S. and W Musial, 2010. Assessment of Offshore Wind Energy Resources for the United States . NREL, Technical Report, TP-500-45889.

Shore Protection Manual (SPM), 1984. Coastal Engineering Research Center DEPARTMENT OF THE ARMY, Waterways Experiment Station, Corps of Engineers

Stoa, P. N. ,1978. Revised Wave Runup Curves For Smooth Slopes (No. CercCeta-78-2).

Stockdon, H. F., Holman, R. A., Howd, P. A., and Sallenger, A. H. , 2006. Empirical parameterization of setup, swash, and runup. Coastal engineering, 53(7), 573-588. 
Spaulding, M.L., T. Isaji, C. Damon, and G Fugate, 2015. Application of STORMTOOLSs simplified flood inundation model, with and without sea level rise, to RI coastal waters. ASCE Solutions to Coastal Disasters Conference, Boston, MA. September 2015.

Van der Meer, J.W. and C.-J.M. Stam, 1992. Wave runup on smooth and rock slopes of coastal structures. Journal of Waterway, Port, Coastal, and Ocean Engineering, 118(5), 534550.

Van der Meer, J.W., 2002. Technical Report Wave Run-up and Wave Overtopping at Dikes. Technical Advisory Comitte on Flood Defence, Delft, ND.

Wamsley, T.V., Cialone, M. A., Smith, J. M., Atkinson, J. H., and J.D. Rosati, 2010. The potential of wetlands in reducing storm surge. Ocean Engineering, $37(1), 59-68$.

Wamsley, T. V., Cialone, M. A., Smith, J. M., Ebersole, B. A., and A.S. Grzegorzewski, 2009. Influence of landscape restoration and degradation on storm surge and waves in southern Louisiana. Natural Hazards, 51(1), 207-224.

Wave Information Studies (WIS), 2010.US Army Corps of Engineers. Wave Information Studies Project Documentation. http://wis.usace.army.mil/

Xian, S., Lin, N. and Hatzikyriakou, A., 2015. Storm surge damage to residential areas: a quantitative analysis for Hurricane Sandy in comparison with FEMA flood map. Natural Hazards, 79(3), pp.1867-1888. 


\section{Appendix}

\begin{tabular}{|c|c|c|c|c|c|c|}
\hline FEMA Transect ID & $\begin{array}{c}\text { URI } \\
\text { SWEL (m) }\end{array}$ & $\begin{array}{c}\text { URI } \\
\text { VE (m) }\end{array}$ & $\begin{array}{c}\text { URI } \\
\mathrm{AE}(\mathrm{m})\end{array}$ & $\begin{array}{c}\text { FEMA } \\
\text { SWEL }(\mathrm{m})\end{array}$ & $\begin{array}{c}\text { FEMA } \\
\text { VE (m) }\end{array}$ & $\begin{array}{l}\text { FEMA } \\
\text { AE }(m)\end{array}$ \\
\hline 33 & 3.89 & 5.89 & 4.33 & 3.17 & 5.18 & 0.00 \\
\hline 34 & 3.98 & 5.79 & 4.31 & 3.17 & 4.57 & 4.27 \\
\hline 35 & 4.01 & 5.97 & 4.07 & 3.17 & 5.18 & 4.27 \\
\hline 36 & 4.13 & 6.08 & 4.18 & 3.17 & 5.18 & 3.96 \\
\hline 37 & 4.06 & 6.07 & 4.74 & 3.17 & 4.88 & 4.27 \\
\hline 38 & 3.97 & 5.88 & 4.42 & 3.18 & 4.57 & 4.27 \\
\hline 39 & 4.05 & 5.87 & 4.59 & 3.18 & 4.88 & - \\
\hline 40 & 3.76 & 5.72 & 4.42 & 3.18 & 4.88 & - \\
\hline 41 & 3.83 & 5.73 & 4.21 & 3.18 & 5.79 & 4.27 \\
\hline 42 & 3.94 & 5.98 & 4.25 & 3.19 & 4.88 & 3.96 \\
\hline 43 & 3.96 & 5.95 & 4.18 & 3.19 & 4.57 & 4.27 \\
\hline 44 & 3.84 & 5.84 & 3.96 & 3.19 & 4.88 & 4.27 \\
\hline 45 & 4.05 & 5.11 & 4.62 & 3.20 & 4.27 & - \\
\hline 46 & 4.24 & 6.15 & 4.72 & 3.21 & 4.57 & 3.96 \\
\hline 47 & 4.12 & 6.22 & 4.24 & 3.21 & 4.88 & 3.66 \\
\hline 48 & 4.11 & 5.76 & 4.57 & 3.21 & 6.10 & - \\
\hline 49 & 3.94 & 5.49 & 4.24 & 3.22 & 4.88 & 3.66 \\
\hline 50 & 4.13 & 6.08 & 4.80 & 3.22 & 4.88 & - \\
\hline 51 & 4.78 & 5.10 & 5.80 & 3.22 & 4.88 & - \\
\hline 52 & 3.98 & 5.51 & 4.45 & 3.23 & 4.88 & - \\
\hline 53 & 4.24 & 0.00 & 4.53 & 3.27 & 6.71 & - \\
\hline 54 & 4.04 & 4.98 & 4.79 & 3.30 & 5.18 & - \\
\hline 55 & 4.10 & - & 4.28 & 3.33 & 4.57 & 3.96 \\
\hline 56 & 4.13 & - & 4.31 & 3.36 & 4.88 & 3.96 \\
\hline 57 & 4.26 & - & 4.69 & 3.39 & 5.79 & 3.96 \\
\hline 58 & 4.28 & - & 4.42 & 3.42 & 6.71 & 3.66 \\
\hline 59 & 4.23 & - & 4.52 & 3.44 & 5.79 & 4.27 \\
\hline 60 & 4.31 & - & 4.46 & 3.45 & 5.18 & 3.96 \\
\hline 61 & 4.23 & - & 4.75 & 3.47 & 6.40 & 4.27 \\
\hline 62 & 4.20 & - & 4.72 & 3.48 & 4.27 & 3.66 \\
\hline 63 & 4.22 & - & 4.57 & 3.51 & 4.57 & 3.66 \\
\hline 64 & 4.41 & - & 4.66 & 3.62 & 4.57 & 3.96 \\
\hline 65 & 4.45 & - & 4.71 & 3.65 & 5.79 & 4.27 \\
\hline 66 & 4.51 & - & 4.82 & 3.68 & 5.18 & 4.27 \\
\hline
\end{tabular}




\title{
MANUSCRIPT 2
}

Modeling the erosion associated with the 100-year storm on the southern Rhode Island coast

\author{
by \\ Lauren Schambach, Annette R. Grilli, M. Reza Hashemi, John King, and \\ Stéphan T. Grilli \\ In preparation for submission to the American Society of Civil Engineers Journal \\ of Waterway, Port, Coastal, and Ocean Engineering
}


Abstract. The erosion due to a synthetic 100-year storm is modeled on the southern shore of Rhode Island using the process-based morphodynamic model XBeach (Roelvink et al., 2009). The study area includes barrier beaches, coastal ponds, and residential areas. The model is forced using a synthetic storm time series extracted from the North Atlantic Coast Comprehensive Study (NACCS; Cialone et al., 2015, Nadal-Caraballo et al., 2015) database, selected as a proxy 100-year storm.

An empirical method (Stockdon et al., 2006; Stockdon et al., 2012) is used to parameterize wave setup, swash, and runup to estimate the erosion impact regime (Sallenger, 2000), using NACCS water levels and offshore wave heights as inputs at seven cross-shore transects within the study area. As the storm is expected to evolve from the collision regime to the overwash and inundation regimes over time, the two-step XBeach model calibration process suggested by Nederhoff (2014) is followed. The first step consists of adjusting the facua wave skewness/asymmetry parameter to calibrate the collision regime. The second step involves testing the sensitivity to friction across the dune to calibrate the overwash regime. The sensitivity of the model to the facua parameter is tested by modeling a historical storm that stayed within the collision regime. Hurricane Irene (August, 2011) is selected and simulated erosion is compared to measured erosion at five cross-shore profiles monitored by the University of Rhode Island Graduate School of Oceanography (GSO). GSO performed measurements and data collection before and after Irene's impact at the site. For the 100-year storm, results of four simulation scenarios are presented: the facua parameter is tested for the default and maximum suggested values of 0.1 and 0.3 , respectively, and the bottom friction is either set to a constant Manning's $n$ of 0.02 or a variable Manning's $n$ bed friction coefficient based on land cover. 
The resulting eroded dunes for the four simulations are presented in 2-D maps as well as 1-D cross-sections at the seven cross-shore locations. Two additional transects to the GSO transects are included, located at the Federal Emergency Management Agency (FEMA) coastal transect sites that were used to create the 100-year Flood Insurance Rate Map (FIRM) for the region. Results are compared at these two sites with FEMA's dune erosion protocol. Additionally, the simulated dune is compared to the generalized barrier profile for a 100-year storm developed for the region by Oakley (2015).

\subsection{Introduction}

Modeling the 100-year event is an integral part of coastal floodplain mapping and risk analysis. The Federal Emergency Management Agency (FEMA) defines special flood hazard areas as regions that will be inundated by a flood that has a 1percent chance of being equaled or exceeded in any given year (100-year flood). In coastal regions, the additional risk due to storm surge and waves is independently assessed for each of those hazards. FEMA defines two main coastal zones based on the expected wave crest elevation of the 1-percent of the highest waves $\left(\eta_{c}\right)$ : the $\mathrm{VE}$ zone with $\eta_{c}$ greater than or equal to 3 feet, and the AE zone with $\eta_{c}$ less than 3 feet.

Dune erosion occurs over the evolution of the storm, resulting in sediment transport landward, cross-shore, and offshore. Correlatively, the resulting changes in beach profile and coastline shape modify wave propagation and their impact on the coastline, as well as on the expected total inundation elevation. Consequently, the dynamics of the dune erosion can potentially have a large impact on the limit and characteristics of the 100-year flood zones.

Long-term time scale predictions of shoreline erosion due to sea-level rise (SLR) are part of a dynamic field of research. Modeling teams are attempting 
to assess the impact of climatic change on the potential hazards using either a scenario-based risk analysis (Oumeraci et al., 2015) or dynamical-statistical modeling (Lin et al., 2012). Few approaches include the complex process of shoreline changes (Bilksie et al., 2014; Grilli et al., 2016), but these long term erosion processes must be included if one expects the 100-year storm to occur later in the century. FEMA, however, does not currently consider the effects of SLR in the FIRMs. To be consistent with FEMA's current protocol, we assumed that the 100-year storm is occurring in the near future, when the SLR is negligible, and the erosion processes are at the time scale of the storm event only.

The study area is located on the southern coast of Rhode Island (RI) and includes East and Charlestown barrier beaches, Ninigret Pond, as well as the surrounding residential and wildlife preserve areas (Figure 2.1). The following paragraphs describe the two methods used to determine 100-year flood maps for the region, both taking dune erosion into consideration but using different approaches. The first method is the official FEMA methodology (2013) used to create the RI FIRMs, based on simulations along 1-D transects interpolated along the shoreline. The second method is based on using a suite of 2-D models and was developed as an alternative to FEMA's 1-D methodology for RI (Grilli et al., 2015; Spaulding et al., 2016; Schambach et al, 2016). 


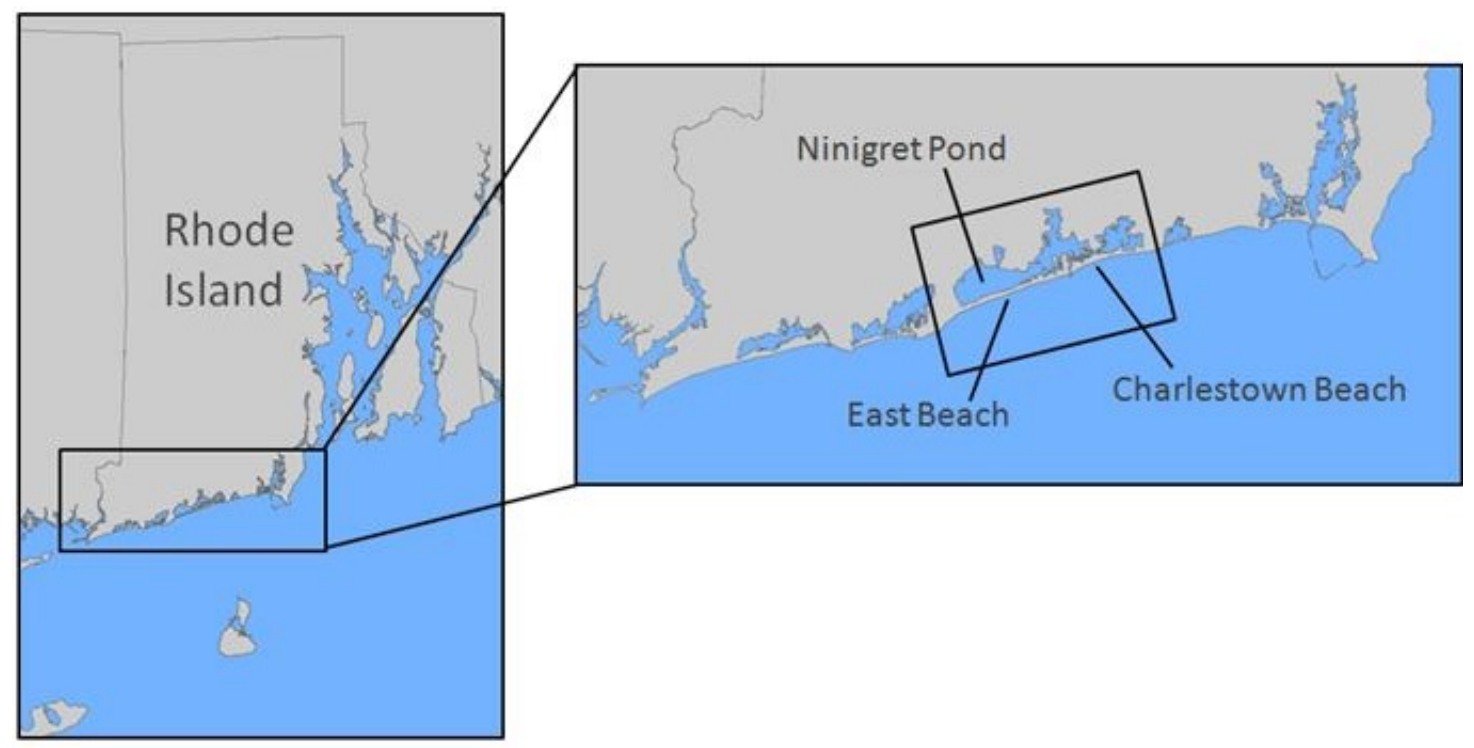

Figure 2.1: Study area on the southern RI coast

RI FEMA FIRMs are based on a combination of storm surge and wave height simulations along 1-D transects, both independently estimated at specific locations along the coastline and then linearly interpolated along the shoreline. The storm surge assessment is based on a statistical extreme value analysis performed at 3 National Oceanic and Atmospheric Administration (NOAA) tidal gauges located closest to the study area, in New London, Connecticut, and Newport and Providence, RI. Results of this analysis were linearly interpolated to provide the stillwater elevation (SWEL) along the RI coast. Transects across the shoreline were defined in areas subject to coastal flooding. Bathymetric and topographic profiles were created for each transect and an erosion assessment was performed. FEMA's erosion protocol involves removing the dune at a positive slope of 1:50, from the dune toe moving landward, when the dune frontal reservoir has less than 540 square feet of volume above the SWEL. This dune removal process was performed on both FEMA transects within the study area (transects 19 and 20 in Figure 2.1). A wind statistical extreme value analysis based on Quonset Airport wind data was performed to provide the 100-year storm wind speed, which in turn 
was used to calculate offshore and nearshore wave heights and periods at the start of each coastal transect. Wave setup was determined by the Direct Integration Method developed by Goda (2000) and added to the SWEL. Wave heights over land were then calculated using the 1-D model Wave Height Analysis for Flood Insurance Studies (WHAFIS), which solves the wave action balance equation over the eroded 1-D transects, inundated with the SWEL plus wave setup. Results from the wave analysis contribute to the concept of base flood elevation (BFE), when added to the SWEL, as well as the resulting delineation of the VE and AE zones, when interpolated in between transects and mapped.

In 2009, the National Research Council released a report entitled "Mapping the Zone: Improving Flood Map Accuracy", in which concerns over various aspects of the FEMA methodology described above were brought into light. These multiple concerns include: "Wave transformation is a 2-D process that cannot be represented in a 1-D model; WHAFIS calculated wave crests and BFEs are not 1-percent annual chance values; surge and wave are completely decoupled, which may lead to overor underestimates of the BFE; the 540-square-foot rule for dune erosion has not been validated; the approach for wave dissipation by vegetation, buildings and levees has not been validated; one-dimensional transects do not reflect 2-D terrain; and manual interpolation of 1-D results to two dimensions is subjective" (NRC, 2009). In RI, the severe impact of Sandy on the southern shoreline led communities to question the accuracy of the 2012 FEMA FIRMs. As a result, the RI Coastal Resource Management Council (CRMC) requested an independent assessment of the FIRM maps for Washington County. The University of Rhode Island (URI) responded with alternative maps based on using a suite of 2-D models.

The URI method was referred to as the NAST method, which makes use of the results of the North Atlantic Coast Comprehensive Study (NACCS), released 
in 2015 by the United States Army Corps of Engineers (USACE; Cialone et al., 2015, Nadal-Caraballo et al., 2015), combined with coastal wave modeling using the Steady State Spectral Wave model (STWAVE; Smith et al., 1999; Massey et al., 2011). The NAST (NACCS-STWAVE) method is described in detail in Grilli et al. (2015) and Schambach et al. (2016).

NACCS performed stochastic simulations of synthetic tropical and historical extra-tropical storms across the Atlantic Ocean using a set of fully integrated models, the cyclone wind model (MORPHOS-PBL, an updated version of TC96 PBL; Thompson and Cardone, 1996), along with the regional wave model WAM (Kommen et al., 1994) used as boundary conditions to the Advanced Circulation model (ADCIRC; Luettich et al., 1992), coupled with STWAVE. Results of the simulations are available at thousands of "save points", as time series or spectral parameters associated with a probability of occurrence (NACCS, 2015). NACCS 100-year spectral parameters were found to be in good agreement with results of an extreme statistical analysis performed at local Wave Information Studies (WIS, 2010) hindcast stations (Spaulding et al., 2016). Grilli et al. (2015) used the NACCS results as boundary conditions to STWAVE, run over local high resolution (10m) grids, with bathymetry and onshore topography inundated by the NACCS 100-year 95\% confidence interval storm surge. Two scenarios were considered in the analysis, one with the dune intact, and one using the generalized $1 \%$ storm barrier profile for the East Beach barrier developed by Oakley (2015). NAST simulations have shown that the dunes strongly protect the pond from large waves. When the dunes are eroded, as in the generalized 1\% dune profile, waves overtop the dunes and propagate across the pond, resulting in a larger BFE in the inundation zone (Figure 2; Spaulding et al., 2016). 

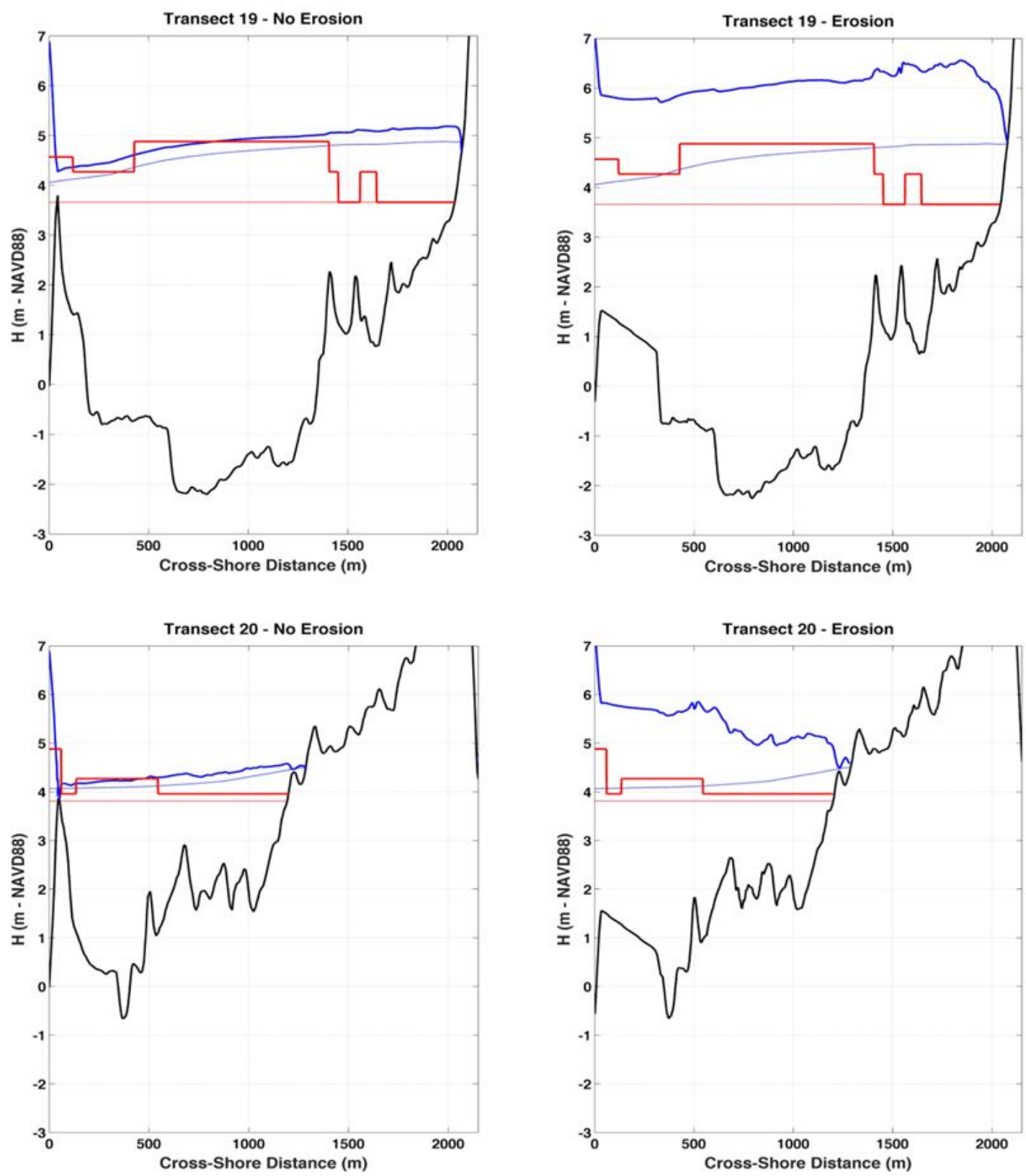

Figure 2.2: Water elevation(m-NAVD88; BFE, bold lines; SWEL + wave setup, light lines) versus landward cross-shore distance (m) along FEMA transects 19 and 20, for FEMA (red) and NAST (blue) (modified from Spaulding et al. (2016)

Both methodologies, FEMA and NAST, make use of predetermined eroded dune profiles to modify the bathymetry/topography and then run stationary wave models assuming a static modified shoreline. An alternative approach to determining the beach erosion is a dynamic approach, which uses process-based erosion 
models to simulate the dune erosion over the time scale of a storm.

In order to properly model erosion, one would expect a wave propagation module containing the physics to simulate the swash motion. Holland and Puleo (2001) indeed showed that swash collisions are directly related to foreshore erosion. Swash motions, or surf-beats, result from wave group forcing of infragravity waves $(0.004<f<0.05 \mathrm{~Hz})$ (Tucker, 1954; Longuett-Higgins and Stewart, 1964). These are slow moving (minutes) oscillations of the mean super-elevated water level (static setup) (Schaffer and Svendsen, 1988, Dean and Bender, 2005). Surf-beats are particularly dominant in storm conditions since the swell frequency band swash (nominally $0.05<f<0.18 \mathrm{~Hz}$ ) is saturated, while the infragravity swash frequency band is not. Infragravity wave dissipation is relatively weak in the surf zone, while reflection from the beach face is strong (Raubenheimer and Guza, 1996). Swash models range from empirical formulations (e.g., Stockdon et al., 2006), analytical approaches (e.g., Schaeffer, 1993; Erikson et al., 2005), 1-D numerical models (e.g., Roelvink, 1993), and 2-D models (e.g., van Dongeren et al., 2003; Reniers et al., 2004, 2006).

In this study we propose to use the 2-D wave propagation and sediment transport model XBeach (Roelvink et al, 2009) to simulate the near-shore wave propagation and dune erosion during a selected historical storm, Hurricane Irene (August, 2011), and during a NACCS 100-year storm. Irene was selected for model calibration because it is the only significant storm for which there are simultaneous wave observations at nearshore buoys in very shallow water and beach cross-section measurements. The XBeach model requires time series of waves and water elevation as boundary conditions. While this data is available for Irene as either direct data at buoys, hindcast data at Wave Information Studies (WIS, 2010) stations, or modeled data at the computational grid boundary, such time series are not 
available for the 100-year storm. In this case, one can select a historical storm representative of the 100-year storm, scale a historical storm to 100-year values, or create a synthetic design storm (e.g., Carley and Cox, 2003). We have chosen to select a time series from the NACCS database as a proxy 100-year storm. The storm was selected based on a comparison of maximum significant wave height, $H_{s}$, and water elevation with the NACCS 100-year spectral parameters at the study area. Let us note that these 100-year conditions do not necessarily lead to the statistical 100-year beach erosion event, as this would also be dependent on other factors such as storm duration and succession of storms (Callaghan et al., 2008).

\subsection{Methods}

\subsubsection{XBeach Model}

XBeach is a 2-D nearshore numerical model developed to assess the natural coastal morphological response during time-varying storm conditions. The response includes dune erosion, overwash and breaching. The model conceptual approach is to simulate processes that are occurring in the four erosion regimes defined by Sallenger (2000): swash, collision, overwash and inundation.

The model employs a 2-D depth averaged description of the wave groups and accompanying infragravity waves to resolve the swash dynamics. The wavegroup forcing is derived from the time-varying wave-action balance (e.g., Phillips, 1977). A dissipation model (Roelvink, 1993) is used in combination with wave groups. A roller model (Svendsen, 1984) is used to represent momentum stored in surface "rollers", leading to a shoreward shift in wave forcing. The model has two hydrodynamic modules, a short wave and a depth-averaged flow module, as well as two morphodynamic modules, a morphology change and a sediment transport module (Figure 2.3; Daly, 2009). These four modules are fully coupled and wave and flow boundary conditions are used to force the hydrodynamic modules. 


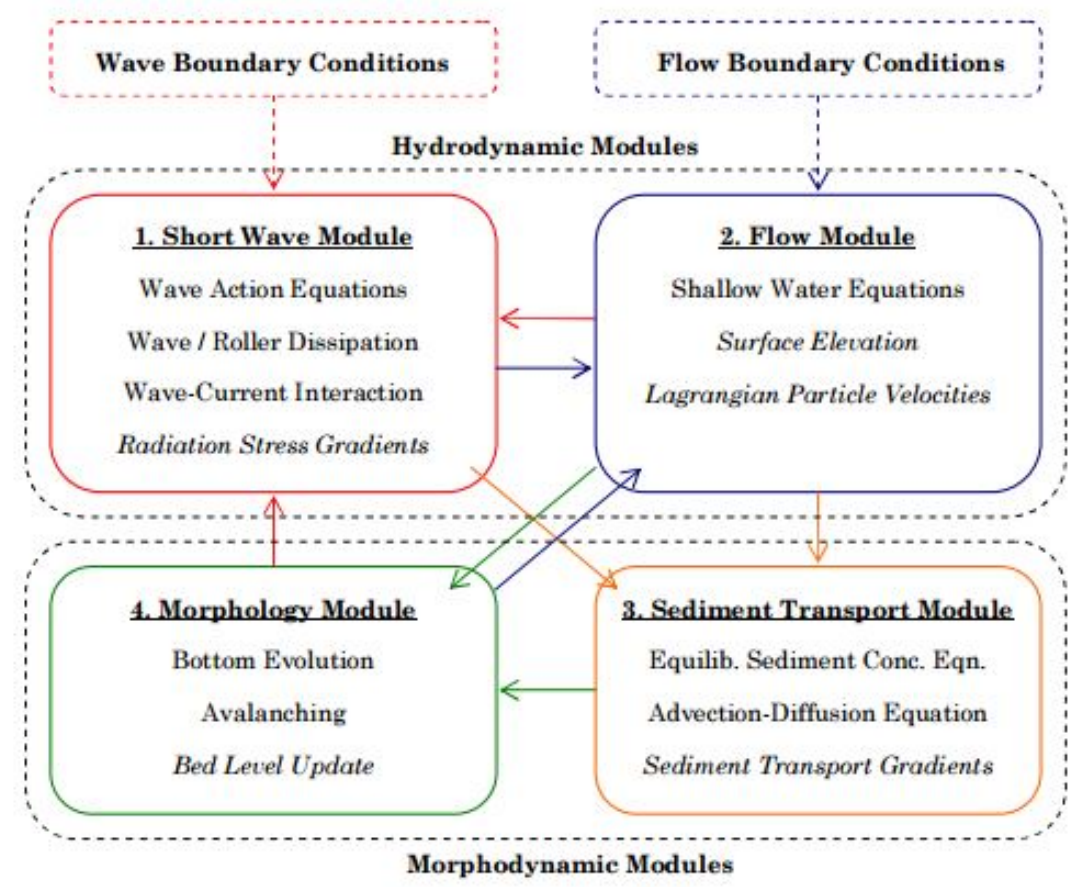

Figure 2.3: Component modules in XBeach. Arrows indicate connectivity and terms in italics indicate relative output parameters. The black dotted lines encompass the hydrodynamic (top) and morphodynamic (bottom) modules. Boundary conditions are only used in the first cycle. (Daly, 2009)

The governing equations for each module is summarized hereafter:

\section{Short Wave Module}

Short wave propagation is based on conservation of wave action, coupled with a roller energy balance. The directional distribution of the action density is taken into account, but the frequency spectrum is parameterized and reduced to a single frequency parameter (Holthuijsen et al., 1989).

The conservation of wave action, $A$, defined as the ratio of the wave energy density, $S_{w}$, to the intrinsic frequency, $\sigma$, is expressed as

$$
\frac{\partial A}{\partial t}+\frac{\partial c_{x} A}{\partial x}+\frac{\partial c_{y} A}{\partial y}+\frac{\partial c_{\theta} A}{\partial \theta}=-\frac{D_{w}}{\sigma}
$$

and, 


$$
A=\frac{S_{w}(x, y, t, \theta)}{\sigma(x, y, t)}
$$

with $D_{w}$, the total wave energy dissipation due to wave breaking; $c_{x}, c_{y}$, are the components of the wave action propagation speed propagating perpendicularly to the wave crest and at an angle $\theta$ from the underlying current $u$, defined as:

$$
\begin{aligned}
& c_{x}(x, y, t, \theta)=c_{g} \cos (\theta)+u^{L} \\
& c_{y}(x, y, t, \theta)=c_{g} \sin (\theta)+v^{L}
\end{aligned}
$$

with $u^{L}$ and $v^{L}$, the cross-shore and alongshore depth-averaged Lagrangian velocities of the current respectively, and $c_{g}$ the group velocity obtained from linear wave theory.

The roller energy balance is coupled to the wave-action energy balance with the dissipation of wave energy, $D_{w}$, acting as a source term for the roller energy balance:

$$
\frac{\partial S_{r}}{\partial t}+\frac{\partial c_{x} S_{r}}{\partial x}+\frac{\partial c_{y} S_{r}}{\partial y}+\frac{\partial c_{\theta} S_{r}}{\partial \theta}=-D_{r}+D_{w}
$$

with $S_{r}$, the roller energy, and $D_{r}$, the total roller energy dissipation. The rollers contribute to the radiation stresses and are added to the wave standard radiation stresses calculated with linear wave theory to create the wave forcing $\left(F_{x}\right.$ and $\left.F_{x}\right)$ for the mean flow equations:

$$
\begin{aligned}
& F_{x}(x, y, t)=-\left(\frac{\partial S_{x x, w}+S_{x x, r}}{\partial x}+\frac{\partial S_{x y, w}+S_{x y, r}}{\partial x}\right) \\
& F_{x}(x, y, t)=-\left(\frac{\partial S_{y y, w}+S_{y y, r}}{\partial y}+\frac{\partial S_{x y, w}+S_{x y, r}}{\partial y}\right)
\end{aligned}
$$




\section{Flow Module}

In the flow module, low-frequency and mean flows are modeled using depthaveraged shallow water equations. To account for the wave-induced mass flux and the subsequent return flow, these are cast into a depth-averaged Generalized Lagrangian Mean (GLM) formulation (Andrews and McIntyre, 1978; Walstra et

al., 2000). Continuity and momentum equations are formulated in terms of the Lagrangian velocity $\left(u^{L}, v^{L}\right)$ defined as the distance a water particle travels in one wave period, divided by the period.

The GLM continuity and momentum equations are therefore given by:

$$
\begin{gathered}
\frac{\partial \eta}{\partial t}+\frac{\partial h u^{L}}{\partial x}+\frac{\partial h v^{L}}{\partial y}=0 \\
\frac{\partial u^{L}}{\partial t}+u^{L} \frac{\partial u^{L}}{\partial x}+v^{L} \frac{\partial u^{L}}{\partial y}-f v^{L}-\nu_{h}\left(\frac{\partial^{2} u^{L}}{\partial x^{2}}+\frac{\partial^{2} u^{L}}{\partial y^{2}}\right)=\frac{\tau_{s x}}{\rho h}-\frac{\tau_{b x}^{E}}{\rho h}-g \frac{\partial \eta}{\partial x}+\frac{F_{x}}{\rho h} \\
\frac{\partial v^{L}}{\partial t}+u^{L} \frac{\partial v^{L}}{\partial x}+v^{L} \frac{\partial v^{L}}{\partial y}+f u^{L}-\nu_{h}\left(\frac{\partial^{2} v^{L}}{\partial x^{2}}+\frac{\partial^{2} v^{L}}{\partial y^{2}}\right)=\frac{\tau_{s y}}{\rho h}-\frac{\tau_{b y}^{E}}{\rho h}-g \frac{\partial \eta}{\partial y}+\frac{F_{y}}{\rho h}
\end{gathered}
$$

Where $\eta$ is the water level, $\tau_{b x}$ and $\tau_{b y}$ are the bed shear stresses, $\nu_{h}$ is the horizontal viscosity, and $f$ is the Coriolis coefficient. The bottom shear stress terms are calculated with the Eulerian velocities experienced by the bed, $u^{E}$, related to the Lagrangian velocities by subtracting the Stokes drift in the $\mathrm{x}$ - and $\mathrm{y}$ - directions respectively. The bed shear stress is calculated with:

$$
\begin{aligned}
& \tau_{b x}^{E}=c_{f} \rho u^{E} \sqrt{\left(1.16 u_{r m s}\right)^{2}+\left(u^{E}+v^{E}\right)^{2}} \\
& \tau_{b y}^{E}=c_{f} \rho v^{E} \sqrt{\left(1.16 u_{r m s}\right)^{2}+\left(u^{E}+v^{E}\right)^{2}}
\end{aligned}
$$

The bottom friction coefficient, $c_{f}$, in this study is specified using a Manning formulation. Manning's $n$ value is related to the dimensionless bed coefficient friction value by: 


$$
c_{f}=\frac{g n^{2}}{h^{1 / 3}}
$$

\section{Sediment Transport Module}

A depth-averaged advection-diffusion equation is used to model sediment transport (Galappatti and Vreugdenhil, 1985). The entrainment or deposition of sediment is controlled by the difference between the actual sediment concentration, $C$, and the equilibrium concentration, $C_{e q}$. This difference is therefore the source term in the sediment transport equation:

$$
\frac{\partial h C}{\partial t}+\frac{\partial h C u^{E}}{\partial x}+\frac{\partial h C v^{E}}{\partial y}+\frac{\partial}{\partial x}\left(D_{h} h \frac{\partial C}{\partial x}\right)+\frac{\partial}{\partial y}\left(D_{h} h \frac{\partial C}{\partial y}\right)=\frac{h C_{e q}-h C}{T_{s}}
$$

with $h$, the water depth, $D_{h}$, the sediment diffusion coefficient, and $T_{s}$, an adaptation time. $T_{s}$ is given by a simple approximation based on local water depth and the sediment fall velocity, $w_{s}$ :

$$
T_{s}=\max \left(0.05 \frac{h}{w_{s}}, 0.2\right)
$$

where a small value of $T_{s}$ corresponds to a nearly instantaneous sediment response.

Since it is well known that wave nonlinearity affects sediment transport (e.g., Janssen et al., 1998), and that the wave modules do not include nonlinearity, the sediment transport equation is modified to include a parametric form of wave nonlinearity based on wave skewness and asymmetry (Van Thiel de Vries, 2009). The wave skewness and asymmetry is used to approximate the part of the sediment advection velocity enhanced by nonlinear wave effects, $u_{a}$. This velocity is added to the Eulerian velocity in the advection-diffusion equation, which is therefore modified as follows: 


$$
\begin{gathered}
\frac{\partial h C}{\partial t}+\frac{\partial h C\left(u^{E}-u_{a} \sin \theta\right)}{\partial x}+\frac{\partial h C\left(v^{E}-u_{a} \sin \theta\right)}{\partial y} \\
+\frac{\partial}{\partial x}\left(D_{h} h \frac{\partial C}{\partial x}\right)+\frac{\partial}{\partial y}\left(D_{h} h \frac{\partial C}{\partial y}\right)=\frac{h C_{e q}-h C}{T_{s}}
\end{gathered}
$$

The parameter $u_{a}$ is calculated as a function of wave skewness $\left(S_{k}\right)$, a wave asymmetry parameter $\left(A_{s}\right)$, root-mean-square velocity $\left(u_{r m s}\right)$ and two calibration factors $\left(f_{S k}, f_{A s}\right)$ :

$$
u_{a}=\left(f_{S k} S_{k}-f_{A s} A_{s}\right) u_{r m s}
$$

A higher value of $u_{a}$ simulates a stronger onshore sediment transport component. Either the individual calibration factors can be adjusted, or the option to set both calibration parameters is done by adjusting the facua calibration parameter.

\section{Morphology Module}

The morphology module includes bed level updating and avalanching. The bed level is updated based on the sediment transport formulation as well as avalanching. The bed level change is given by:

$$
\frac{\partial z_{b}}{\partial t}+\frac{f_{m o r}}{1-p}\left(\frac{\partial q_{x}}{\partial x}+\frac{\partial q_{y}}{\partial y}\right)=0
$$

where $p$ is the porosity, $f_{m}$ or is the morphological acceleration factor of order (110) (e.g. Reniers et al., 2004) and $q_{x}$ and $q_{y}$ represent the sediment transport rates in $\mathrm{x}$ - and $\mathrm{y}$-directions respectively.

Avalanching is introduced to represent the slumping of the sand during the storm induced dune erosion and the bed is updated accordingly:

$$
\left\|\frac{\partial z_{b}}{\partial x}\right\|>m_{c r}
$$


where $m_{c r}$ is the critical bed slope, with a similar expression for the y-direction. There are separate critical slopes for dry and wet points, and inundated areas are considered more prone to slumping.

\section{Boundary Conditions}

The wave energy at the offshore boundary is prescribed in XBeach as a time series of JONSWAP spectral parameters. At the lateral boundaries, Neumann boundary conditions are applied, where the longshore gradient is set to zero.

For the flow boundary conditions, the offshore boundary is set to an absorbinggenerating boundary condition (Van Dongeren and Svedsen, 1997), where outgoing waves can leave the computational domain through the boundary with minimal reflection, while also specifying incoming waves. The water level gradient is set to zero for the lateral boundaries.

\section{Model Calibration}

The impact of Hurricane Sandy was modeled using XBeach in two different case studies, on the coast of New Jersey (Nederhoff, 2014), and Fire Island, New York (De Vet, 2014). In both studies, the model sensitivity to the facua parameter and the bed friction was highlighted. De Vet (2014) showed an extreme overprediction of erosion when these two parameters were kept at default values, with the model performing with much better skill after they were adjusted. As a result of these studies, these parameters are listed in the XBeach tutorial as a two-step calibration process that can be used to calibrate the model when multiple regimes of Sallenger (2000) are expected. The facua parameter is suggested to calibrate the collision regime, and increasing the bed friction on the dune is suggested to calibrate the overwash regime. The sensitivity of the model to these two parameters is tested in this study. 


\subsubsection{XBeach Model Setup}

The XBeach model version used in this study is the v1.22.4867 Kingsday release with the netcdf and MPI options. The bathymetry and topography used in the XBeach simulations was derived from a one meter resolution digital elevation model (DEM) created using data collected by airborne LiDAR between April 22 and May 6, 2011, available from the Rhode Island Geographic Information System (RIGIS, 2011). For all simulations, the XBeach matlab toolbox was used to create a model grid with variable grid spacing in the $\mathrm{x}$ - and $\mathrm{y}$ - directions to reduce computation time. The grid origin for all simulations is located at $\mathrm{X}=284000 \mathrm{~m}, \mathrm{Y}$ $=4580000 \mathrm{~m}$ (UTM Zone 19), indicated by the red circle in the lower right corner of Figure 2.4. The grid extends $6680 \mathrm{~m}$ in the cross-shore direction and $10200 \mathrm{~m}$ in the long shore direction. The grid is at an angle of 116 degrees counterclockwise from East and the minimum grid spacing was set to $10 \mathrm{~m}$ in the cross-shore direction, and $15 \mathrm{~m}$ in the long-shore direction to obtain reasonable computational times for model testing. Figure 2.4 shows the XBeach model domain with the locations of 5 GSO and 2 FEMA transects marked in the figure.

For all simulations the grain size parameters D50 and D90 were set to 0.58 $\mathrm{mm}$ and $1.31 \mathrm{~mm}$ respectively, based on a standard sieve analysis of sandy sediment taken from the study area. All other XBeach parameters were kept at their default values unless noted otherwise in the following sections where we describe the different simulation scenarios considered.

The locations and angles relative to North of the transects shown in Figure 2.4 are specified in Table 2.1. The EST1, EST2, CHABW, CHATB, and GRH transects are located at sites where GSO has been collecting beach profile data over the past 35 years. In Table 2.1 the location of the $\mathrm{R} 0$ stake is the location where the GSO transect measurements start, near the crest of the dune. The heading 
from R0 is in degrees, clockwise from North, and indicates the direction along which the transects are measured, pointing seaward. The FEMA19 and FEMA20 transects are the locations of the FEMA coastal transect lines. In this study, FEMA transects are measured with their origin at the dune crest, the coordinates of which are shown in Table 2.1. The heading from the dune crest is given in degrees, clockwise from North, and indicates the direction along which the FEMA transects are measured, pointing seaward.

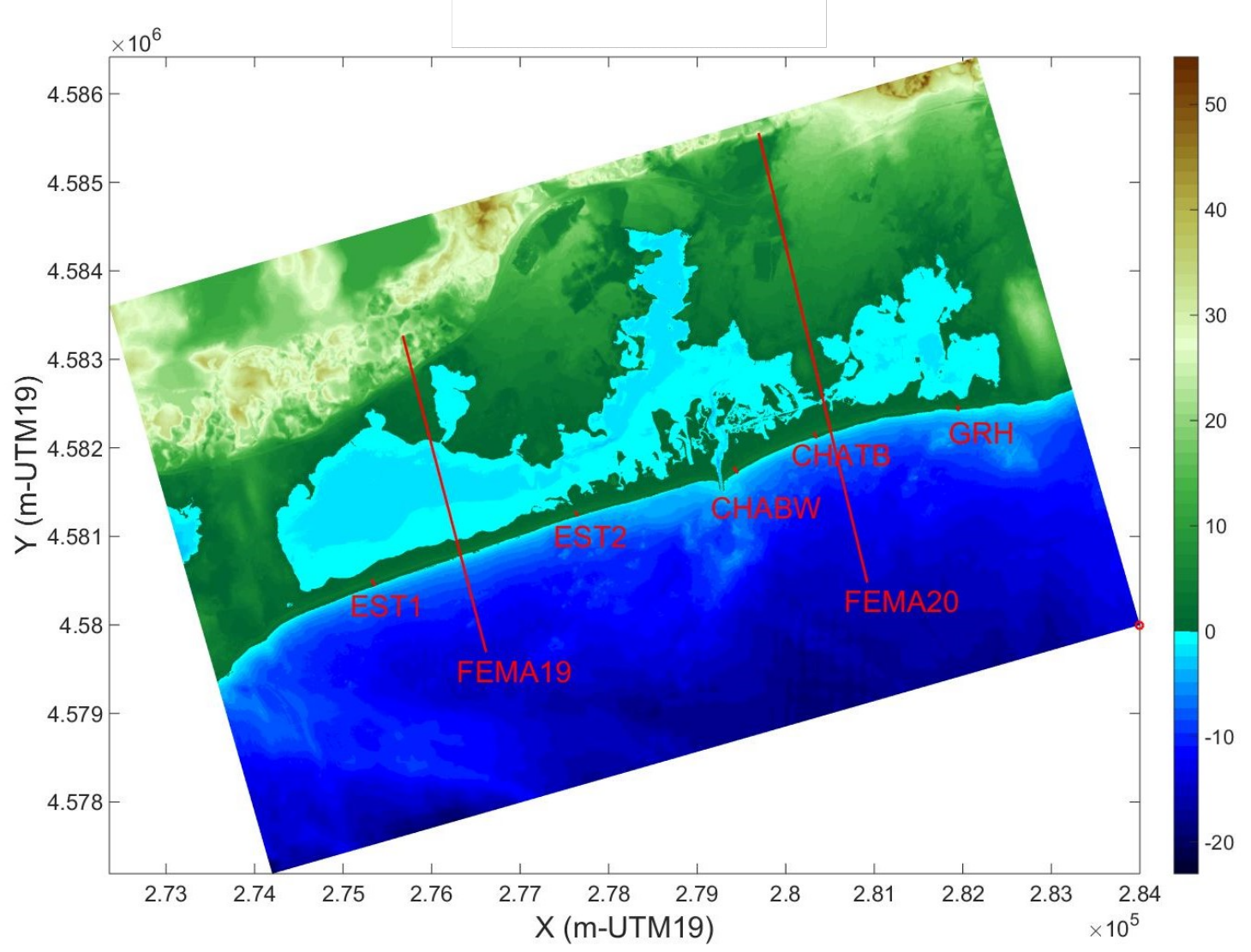

Figure 2.4: XBeach model domain with URI GSO and FEMA transect locations. Grid is at 116 degrees counterclockwise from East. Red dot is grid origin. GSO transects include: EST1, EST2, CHABW, CHATB, GRH; FEMA transects include: FEMA19, FEMA20 


\begin{tabular}{|c|c|c|}
\hline Transect & $\begin{array}{c}\text { Location of R0 stake } \\
\text { (x,y UTM Zone 19) }\end{array}$ & $\begin{array}{c}\text { Heading from R0 stake } \\
\text { (clockwise from N) }\end{array}$ \\
\hline EST1 & $275328.2 \mathrm{~m}, 4580506.6 \mathrm{~m}$ & $155.15 \mathrm{deg}$ \\
EST2 & $277629.9 \mathrm{~m}, 4581273.4 \mathrm{~m}$ & $153.18 \mathrm{deg}$ \\
CHABW & $279418.4 \mathrm{~m}, 4581772.3 \mathrm{~m}$ & $145.00 \mathrm{deg}$ \\
CHATB & $280325.8 \mathrm{~m}, 4582167.1 \mathrm{~m}$ & $160.65 \mathrm{deg}$ \\
GRH & $281946.4 \mathrm{~m}, 4582469.6 \mathrm{~m}$ & $178.39 \mathrm{deg}$ \\
\hline Transect & $\begin{array}{c}\text { Location of dune crest } \\
\text { (x,y UTM Zone 19) }\end{array}$ & $\begin{array}{c}\text { Heading from dune crest } \\
\text { (clockwise from N) }\end{array}$ \\
\hline FEMA19 & $276322.6 \mathrm{~m}, 4580812.7 \mathrm{~m}$ & $165.22 \mathrm{deg}$ \\
FEMA20 & $208502.6 \mathrm{~m}, 4582210.1 \mathrm{~m}$ & $166.45 \mathrm{deg}$ \\
\hline
\end{tabular}

Table 2.1: Study area transect locations, 5 GSO and 2 FEMA transects (Figure 2.4)

\subsubsection{Hurricane Irene}

Hurricane Irene was a tropical storm by the time it impacted the RI area on August 28, 2011. GSO's cross-shore profile measurements taken before and after the storm are given in Figure 2.5. Also shown in Figure 2.5 is the XBeach model input beach topography. 

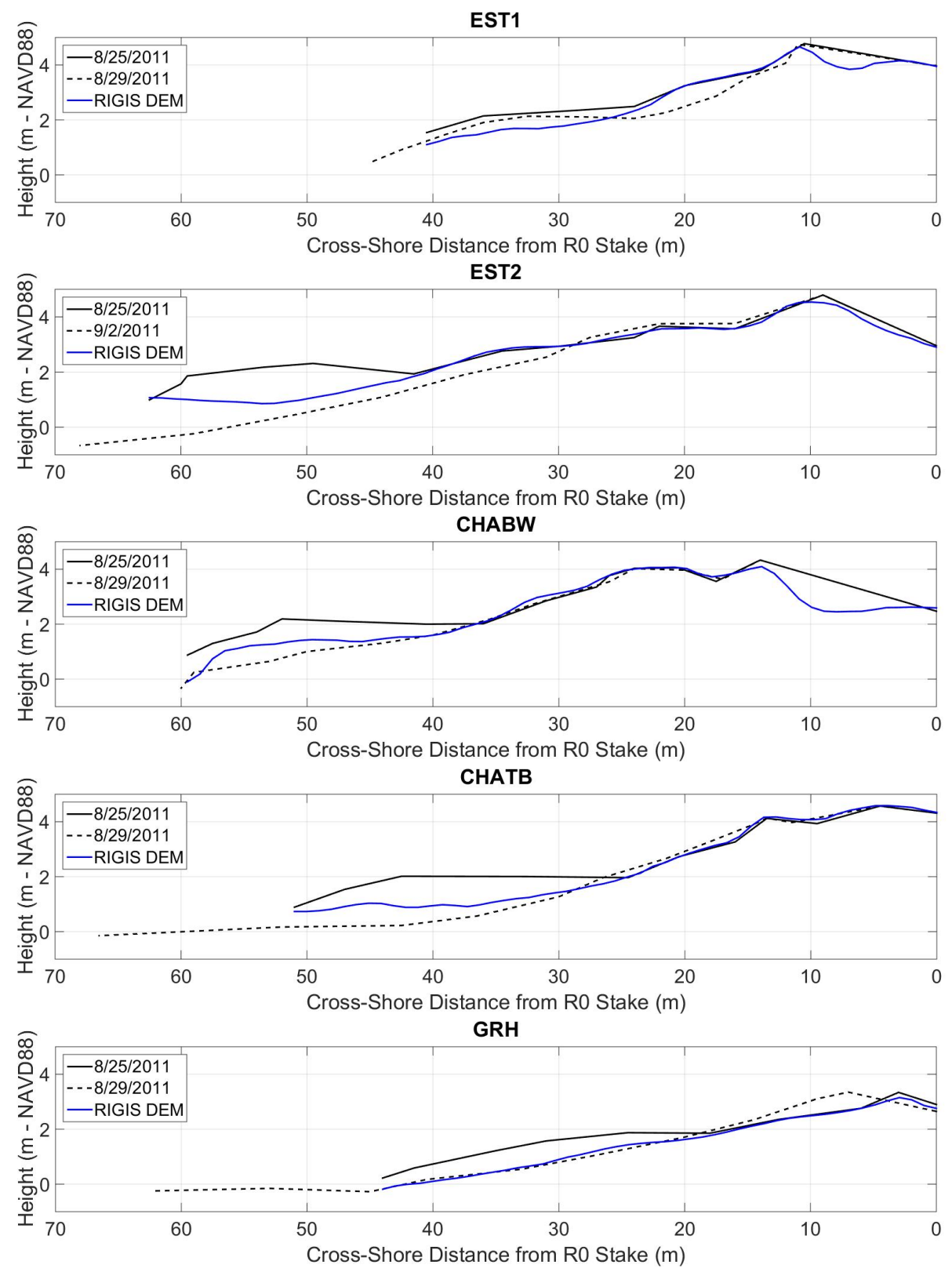

Figure 2.5: GSO cross-shore profiles (black) pre-(solid) and post- (dashed) Hurricane Irene with XBeach model input bathymetry (blue) (Table 2.1, Figure 2.4)

From the available data, comparing pre- and post-storm GSO profiles, it seems that the storm stayed within the collision regime in terms of dune erosion.

Looking at Figure 2.5, three concerns are apparent: 1) the GSO profiles do not extend into the surf zone which is a very active area of erosion and accretion. 2) The 2011 RIGIS DEM shows a different profile than that observed before Irene, 
which adds significant uncertainty to any comparison. 3) Irene is a storm which only had a collision impact, therefore the calibration is possible for the collision regime only.

The XBeach offshore boundary conditions for Hurricane Irene were found using the hydrodynamic model ADCIRC coupled with the wave model SWAN (Booij et al., 1999), forced by wind from the European Centre for Medium Range Weather Forecasts (ECMWF). The ADCIRC+SWAN simulation was run over a Northeast Coastal Ocean Forecast System (NECOFS) unstructured mesh that was modified to have a higher resolution in Rhode Island, with about $200 \mathrm{~m}$ resolution near the coast, and up to 20-30 m resolution in inlets. The ADCIRC+SWAN modeled wave heights and water levels were comparable to offshore buoy data as well as tidal gauge measurements near the study area. The ADCIRC+SWAN simulation was performed by Torres (2017). Figure 2.6 shows the significant wave height, peak period, and water elevation time series that were used to force the XBeach model for Hurricane Irene simulations. 

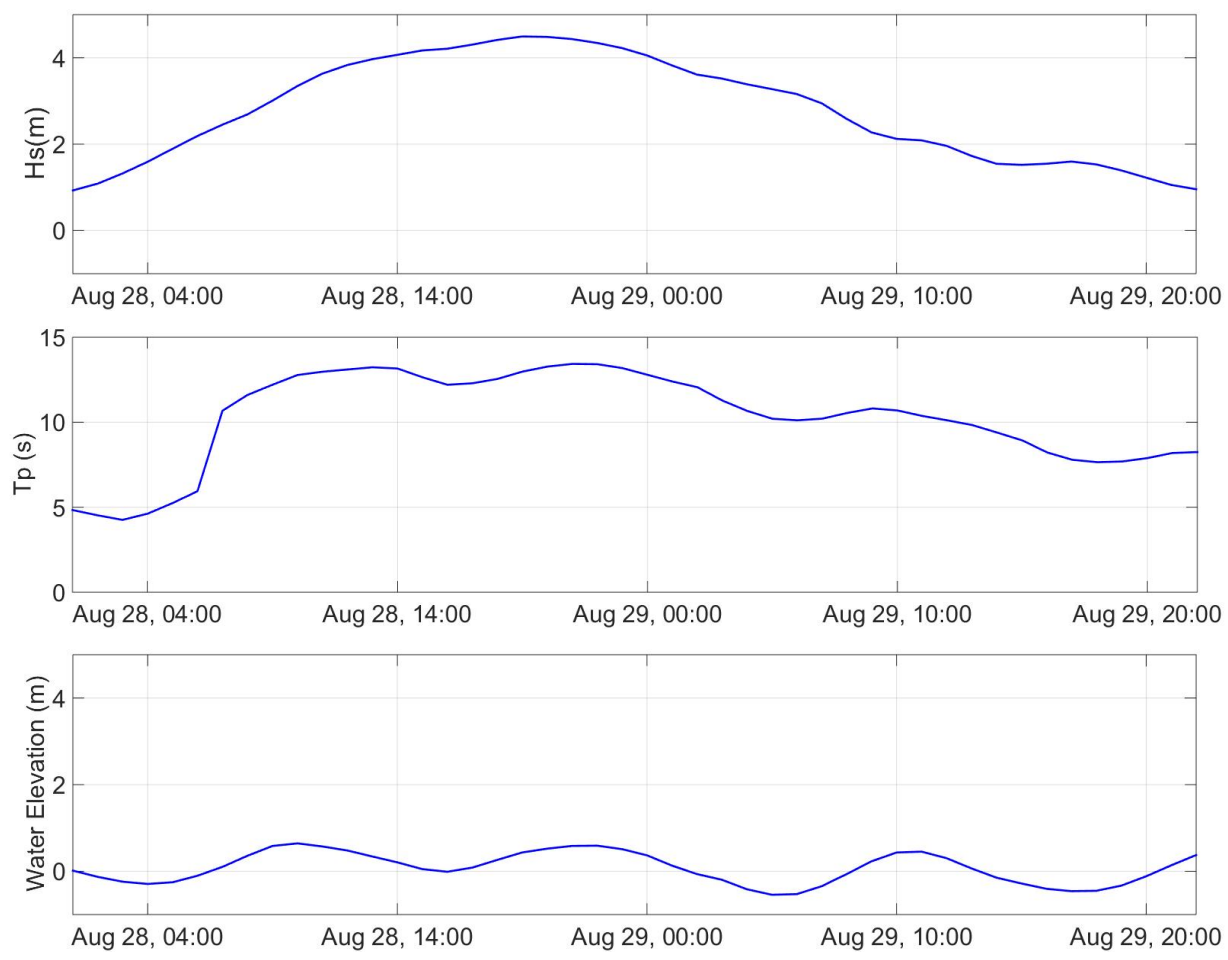

Figure 2.6: Hurricane Irene wave height, peak period, and water elevation time series at XBeach offshore boundary, obtained from an ADCIRC-SWAN regional grid simulation

As discussed above, the collision regime calls for a calibration of the facua parameter. The facua parameter was varied from 0.1 to 0.3 in increments of 0.05 and bed friction was held constant at the default Manning's $n$ of 0.02 . The morphological acceleration factor was set to 1 . The Hurricane Irene simulation scenarios are summarized in Table 2.2.

\begin{tabular}{|c|c|c|}
\hline Simulation ID & facua Parameter & Bed Friction (Manning's $\boldsymbol{n}$ ) \\
\hline Irene Case1 & 0.1 (default) & 0.02 constant (default) \\
Irene Case2 & 0.15 & 0.02 constant (default) \\
Irene Case3 & 0.2 & 0.02 constant (default) \\
Irene Case4 & 0.25 & 0.02 constant (default) \\
Irene Case5 & 0.3 & 0.02 constant (default) \\
\hline
\end{tabular}

Table 2.2: Hurricane Irene Simulation Scenarios

Results are shown in the next section. 


\subsubsection{0-Year Storm}

To obtain a time series of wave and water level conditions to force the XBeach model for the 100-year storm, the NACCS database was searched at two save points, one slightly further offshore than the extent of the XBeach offshore boundary (Save Point ID 9136), and one in the nearshore close to the center of the model domain (Save Point ID 868), for a storm with peak wave height and water levels close to the NACCS 100-year statistical values determined at those same save points. Table 2.3 shows the comparison of the NACCS 100-year mean significant wave height $\left(H_{s}\right)$ and 100-year 95\% confidence interval water elevation at those two save points compared to the peak values of $H_{s}$ and water elevation for the tropical synthetic Storm 457, chosen as our proxy 100-year storm. The mean wave height and $95 \%$ confidence interval water elevation were chosen to be consistent with Grilli et al. (2015), Spaulding et al. (2016), and Schambach et al. (2016).

\begin{tabular}{|c|c|c|c|c|c|}
\hline $\begin{array}{c}\text { NACCS Save } \\
\text { Point ID }\end{array}$ & $\begin{array}{c}\text { Location } \\
(\mathrm{x}, \mathrm{y} \text { UTM Zone 19) }\end{array}$ & $\begin{array}{c}\text { 100-Year } \\
\text { Mean } \boldsymbol{H}_{\boldsymbol{s}}(\mathbf{m})\end{array}$ & $\begin{array}{c}\text { Storm 457 } \\
\text { Peak } \boldsymbol{H}_{\boldsymbol{s}}(\mathbf{m})\end{array}$ & $\begin{array}{c}\text { 100-year 95 \% CI } \\
\text { Water Elevation (m) }\end{array}$ & $\begin{array}{c}\text { Storm 457 Peak } \\
\text { Water Elevation }(\mathbf{m})\end{array}$ \\
\hline 9136 & 277395.43, & 7.48 & 7.24 & 3.05 & 3.22 \\
\hline 868 & 4573492.80 & & & & 3.49 \\
& 278716.24, & 7.42 & 7.61 & & \\
\hline
\end{tabular}

Table 2.3: NACCS 100-Year Parameters vs. Storm 457 Parameters

Figure 2.7 shows the NACCS Storm 457 time series of wave height, period, and water elevation at the XBeach offshore boundary. The time series is 48 hours long, with the peak wave height and water levels occurring between hours 30-35. 

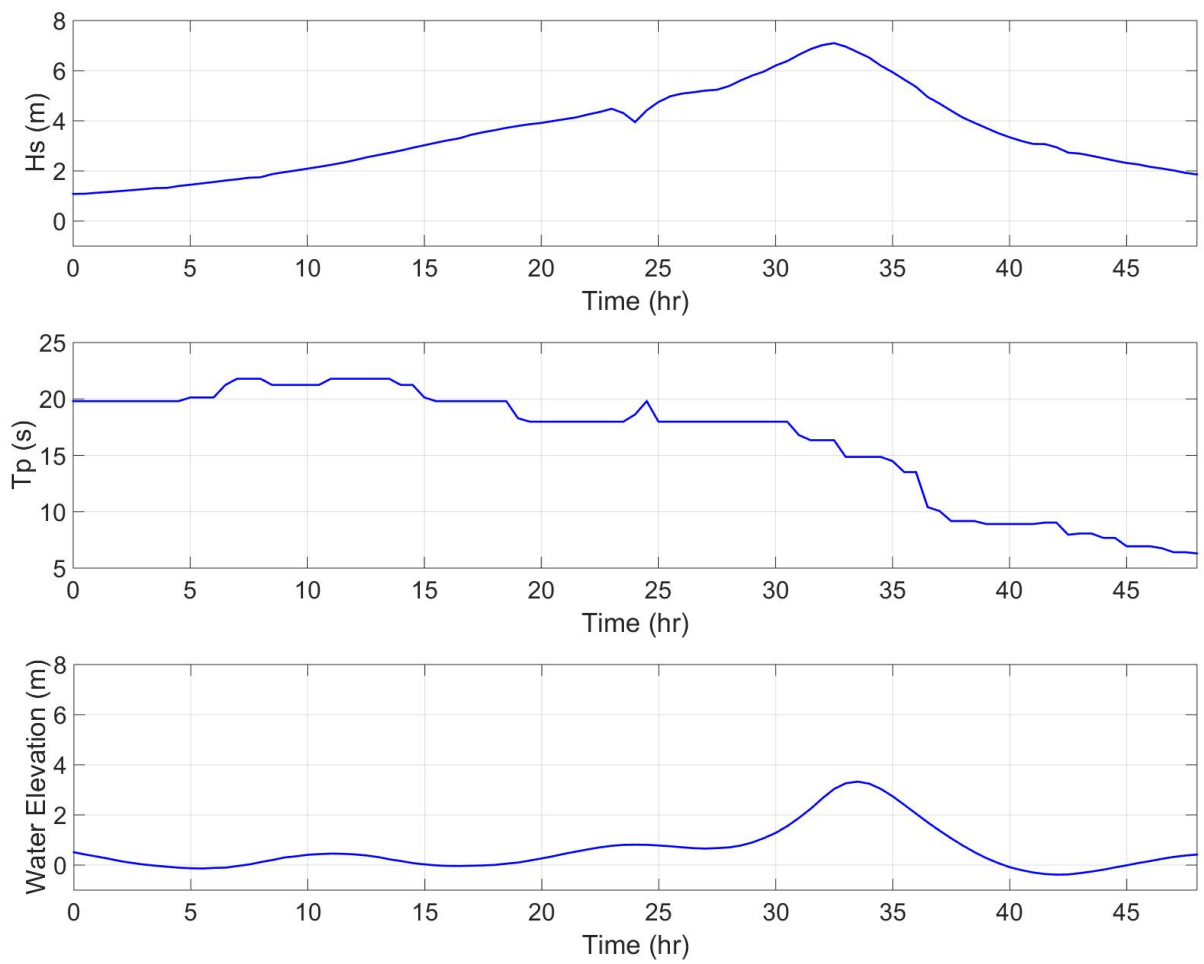

Figure 2.7: NACCS 457 significant wave height, peak period, and water elevation time series at XBeach offshore boundary

The 100-year XBeach simulations were run for four scenarios, 1) considering the facua parameter and bed friction at their default values, 2) increasing the facua parameter and holding the bed friction at its default value, 3) holding the facua parameter at its default value and increasing the bed friction, and 4) increasing both the facua parameter and bed friction. The results from each of these scenarios are presented to show the model sensitivity to these parameters. Additionally, at FEMA transects 19 and 20 results are compared to the FEMA eroded dune profile, as well as the generalized 1\% barrier profile by Oakley (2015). Table 2.4 summarizes the 100-year storm simulation scenarios considered. For the 100-year storm simulation scenarios, the morphological acceleration factor was set to 10 . 


\begin{tabular}{|c|c|c|}
\hline Simulation ID & facua Parameter & Bed Friction (Manning's $\boldsymbol{n}$ ) \\
\hline 457 Case1 & 0.1 (default) & 0.02 constant (default) \\
457 Case2 & 0.3 & 0.02 constant (default) \\
457 Case3 & 0.1 (default) & Variable based on land cover \\
457 Case4 & 0.3 & Variable based on land cover \\
\hline
\end{tabular}

Table 2.4: 100-Year Storm Simulation Scenarios modeled with XBeach

\subsubsection{Expected 100-Year Storm Erosion Impact Regime}

In order to get a feel for the erosion impact regime expected for the 100-year storm at different locations along the dune in the study area, the equations and definitions given in Stockdon et al. (2012), based on empirical parameterization of wave setup, swash, and runup (Stockdon et al., 2006), are used and related to the storm impact model by Sallenger (2000) (Figure 2.8).

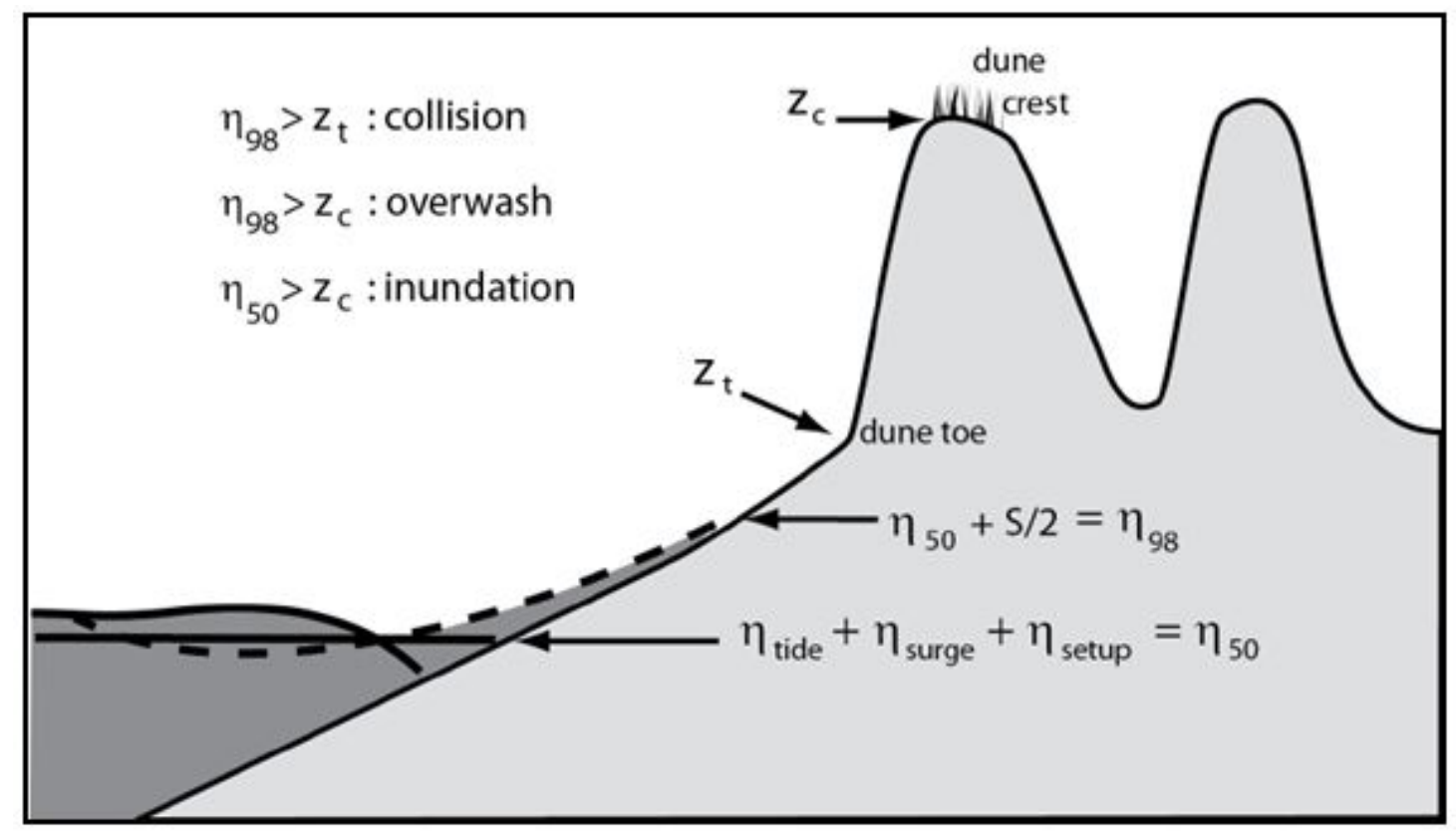

Figure 2.8: Sketch defining the relevant morphologic and hydrodynamic parameters in the storm impact scaling model of Sallenger (2000) (modified from Stockdon et al., 2009)(from Stockdon et al., 2012)

Figure 2.8 defines the different impact regimes as related to the parameter $\eta_{98}$, which is the extreme high water level attained during a storm, defined as the 
98-percent non-exceedance level. If $\eta_{98}$ is larger than the dune toe but smaller than the dune crest, the collision regime is expected. If the $\eta_{98}$ is larger than the dune crest, the overwash regime is expected. The worst case scenario occurs when $\eta_{50}$, the combination of the tide $\left(\eta_{\text {tide }}\right)$, surge $\left(\eta_{\text {surge }}\right)$ and wave setup $\left(\eta_{\text {setup }}\right)$, is greater than the dune crest. Equations 2.20 through 2.24 are used to determine the relevant parameters (Stockdon, 2012).

$$
\begin{gathered}
\eta_{50}=\eta_{\text {tide }}+\eta_{\text {surge }}+\eta_{\text {setup }} \\
\eta_{\text {setup }}=0.35 \beta_{m}\left(H_{0} L_{0}\right)^{1 / 2} \\
\eta_{98}=\eta_{50}+1.1(S / 2) \\
S=\left[H_{0} L_{0}\left(0.563 \beta_{m}^{2} \pm 0.005\right)\right]^{1 / 2} \\
L_{0}=\frac{g T^{2}}{2 \pi}
\end{gathered}
$$

With $S$, the total swash excursion about the setup level, $H_{0}$, the deepwater wave height, $L_{0}$, the deep water wave period, $T$, the wave period, $g$, the gravitational acceleration $\left(9.81 \mathrm{~m} / \mathrm{s}^{2}\right)$, and $\beta_{m}$, the beach slope. The beach slope is defined as the slope of the line from the mean high water mark to the dune toe. Note that the equation for $\eta_{98}$ is slightly different from what is shown in Figure 2.8, with the factor 1.1 used to account for parameterization bias (Stockdon et al., 2012).

This analysis was performed at the seven cross-shore transects, previously introduced: the 5 GSO transect locations, and the 2 FEMA transect locations (Table 2.1). The inputs for $\eta_{\text {surge }}, H_{0}$ and $T_{p}$ were taken from the peak of the 
Storm 457 time series at the offshore XBeach boundary (Figure 2.7). Note that the surge value includes the tide. The analysis indicates that all transects should show significant erosion, with all transects in either the overwash or inundation regimes (Table 2.5).

\begin{tabular}{|c|c|c|c|c|c|c|c|c|c|c|}
\hline Transect & $\begin{array}{c}\boldsymbol{\eta}_{\text {surge }} \\
(\mathrm{m})\end{array}$ & $\begin{array}{c}\boldsymbol{H}_{\mathbf{0}} \\
(\mathrm{m})\end{array}$ & $\begin{array}{c}\boldsymbol{T}_{\boldsymbol{p}} \\
(\mathrm{s})\end{array}$ & $\begin{array}{c}\boldsymbol{L}_{\mathbf{0}} \\
(\mathrm{m})\end{array}$ & $\boldsymbol{\beta}_{\boldsymbol{m}}$ & $\begin{array}{c}\boldsymbol{\eta}_{\text {setup }} \\
(\mathrm{m})\end{array}$ & $\begin{array}{c}\boldsymbol{S} \\
(\mathrm{m})\end{array}$ & $\begin{array}{c}\boldsymbol{\eta}_{\mathbf{9 8}} \\
(\mathrm{m})\end{array}$ & $\begin{array}{c}\text { Dune Crest } \\
(\mathrm{m})\end{array}$ & Erosion Regime \\
\hline EST1 & 3.32 & 7.10 & 16.34 & 416.86 & 0.045 & 0.86 & 4.26 & 6.52 & 2.80 & Inundation \\
EST2 & 3.32 & 7.10 & 16.34 & 416.86 & 0.065 & 1.24 & 4.67 & 7.13 & 3.95 & Inundation \\
CHABW & 3.32 & 7.10 & 16.34 & 416.86 & 0.080 & 1.52 & 5.05 & 7.62 & 3.39 & Inundation \\
CHATB & 3.32 & 7.10 & 16.34 & 416.86 & 0.032 & 0.61 & 4.06 & 6.16 & 4.49 & Overwash \\
GRH & 3.32 & 7.10 & 16.34 & 416.86 & 0.079 & 1.50 & 5.02 & 7.59 & 3.64 & Inundation \\
FEMA19 & 3.32 & 7.10 & 16.34 & 416.86 & 0.100 & 1.90 & 5.61 & 8.31 & 4.53 & Inundation \\
FEMA20 & 3.32 & 7.10 & 16.34 & 416.86 & 0.046 & 0.88 & 4.28 & 6.55 & 4.57 & Overwash \\
\hline
\end{tabular}

Table 2.5: Sallenger regime calculated with Stockdon parameterization for NACCS 100-year values

\subsection{Results and Discussion}

\subsubsection{Hurricane Irene}

Results of the five simulations of Hurricane Irene defined in Table 2.2 are shown at the GSO cross-section sites (Table 2.1) in Figure 2.9. Results show that an increase in the facua parameter increases the erosion above the toe of the dune. However, as underlined in the previous section, there is so much uncertainty due to the limited size of the transects as well as to the differences in the current and 2011 bathymetry that any calibration of this parameter seems inappropriate. Consequently, in the absence of additional data we elected to approach the 100-year storm from a sensitivity perspective, providing a range of possible dune profiles associated with a range of potential values of the facua and bottom friction parameters. 

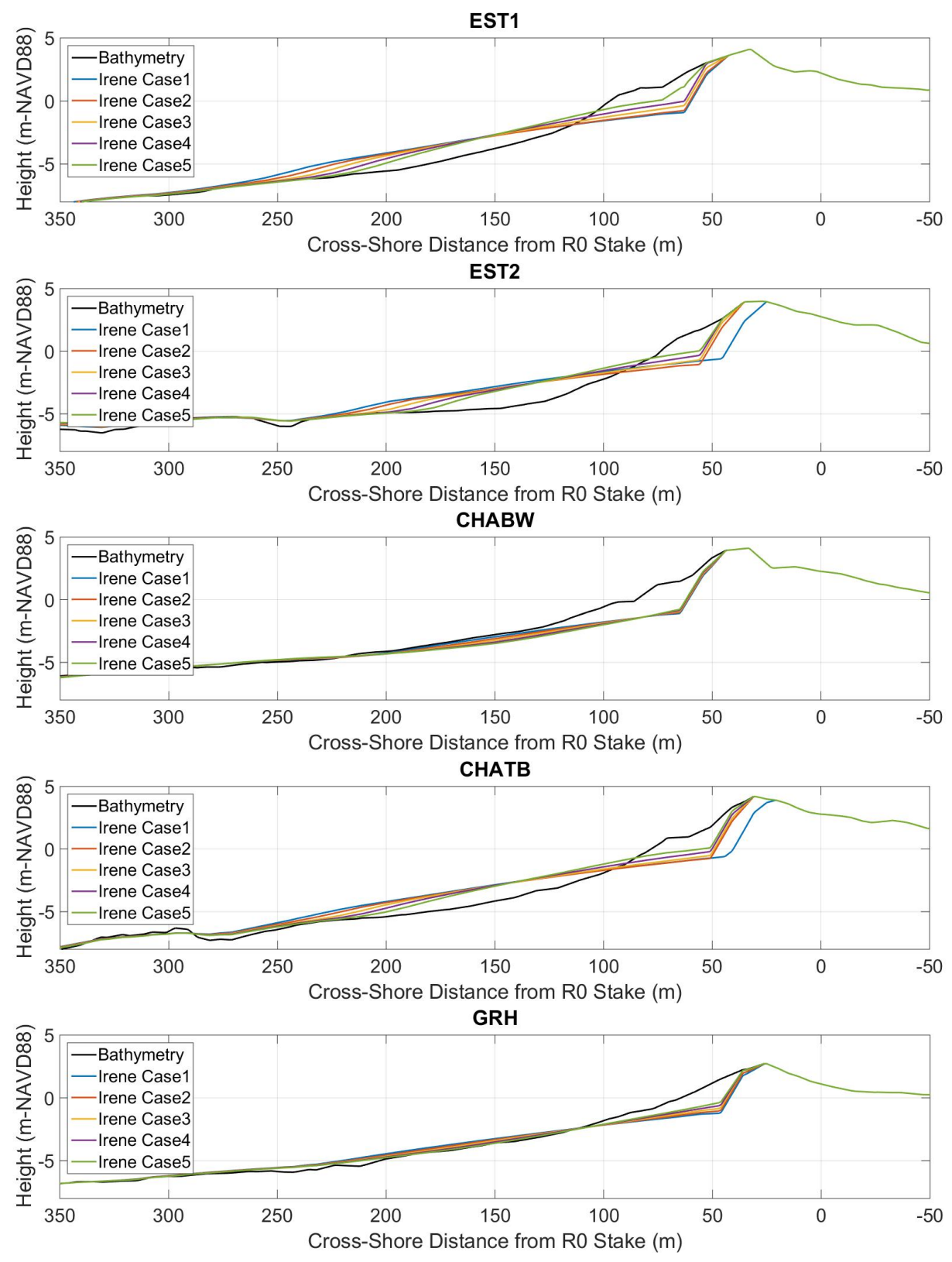

Figure 2.9: Hurricane Irene simulation results at GSO transects for 5 scenarios in Table 2.2

\subsubsection{0-Year Storm}

Figure 2.10 shows the difference between the pre- and post-storm elevation for each 100-year storm scenario, with the black contour line showing the original shoreline location. Blue indicates a lowering of elevation, and red indicates an increase of elevation $(\mathrm{m})$. 


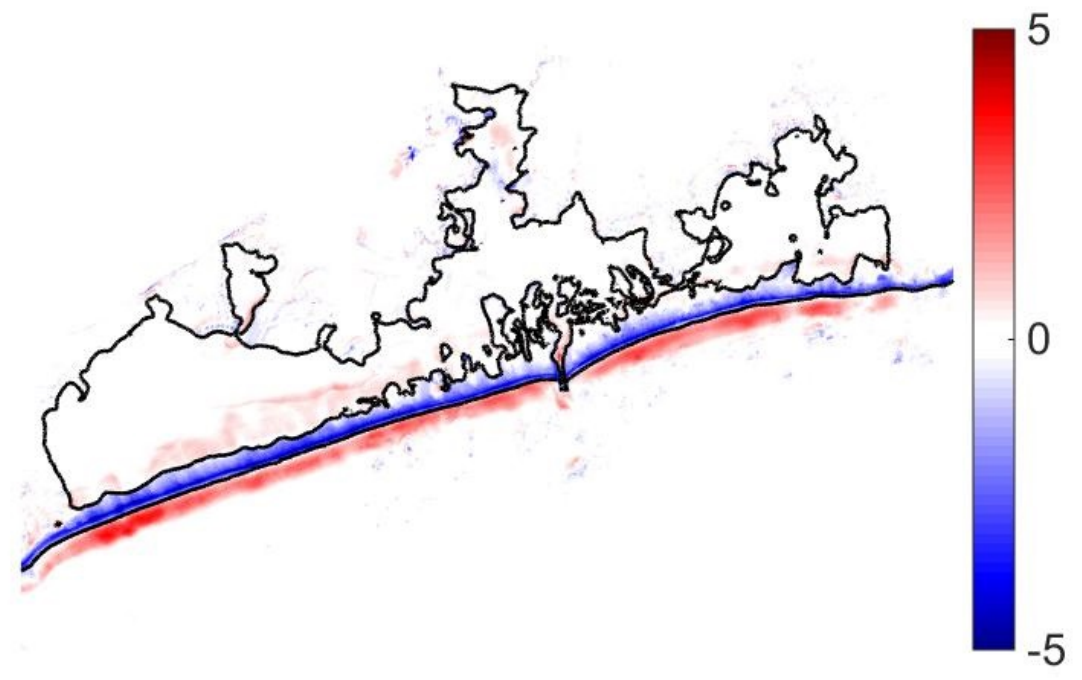

(a)

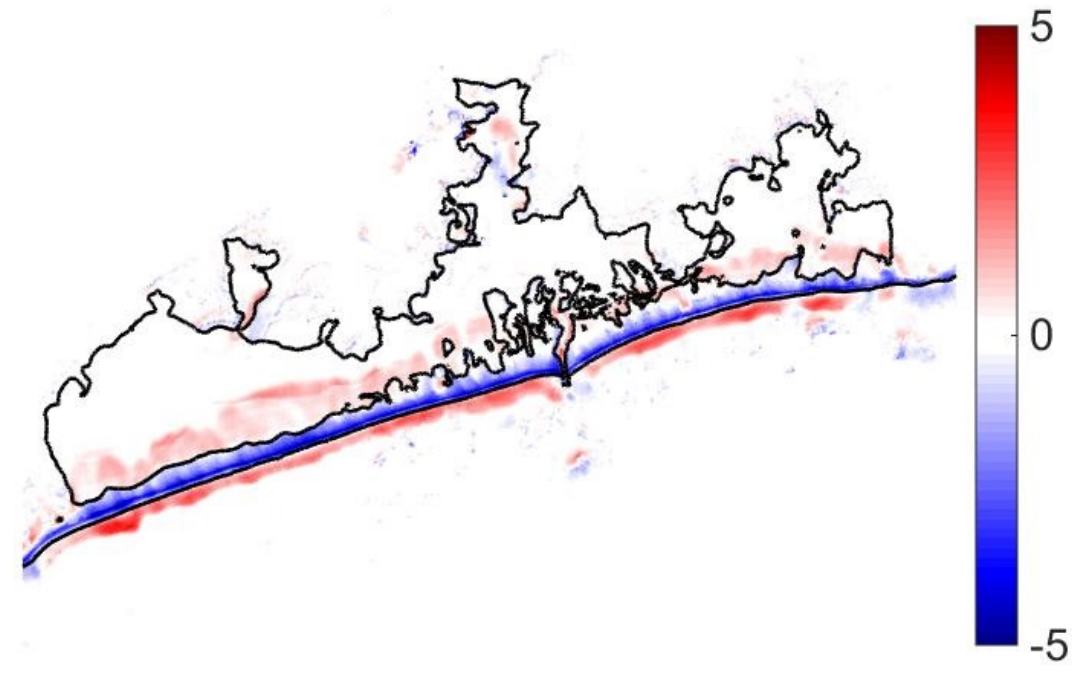

(b) 


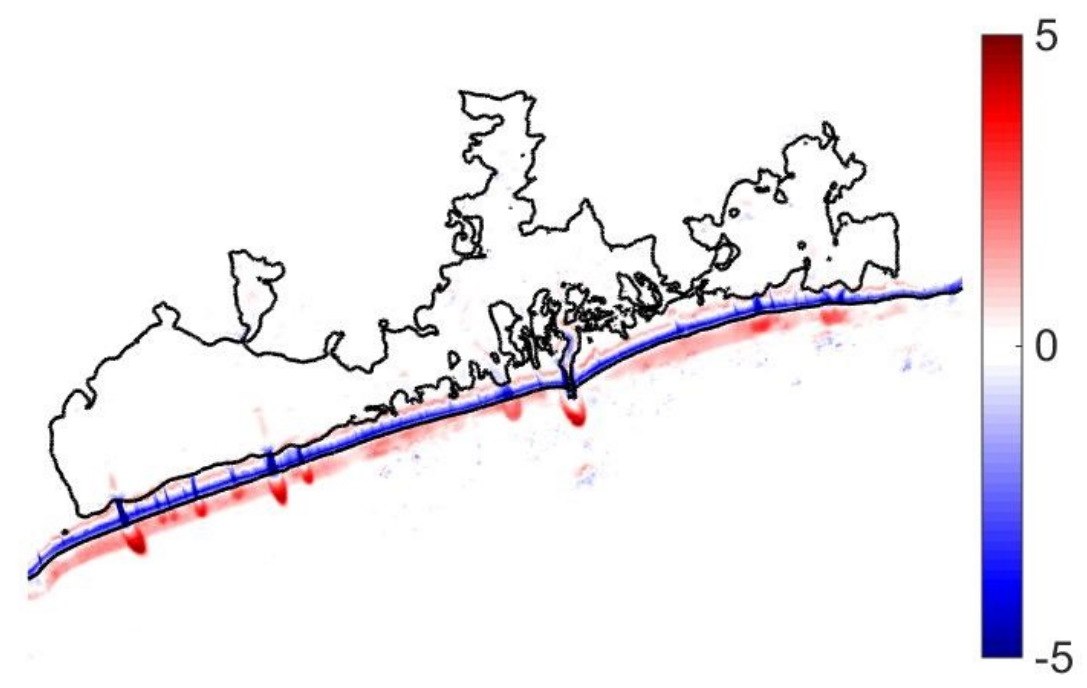

(c)

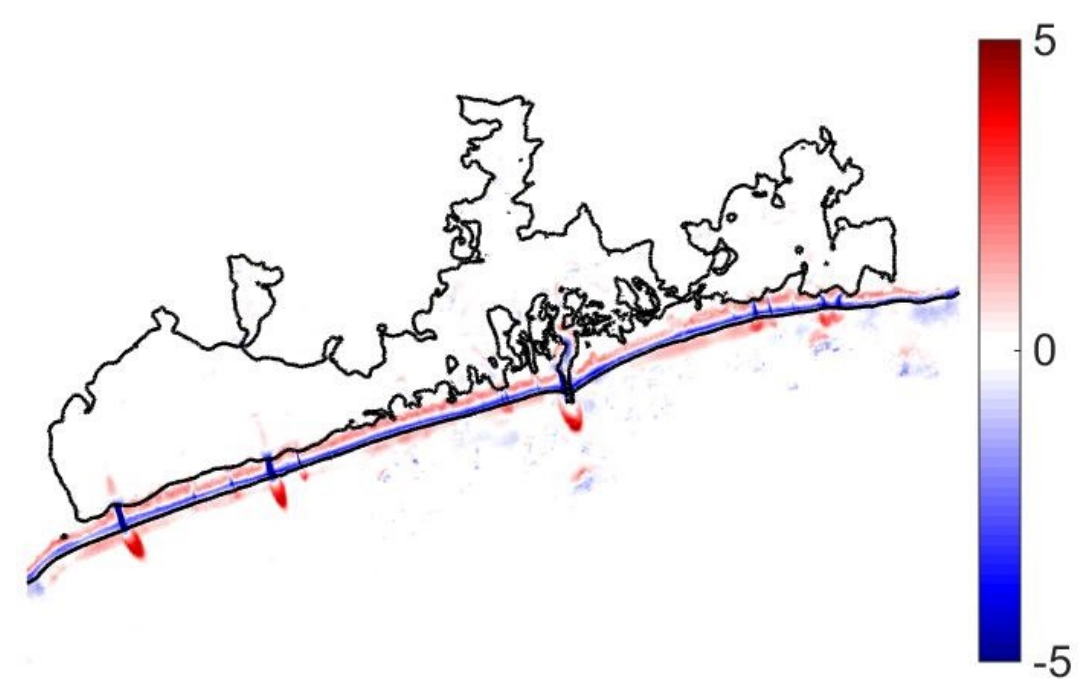

(d)

Figure 2.10: Difference between pre- and post- storm elevation (m) for the 4 scenarios in Table 2.4: a) 457 Case1 (facua $=0.1$, bed friction $=0.02$ ); b) 457 Case2 (facua $=0.3$, bed friction $=0.02)$; c) 457 Case3 (facua $=0.1$, bed friction $=$ variable); d) 457 Case 4 (facua $=0.3$, bed friction $=$ variable $)$ 
Results of simulations for the 100-year storm show that the difference in preand post-storm elevations is very sensitive to both parameters, facua and bottom friction. The default values lead to a total flattening of the dunes, moving the majority of sediment offshore, and some to overwash fans onshore of the original dune crest. Increasing the facua parameter without calibrating the bed friction leads to less movement of sediment offshore, but much more sediment deposited in overwash fans as seen inside the west side of Ninigret Pond. A default facua parameter with increased bed friction leads to more breached locations than when the facua parameter is also increased. The dunes in the increased friction cases migrate landward and do not get leveled.

Figure 2.11 shows the resultant profiles generated for each of the 100-year storm scenarios defined in Table 2.4 at the GSO transect locations. The $\mathrm{x}$-axis is centered at the location of the R0 stake that GSO measurements start from, with positive $\mathrm{x}$ values seaward, and negative values landward. The model bathymetry is shown in black, 457 Case1 as the blue solid line, 457 Case2 as the red solid line, 457 Case 3 as the blue dashed line, and 457 Case4 as the red dashed line (i.e. lower value of facua parameter is in blue; higher value of facua parameter is in red; solid line indicates the lower bed friction; dashed line indicates a higher bed friction). 

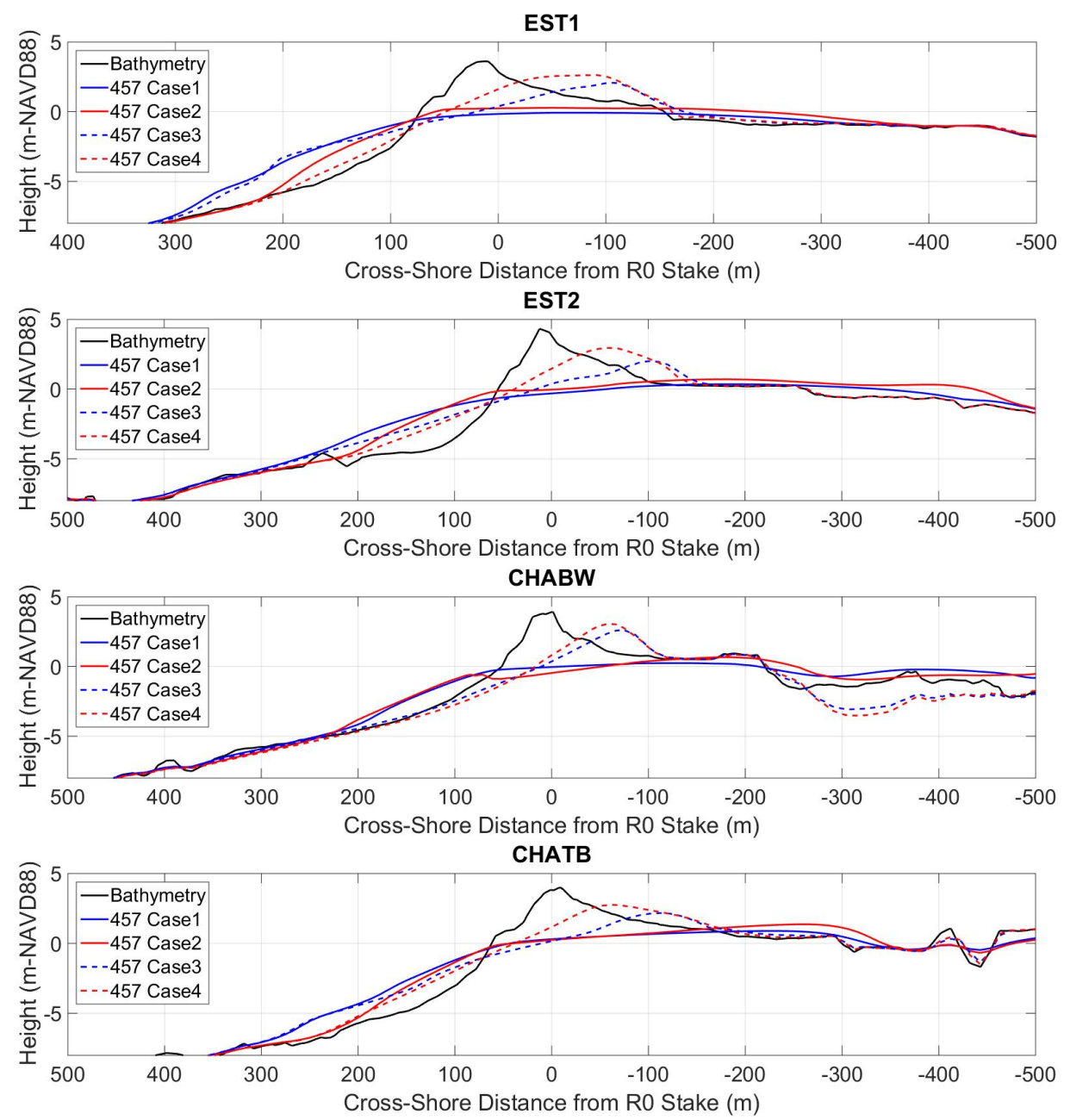

GRH

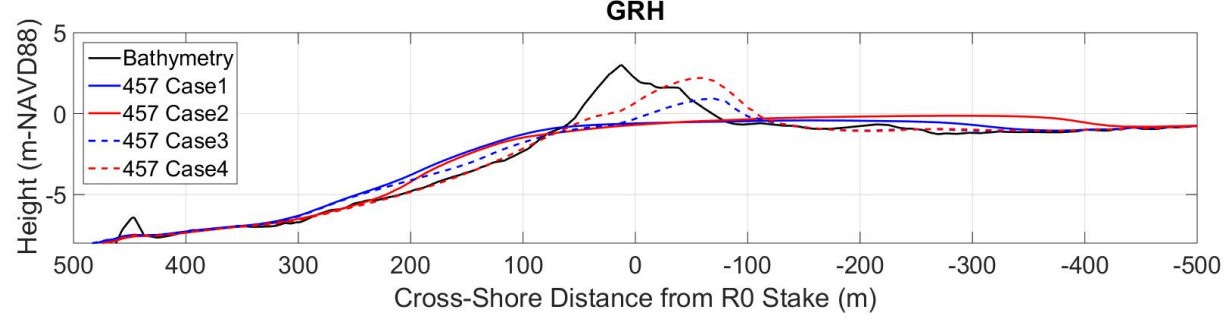

Figure 2.11: 100-Year Storm Simulated Profiles at 5 URI GSO Transects (positive $\mathrm{x}$ seaward) with blue lines indicating a facua parameter $=0.1$, red lines indicating a facua parameter of 0.3 , solid lines indicating constant bed friction coefficient $=$ 0.02 , dashed lines indicating variable bed friction, and black as the input model bathymetry

Figure 2.11 confirms the patterns observed in Figure 2.10. Increasing the facua parameter decreases the erosion in the collision zone under the dune toe but does not significantly affect the eroded profile as far as resulting dune elevation 
goes; however, the overwash fans are in general longer. Increasing bed friction results in significantly less erosion of the dune as well as a landward migration of the dune. The simulation with high facua and friction parameters is the most resilient scenario, in which the dunes are the least eroded.

Figure 2.12 shows results of the 100-year storm simulations at the 2 FEMA transects. Figure 2.13 shows the FEMA erosion protocol as well as the generalized 1\% storm barrier profile developed by Oakley (2015) at the FEMA transects for comparison. FEMA transect 19 is located near a breach for both cases with increased friction.
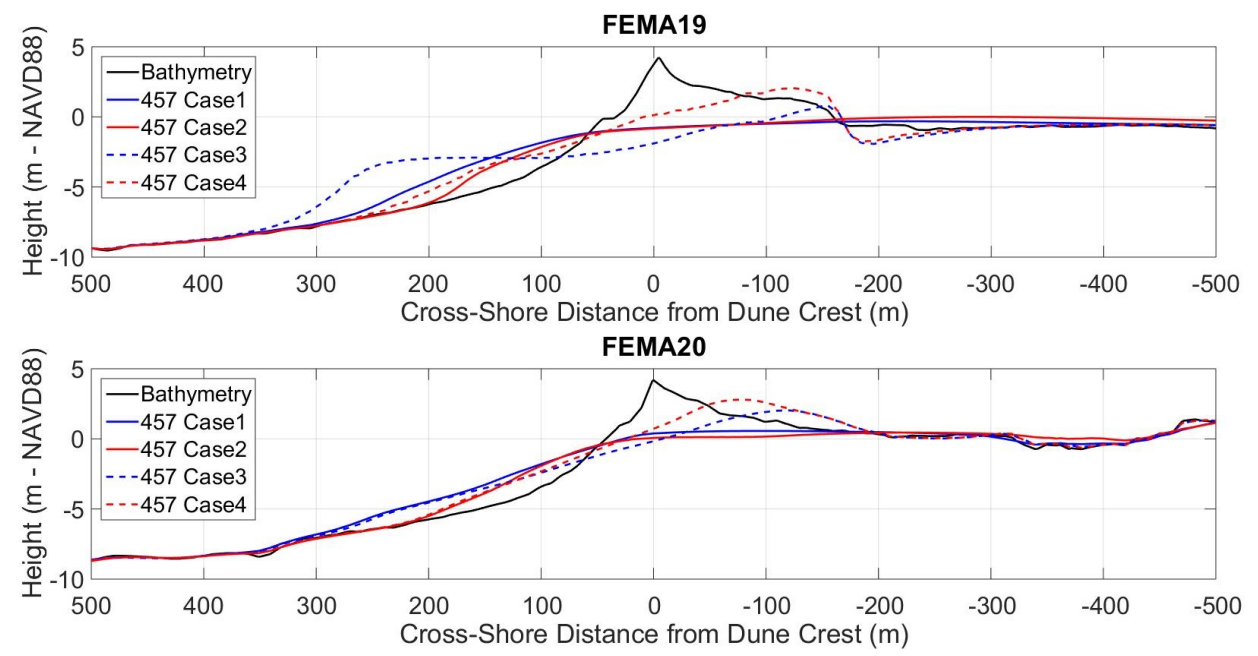

Figure 2.12: 100-Year Storm Simulated Profiles at FEMA Transects (positive x seaward) with blue lines indicating a facua parameter $=0.1$, red lines indicating a facua parameter of 0.3 , solid lines indicating constant bed friction coefficient = 0.02, dashed lines indicating variable bed friction, and black as the input model bathymetry 

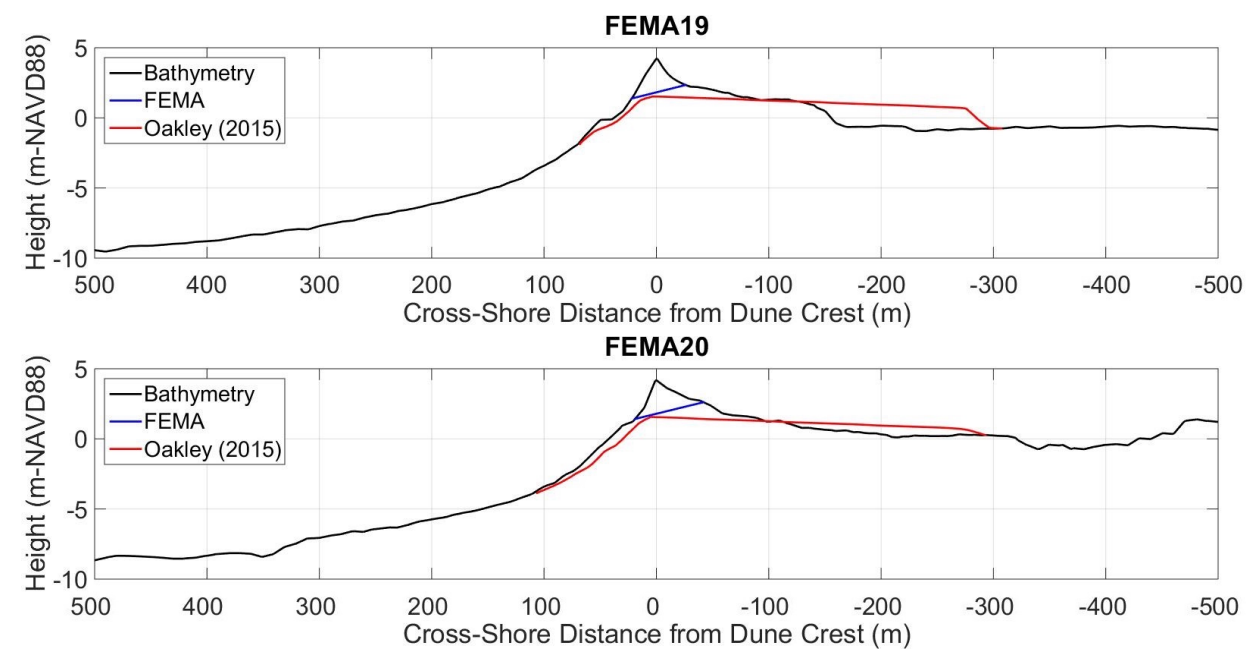

Figure 2.13: FEMA and Oakley eroded profiles at FEMA transects (positive $\mathrm{x}$ seaward)

Comparing Figures 2.12 and 2.13, the high friction simulations and FEMA profiles predict a positive slope. The FEMA protocol removes the sediment from the system. The simulations, however, give a more complete picture, showing that the sediment would be moved into the nearshore area between about $50 \mathrm{~m}$ to $300 \mathrm{~m}$. The Oakley profile appears to be in better agreement with the lower friction simulations as far as the flattening and widening of the dune is concerned, however, the simulations completely erode the dune at transect 19 to a level below zero NAVD88, and at transect 20 just slightly above zero NAVD88. The Oakley profile assumes a maximum elevation of about $1.6 \mathrm{~m}$ NAVD88, and is located more or less where the dune toe used to be.

A clear advantage of using the XBeach model is that the resultant dune profiles are known everywhere, rather than just at the site of specific transects. The Oakley and FEMA profiles do not indicate areas of breaching such as the XBeach model shows. 


\subsection{Conclusion}

The 100-year storm erosion was simulated using the morphodynamic model XBeach. The NACCS database was used to find a synthetic storm time series at the offshore XBeach boundary to force the model. The storm chosen had peak wave height and water levels similar to the NACCS 100-year statistical values for each of those parameters at the study area location. The results are presented in map form as well as at cross-shore transects within the study area. The model shows sensitivity to the two parameters suggested by Nederhoff (2014) for XBeach calibration, the facua parameter and the bottom friction.

Results of modeling the historical storm Hurricane Irene demonstrate XBeach's sensitivity to the facua parameter. In view of the uncertainty associated with the limited size of the observed transects, an exact calibration of this parameter was not possible and it was decided to approach the 100-year storm simulations from a sensitivity perspective, providing a range of possible dune profiles associated with a range of potential parameter values. As the erosion process was limited to the collision regime during Hurricane Irene, the calibration was therefore limited to this regime; the 100-year storm is expected to be in the overwash and inundation regimes and no data was readily available for bottom friction calibration.

Simulations of the 100 -year storm for a range of realistic parameters show a range of results from a fully eroded dune to a dune progressing landward with a crest elevated above $2 \mathrm{~m}$ in some locations. Coastal geologist Oakley (2015) shows that, based on historical storms, the 100-year profile would provide a flattened dune with a crest of about $1.6 \mathrm{~m}$ NAVD88 located at about where the original dune toe was. The simulation with variable bottom friction results in the closest predicted elevation to this scenario, although there are significant differences where 
the dune is located as well as dune shape, when comparing the simulation results to the generalized barrier profile.

The high sensitivity of the model to both the facua and bed friction parameters demonstrates the necessity to have reliable field measurements covering not just the dune profile but also the full equilibrium beach profile, ideally extending underwater up to $300 \mathrm{~m}$ offshore. The recent practice of collecting pre- and post-storm LiDAR data when extreme storm events are expected will aid in the calibration of such a model so that it can be used to make predictions with more certainty.

Acknowledgments. The authors gratefully acknowledge support for this work from the RI Sea Grant.

\section{List of References}

Bilskie, M. V., S. C. Hagen, S. C. Medeiros, and Passeri , D. L., 2014. Dynamics of sea level rise and coastal flooding on a changing landscape, Geophys. Res. Lett., 41, 927934.

Booij, N., Ris, R. C., Holthuijsen, L. H., 1999. A third-generation wave model for coastal regions: 1. Model description and validation. Journal of Geophysical Research: Oceans, 104, C4: 76497666. 10.1029/98JC02622

Callaghan, D.P., Nielsen, P., Short, A., Ranasinghe, R., 2008. Statistical simulation of wave climate and extreme beach erosion. Coastal Engineering V. 55 pp. 375-390.

Carley, J.T., and Cox, R.J., 2003. A methodology for utilizing time-dependent beach erosion models for design events. Coastal and Ports Australian Conference 
2003.

Cialone,M.A., Massey C.T., Anderson,M.E., Grzegorzewski, A.S., Jensen,R.E., Cialone, A., Mark, D.J., Pevey, K.C., Gunkel, B.L., McAlpin,T.O., NadalCaraballo, N.N., Melby, J.A., and J.J. Ratcliff, 2015. North Atlantic Coast Comprehensive Study (NACCS) Coastal Storm Model Simulations: Waves and Water Levels. U.S. Army Engineer Research and Development Center, Technical Report. ERDC-CHL-TR-XX-draft

Daly, C., 2009. Low frequency waves in the shoaling and nearshore zone: A validation of XBeach. Technical report, Master of Science Thesis, Delft University of Technology, Delft.

Dean, R. G., and C.J. Bender, C. J., 2006. Static wave setup with emphasis on damping effects by vegetation and bottom friction. Coastal engineering, 53(2), $149-156$.

De Vet, P., 2014. Modelling sediment transport and morphology during overwash and breaching events. Technical report, Master of Science Thesis, Delft University of Technology, Delft.

Deltares, 2015. XBeach Technical Reference: Kingsday Release. Model description and reference guide to functionalities.

Erikson, L., Larson, M., Hanson, H., 2005. Prediction of swash motion and run-up including the effects of swash interaction. Coast. Eng. 52, 285302. 
Galappatti, R., Vreugdenhil, C.B., 1985. A depth integrated model for suspended transport. J. Hydraul. Res. 23 (4), 359377.

Grilli, A. R, Spaulding, M. L., Schambach L., Smith J., and M. Bryant, 2015. Comparing Inundation Maps developed using WHAFIS and STWAVE. A Case Study in Washington County, Rhode Island. In Proc. ASCE Conf. Solutions to Coastal Disasters, Boston, MA, 2015 (In process)

Grilli, A.R., Spaulding, M.L., Oakley, B.A., Damon,C., 2016. Mapping the Coastal risk for the next century including sea level rise and change in the coastline: application to Charlestown, Rhode Island. Submitted to Natural Hazard.

Holland, K.T., Puleo, J.A., 2001. Variable swash motions associated with foreshore profile change. J. Geophys. Res. 106 (C3), 16234613.

Holthuijsen, L.H., Booij, N., Herbers, T.H.C., 1989. A prediction model for stationary short-crested waves in shallow water with ambient currents. Coast. Eng. 13, 2354.

Lin, N., Emanuel, K., Oppenheimer, M., and Vanmarcke, E., 2012. Physically based assessment of hurricane surge threat under climate change. Nature Climate Change 2:16.

Longuet-Higgins, M.S., Stewart, R.W., 1964. Radiation stresses in water waves; a 
physical discussion, with applications. Deep-Sea Research 11, 529562.

Massey, T.C., Anderson, M.E., McKee-Smith, J., Gomez, J., and J. Rusty, 2011. STWAVE: steady state spectral wave model. Users manual for STWAVE, version 6.0 .

Nadal-Caraballo, N. C., Melby, J.A, Gonzalez V. M., and A.T. Cox, 2015. North Atlantic Coast Comprehensive Study (NACCS): Coastal Storm Hazards from Virginia to Maine. U.S. Army Engineer Research and Development Center (ERDC), Technical Report. ERDC-CHL-TR-15-5

National Research Council. 2009. Mapping the Zone: Improving Flood Map Accuracy. Washington, DC: The National Academies Press. doi: 10.17226/12573.

Nederhoff, C.M., 2014. Modeling the effects of hard structures on dune erosion and overwash: Hindcasting the impact of Hurricane Sandy on New Jersey with XBeach. Technical report, Master of Science Thesis, Delft University of Technology, Delft.

Oakley, B.A., 2016. Generalized 1\% Storm Barrier Profile For The East Beach and Quonochontaug Barriers, Rhode Island: Technical report prepared for the Shoreline Change Special Area Management Plan.

Raubenheimer, B., and R.T. Guza, 1996. Observations and predictions of runup. Journal of Geophysical Research: Oceans (19782012), 101(C11), 25575-25587. 
RIGIS, 2013. Digital Elevation Model, DEM11. Rhode Island Geographic Information System (RIGIS) Data distribution System, URL: http://www.rigis.org/data/topo/2011, Environmental Data Center, University of Rhode Island (last date accessed: 8 December 2016).

Roelvink, J.A., 1993. Surf beat and its effect on cross-shore profiles. Ph.D. thesis. 150 pp., Delft Univ. of Technology., Delft, Netherlands.

Roelvink, J.A., 1993. Dissipation in random wave groups incident on a beach. Coast. Eng. 19, 127150

Roelvink, D., Reniers, A., van Dongeren, A., van Thiel de Vries, J., McCall, M., and Lescinski, J., 2009. Modelling storm impacts on beaches, dunes and barrier islands. Coastal Engineering, v. 56, pp 1133-1152.

Reniers, A.J.H.M., Roelvink, J.A., Thornton, E.B., 2004. Morphodynamic modelling of an embayed beach under wave group forcing. J. Geophys. Res. 109, C01030.

Reniers, A.J.H.M., MacMahan, J., Thornton, E.B., Stanton, T.P., 2006. Modelling infragravity motions on a rip-channel beach. Coast. Eng. 53, 209222.

Sallenger Jr, A. H., 2000. Storm impact scale for barrier islands. Journal of Coastal Research, 890-895

Schaffer, H.A. and Svendsen, I.A., 1988. Surf beat generation on a mild-slope 
beach. Coastal Engineering Proceedings, 1(21).

Schaffer, H.A. and Svendsen, I.A., 1988. Surf beat generation on a mild-slope beach. Coastal Engineering Proceedings, 1(21).

Spaulding, M.L., Grilli, A.R., Damon, C., Fugate, G., Oakley, B.A., Isaji, T., and Schambach, L., 2016. Application of state of art modeling techniques to predict flooding and wave for an exposed coastal area.

Stockdon, H. F., Holman, R. A., Howd, P. A., and Sallenger, A. H. , 2006. Empirical parameterization of setup, swash, and runup. Coastal engineering, 53(7), 573-588.

Stockdon, H.F., Doran, K.J., Thompson, D.M., Sopkin, K.L., Plant, N.G., Sallenger, A.H., 2012. National Assessment of Hurricane-Induced Coastal Erosion Hazards: Gulf of Mexico: U.S. Geological Survey Open-File Report 2012-1084, 51 p.

Thompson, E. F. and V. J. Cardone, 1996. Practical modeling of hurricane surface wind fields. ASCE J. of Waterway, Port, Coastal and Ocean Engineering. $122,4,195-205$.

Torres, M., Hashemi, M.R., Hayward, S., Ginis, I., and Spaulding, M. 2017. Simulation of Storm Surge in Northeast Coast of the US; A Closer Look at the Wind Forcing. International Journal of Offshore and Polar Engineering. The 27th (2017) International Ocean and Polar Engineering Conference. (In Review) 
Tucker, M.J., 1950, August. Surf beats: sea waves of 1 to 5 min. period. In Proceedings of the Royal Society of London A: Mathematical, Physical and Engineering Sciences (Vol. 202, No. 1071, pp. 565-573). The Royal Society.

Van Dongeren, A.R., and Svedson, I.A., 1997. Absorbing-generating boundary condition for shallow water models. ASCE J. of Waterway, Port, Coastal and Ocean Engineering. 123, 6, 303.

Van Dongeren, A., Reniers, A., Battjes, J., Svendsen, I., 2003. Numerical modeling of infragravity wave response during DELILAH. J. Geophys. Res. 108 (C9), 3288.

Van Thiel de Vries, J.S.M., 2009. Dune erosion during storm surges. Technical report, PHD Thesis, Delft University of Technology, Delft.

WIS, 2010. Wave Information Studies. US Army Corps of Engineers. Wave Information Studies Project Documentation: http://wis.usace.army.mil/ 